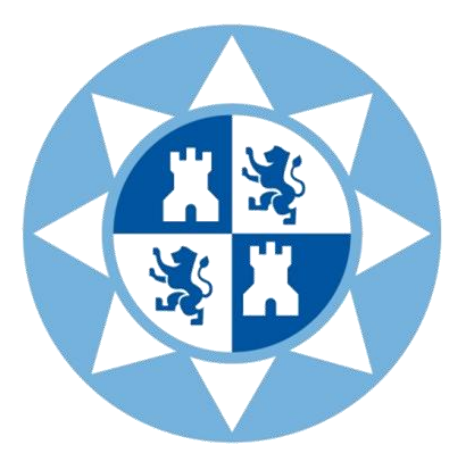

\author{
Universidad Politécnica de Cartagena \\ Departamento de Producción Vegetal
}

\title{
Resistencia a insecticidas en Bemisia tabaci (Gennadius): nivel de resistencia, resistencias cruzadas y mecanismos implicados
}

\section{Tesis Doctoral}

$\mathbf{M}^{\mathrm{a}}$ Esther Fernández García

2013 


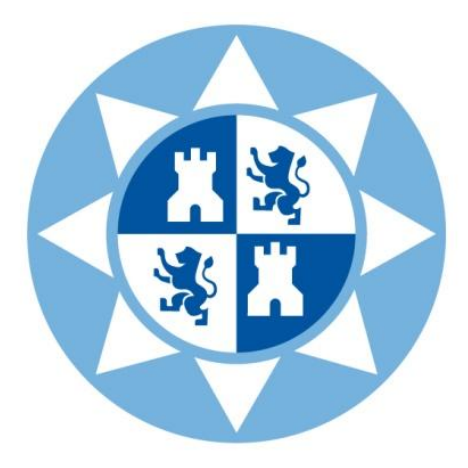

Universidad Politécnica de Cartagena

Departamento de Producción Vegetal

\title{
Resistencia a insecticidas en Bemisia tabaci (Gennadius): nivel de resistencia, resistencias cruzadas y mecanismos implicados
}

$M^{a}$ Esther Fernández García

\author{
Director \\ Pablo Bielza Lino
}

2013 


\section{Resumen}

La mosca blanca del tabaco, Bemisia tabaci (Gennadius, 1889), desde la década de los 90 es una de las plagas más importantes de muchos cultivos hortícolas y ornamentales españoles, tanto por sus daños directos como por la aparición de virus transmitidos por este insecto. A lo largo de estos años el uso excesivo de insecticidas para su control ha hecho que esta plaga desarrolle resistencias a diversos grupos de insecticidas. Para evitar esto y poder plantear estrategias de control adecuadas es necesario el conocimiento de la eficacia actual en insecticidas, así como la existencia de resistencias cruzadas y los mecanismos implicados en la detoxificación de los insecticidas.

En este trabajo se determinó el estado actual de los niveles de resistencia a los principales insecticidas (alfa-cipermetrín, azadiractina, buprofecín, imidacloprid, metomilo, pimetrocina, piridabén, piriproxifén y tiametoxam) de uso habitual en el control de la mosca en invernaderos del sureste de España (Murcia y Almería). Se realizó sobre ninfas de siete poblaciones de campo. Los resultados mostraron una alta tasa de eficacia de los diversos insecticidas, contrariamente a lo que se había publicado hasta ahora. Esto refleja la disminución del uso excesivo de insecticidas en las estrategias de manejo integrado de la plaga. No obstante, en aquellas poblaciones sometidas a una exposición elevada de insecticidas la expresión de la resistencia fue alta, lo que nos indica la rápida selección para la resistencia que presenta esta plaga.

Respecto a las resistencias cruzadas, a pesar de que no se encontró entre los neonicotinoides y la pimetrocina, como se ha publicado en otros estudios, nuestros resultados nos sugieren la existencia de un mecanismo alternativo a la sobreexpresión del citocromo P450 monooxigenasa en la resistencia a la pimetrocina. Además nos revelan que la expresión de la resistencia para estos insecticidas es en función del estado de desarrollo de Bemisia tabaci, es decir, expresándose en adultos en los neonicotinoides y en ninfas en pimetrocina para las poblaciones seleccionadas.

Para al acaricida piridabén ocurre lo mismo, la expresión de la resistencia es en función del estado de desarrollo, siendo en este caso en los adultos. Por tanto es una herramienta excelente para el control de las ninfas de la mosca blanca en las estrategias de control. Nuestros estudios para determinar el mecanismo implicado en la resistencia del piridabén mostraron que la P450 están involucradas, ya que el PBO reducía la resistencia de la población seleccionada. 
Por otro lado, sí que encontramos resistencia cruzada entre los reguladores de crecimiento (IGR) azadiractín y buprofecín, aunque no para piriproxifén. También se encontró resistencia cruzada entre buprofecín y la pimetrocina, aunque son de grupos diferentes. En los estudios de los mecanismos de resistencia en Bemisia para estos IGR, las poblaciones seleccionadas mostraron una disminución de la resistencia cuando se utilizaron sinergistas que inhibían las esterasas, y la mantenían cuando los sinergistas utilizados eran los que inhibían las P450 monooxigenasas.

Por tanto, se puede concluir con los resultados obtenidos de la existencia de resistencia cruzada y los conocimientos de los mecanismos implicados en la resistencia, la necesidad de implementar programas de control integrado y de manejo de la resistencia en Bemisia tabaci utilizando distintos sistemas de control e insecticidas con diferentes mecanismos de acción que permitan su sostenibilidad en el tiempo. 


\section{Abstract}

The tobacco whitefly, Bemisia tabaci (Gennadius, 1889), is one of the most important pests of many vegetable and ornamental crops in Spain since the 90s, both for its direct damage and by acting as a vector of plant gemini viruses. Throughout these years the excessive use of insecticides to control this pest has caused the development of resistance to several groups of insecticides. To avoid this and to propose appropriate control strategies is necessary to know the current effectiveness of insecticides, the existence of cross-resistance and the mechanisms involved in the detoxification of insecticides.

In this work, it was determined the current state of the resistance levels to the main insecticides (alpha-cypermethrin, azadirachtin, buprofezin, imidacloprid, methomyl, pymetrozine, pyridaben, pyriproxyfen and thiamethoxam) commonly used in whitefly control in greenhouses of southeastern Spain (Murcia and Almeria). Bioassays were conducted with nymphs of seven field populations. The results showed a high rate of effectiveness of various insecticides, contrary to what has been published so far. This reflects the reduction of use of insecticides in the integrated pest management strategies. However, resistance expression was high in populations subjected to high exposure to insecticides, which indicates the rapid selection for resistance in this pest.

No cross-resistance between neonicotinoids and pymetrozine was found, unlike published in other studies. Our results suggest the existence of an alternative mechanism to overexpression of cytochrome P450 monooxygenase in resistance to pymetrozine. Moreover, it was shown that the expression of resistance to these insecticides is specific for the stage of development of Bemisia tabaci, being expressed in adults for neonicotinoids and in nymphs for pymetrozine.

Similarly, the expression of resistance is age-specific for the acaricide pyridaben, being expressed in adults. Therefore pyridaben is an excellent tool for the control of whitefly nymphs in management strategies. Our studies to determine the mechanism involved in the resistance showed that $\mathrm{P} 450 \mathrm{~s}$ are involved, since the $\mathrm{PBO}$ reduced resistance in the resistant population.

On the other hand, we did find cross-resistance between the insect growth regulators (IGR) buprofezin and azadirachtin, although not with pyriproxyfen. We also found crossresistance between buprofezin and pymetrozine, although they belong to different groups. 
In studies on the mechanisms of resistance to these IGRs, selected resistant populations exhibited a decreased resistance when esterase inhibitors were used, but not with P450 inhibitors.

Therefore, the knowledge of the cross-resistance patterns and the resistance mechanisms involved allows for the implementation integrated control programs and resistance management in Bemisia tabaci using different control systems and insecticides with different mechanisms of action, promoting their sustainability. 


\section{ÍNDICE GENERAL}

\section{INTRODUCCIÓN}

1.1 Bemisia tabaci (Gennadius 1889) 1

1.1.1 Clasificación taxonómica 1

1.1.2 Origen, distribución geográfica e importancia económica 1

1.1.3 Biotipo o especie 3

1.1.4 Morfología

$\begin{array}{ll}\text { 1.1.5 Biología } & 7\end{array}$

1.1.6 Etología 9

1.1.7 Hospedantes 9

$\begin{array}{ll}\text { 1.1.8 Daños } & 10\end{array}$

1.2 Métodos de control de Bemisia tabaci 11

$\begin{array}{ll}\text { 1.2.1 Control biológico } & 11\end{array}$

$\begin{array}{ll}\text { 1.2.2 Control químico } & 13\end{array}$

1.2.2.1. Principales grupos de insecticidas utilizados en el control de Bemisia tabaci 13

$\begin{array}{ll}1.3 \text { Resistencia a insecticidas } & 17\end{array}$

$\begin{array}{ll}\text { 1.3.1 Definiciones y tipos } & 17\end{array}$

1.3.2 Factores que influyen en la resistencia a insecticidas $\quad 18$

1.3.3 Mecanismos implicados en la resistencia a insecticidas $\quad 19$

1.4 Resistencia a insecticidas en Bemisia tabaci 23

$\begin{array}{ll}\text { 1.5 Bibliografía } & 25\end{array}$

2. OBJETIVOS DE LA TESIS 37 
3.1 Jaulas de cría 41

$\begin{array}{ll}\text { 3.2 Material vegetal } & 42\end{array}$

$\begin{array}{ll}3.3 \text { Insectos } & 42\end{array}$

3.3.1. Poblaciones de campo 42

3.3.2. Poblaciones seleccionadas 45

3.4. Insecticidas 46

3.5. Mantenimiento de poblaciones 48

$\begin{array}{ll}\text { 3.6. Bioensayos } & 48\end{array}$

3.6.1. Material empleado 49

3.6.1.1. Cajas-pinza $\quad 49$

3.6.1.2. Cajas adultos $\quad 50$

3.6.2. Bioensayos de huevos $\quad 51$

3.6.3. Bioensayo de ninfas 52

3.6.4. Bioensayos de adultos $\quad 54$

3.6.5. Selección de poblaciones $\quad 55$

3.6.6. Bioensayos de sinergistas 57

3.7. Bibliografía

4. CAPÍTULO 1: ESTADO DE LA RESISTENCIA A INSECTICIDAS DE Bemisia tabaci BIOTIPO Q EN EL SURESTE DE ESPAÑA

1. Introducción 65

2. Material y métodos 67

2.1. Poblaciones de Bemisia tabaci 67 
5. CAPÍTULO 2: RESISTENCIA CRUZADA ENTRE NEONICOTINOIDES Y PIMETROCINA EN POBLACIONES DE Bemisia tabaci EN ADULTOS Y NINFAS 
2.5. Análisis de datos 96

3. Resultados y discusión $\quad 97$

4. Bibliografía 103

6. CAPÍTULO 3: MECANISMOS DE RESISTENCIA AL ACARICIDA METI PIRIDABÉN EN Bemisia tabaci

1. Introducción 111

2. Material y métodos 113

2.1. Poblaciones de Bemisia tabaci 113

2.2. Insecticidas 113

2.3. Bioensayos de ninfas, adultos y huevos 113

2.4. Selección de poblaciones 113

2.5. Bioensayos de sinergistas 114

2.6. Análisis de datos 114

3. Resultados y discusión 115

$\begin{array}{ll}\text { 4. Bibliografía } & 121\end{array}$

\section{CAPÍTULO 4: RESISTENCIA CRUZADA Y MECANISMOS DE RESISTENCIA ENTRE INSECTICIDAS REGULADORES DEL CRECIMIENTO EN Bemisia tabaci GENNADIUS}

1. Introducción 127

2. Material y métodos 129

2.1. Poblaciones de Bemisia tabaci 129

2.2. Insecticidas 129

2.3. Bioensayos de ninfas y huevos 129 


\section{INTRODUCCIÓN}

\subsection{Bemisia tabaci (Gennadius 1889)}

Bemisia tabaci es conocida con los nombres de: mosca blanca del tabaco, mosca blanca de la batata, mosca blanca del boniato, mosca blanca del algodonero, mosca blanca del camote; y en inglés como "sweetpotato whitefly", "tobacco whitefly", "cotton whitefly" y en francés como "aleurode du cotonnier".

\subsubsection{Clasificación taxonómica}

La especie Bemisia tabaci (Gennadius) se encuadra taxonómicamente en:

Phylum Arthopoda

Clase: Insecta

Subclase: Pterygota

División: Exopterygota (= Hemimetabola)

Orden: Hemiptera

Suborden: Sternorryncha

Superfamilia: Aleyrodoidea

Familia: Aleyrodidae, Westwood, 1840

Subfamilia: Aleyrodinae

Género: Bemisia, Quaintance \& Baker, 1914

Especie B. tabaci, Gennadius, 1889

\subsubsection{Origen, distribución geográfica e importancia económica}

La mosca blanca del tabaco, cuyo nombre científico es Bemisia tabaci, se cree que tiene su origen en el continente africano o bien en la zona de la India y Pakistán (Brown et al., 1995).

Fue descrita por primera vez por Gennadius en el año 1889, en Grecia, sobre planta de tabaco (Nicotiana sp.), con el nombre de Aleurodes tabaci (Gennadius, 1889). Cinco años después, en el Nuevo Continente, en concreto en Florida, Quaintance (1900) la describe de nuevo a partir de 
ejemplares capturados sobre varias especies vegetales, y la denomina Aleurodes incospicua. Quaintance y Baker (1914), al describir Bemisia como un nuevo género utilizando como especie tipo a Aleurodes incospicua, cambia su nombre por el de Bemisia incospicua. En 1957 esta especie y otras 18 previamente descritas, fueron sinonimizadas por Russell (1957) en una especie única, Bemisia tabaci. En 1978 se hizo una revisión de las especies incorporando todas las sinonimias de Russell y posteriores (Mound y Halsey, 1978a), se obtuvieron un total de 22 sinónimos que se atribuye a la variabilidad en la morfología de la cápsula pupal.

En España se describió por primera vez en el año 1943 (Gómez-Menor, 1943), descubriéndose además que se encontraba ampliamente distribuida por la zona sur y levantina de nuestro país. También se tiene constancia de su presencia en las Islas Canarias y las Islas Baleares.

Por otro lado en los últimos años se ha detectado en nuestro país la presencia de dos biotipos de esta especie. Estos biotipos son el B, que es de origen extranjero y que se ha introducido en nuestro país por medio del comercio y otro el Q, y que es el autóctono de nuestro país. Ambos biotipos se diferencian en características de tipo genético y biológico (Guirao et al., 1996).

Las referencias a Bemisia tabaci en España son escasas hasta 1988, y solamente la mencionan como especies asociada a cultivos de algodón (Alfaro, 1953) y tabaco (Izquierdo y Durán, 1967). Pero a partir de 1988, en la isla de Tenerife, se producen los primeros ataques importantes de Bemisia tabaci en poinsettias y en los cultivos hortícolas: calabacín, tomate, melón pimiento, etc., con poblaciones muy elevadas presentando un elevado grado de resistencia a insecticidas (Carnero et al., 1990). Desde julio de 1989 se empieza a detectar la presencia masiva de Bemisia tabaci en Almería.

En otoño de 1990, se presentan en las zonas costeras de Murcia elevadas poblaciones de Bemisia tabaci (Lacasa, 1995), detectándose también en la Comunidad Valenciana (MAPA, 1992).

Los niveles de población que Bemisia tabaci ha alcanzado durante la década de los 90 en la costa mediterránea y en los dos archipiélagos, han convertido esta especie en una de las más importantes de muchos cultivos hortícolas y ornamentales, agravados en algunos de estos por la aparición de virus transmitidos por este insecto.

A escala mundial, Bemisia tabaci se encuentra distribuida por todos los continentes. En el inventario efectuado por Mound y Halsey (1978), encuentra referencias de su presencia en un 
total de 57 países distribuidos en las nueve regiones zoológicas: Paleártica, Etiópica, Malgache, Oriental, Austro-Oriental, Australiana, Pacífica, Neártica y Neotropical.

La gran importancia económica actual sobre Bemisia tabaci se centra en una serie de eventos de invasión importantes, el primero ocurrió en la década de los 80 con el biotipo B, principalmente a través del comercio de plantas ornamentales (Broadbent et al., 1989 y Cheek et al., 1994). Desde sus orígenes en el Medio Este y la región de Asia Menor (Irán, Israel, Jordania, Kuwait, Pakistán, Arabia Saudita, Siria, República Árabe Unida, Yemen) a al menos 54 países (Samoa Americana, Antigua y Barbados, Argentina, Australia, Austria, Belice, Brasil, Canadá, China, Colombia, Islas Cook, Costa Rica, Chipre, Dinamarca, República Dominicana, Egipto, Fiji, Francia, Polinesia Francesa, Alemania , Grecia, Granada, Guadalupe, Guam, Guatemala, Honduras, India, Italia, Japón, Martinica, Islas Marshall, Mauricio, Mayotte, México, Nueva Caledonia, Nueva Zelanda, Países Bajos, Niue, Islas Marianas del Norte, Noruega, Panamá, Polonia, Puerto Rico, Reunión, Saint Kitts y Nevis, Sudáfrica, corea del Sur, España, Taiwán, Tonga, Trinidad-Tobago, Túnez, Estados Unidos, Venezuela).

En los últimos años esto ha sido seguido por la difusión global del biotipo Q, que se ha extendido desde su origen en los países ribereños del Mediterráneo (Argelia, Creta, Croacia, Egipto, Francia, Grecia, Israel, Italia, Marruecos, Portugal, España, Sudán, Siria, Turquía) a por lo menos 10 países (Canadá, China, Guatemala, Japón, México, Holanda, Nueva Zelanda, Corea del Sur, Uruguay, Estados Unidos)

\subsubsection{Biotipo o especie}

En los últimos 20 años hemos visto una proliferación de designaciones de biotipos en Bemisia tabaci por todo el mundo y estas designaciones se han basado principalmente en los marcadores genéticos, ya sea proteínas o $\mathrm{ADN}$, y no en datos biológicos o fronteras entre biotipos. Esta práctica ha dado lugar a un mal uso del biotipo (Downie 2010).

Desde la publicación de Boykin et al. (2007), la investigación sobre las relaciones genéticas entre los diferentes Bemisia tabaci (Gennadius) comenzó a adoptar un enfoque más estructurado y sistemático. En 2010, Dinsdale et al. (2010) refinan el trabajo de Boykin et al. (2007), y Xu et al. (2010), seguido por una serie de estudios como Elbaz et al. (2010), Wang et al. (2010, 2011), Sun et al. (2011), y Liu et al. (2012) que demostraron el soporte biológico para el concepto de que en lugar de una mezcla de biotipos, Bemisia tabaci es un complejo de especies crípticas (un grupo de especies que satisfacen la definición biológica de especie —esto es, que están aislados reproductivamente de otras especies- pero no son distinguibles 
morfológicamente), una conclusión que se alcanzó en la revisión de De Barro et al. (2011); donde define a $B$. tabaci como un conjunto de 11 grupos de alto nivel bien definidos que contiene por lo menos 24 especies morfológicamente indiferenciables.

Las especies del complejo se pueden distinguir por la secuenciación del gen mitocondrial CO1. El análisis de esas secuencias muestran que la diferencia genética de las poblaciones de Bemisia tabaci corresponde al origen geográfico excepto para dos especies que se encuentran en todo el mundo (Guirao et al., 1997, De la Rúa et al., 2006, De Barro et. al., 2005, De Barro et al., 2011, Hu et al., 2011, Alemandri et al., 2012, De Barro, 2012).

La figura 1 se muestra un resumen de la reconstrucción evolutiva utilizado un análisis Bayesiano de la oxidasa del citocromo mitocondrial 1 (mtCO1). Esta es la imagen de la estructura genética de B. tabaci, junto con la asignación de los biotipos a determinados grupos genéticos (De Barro et al., 2011. Estructura genética de Bemisia tabaci) 


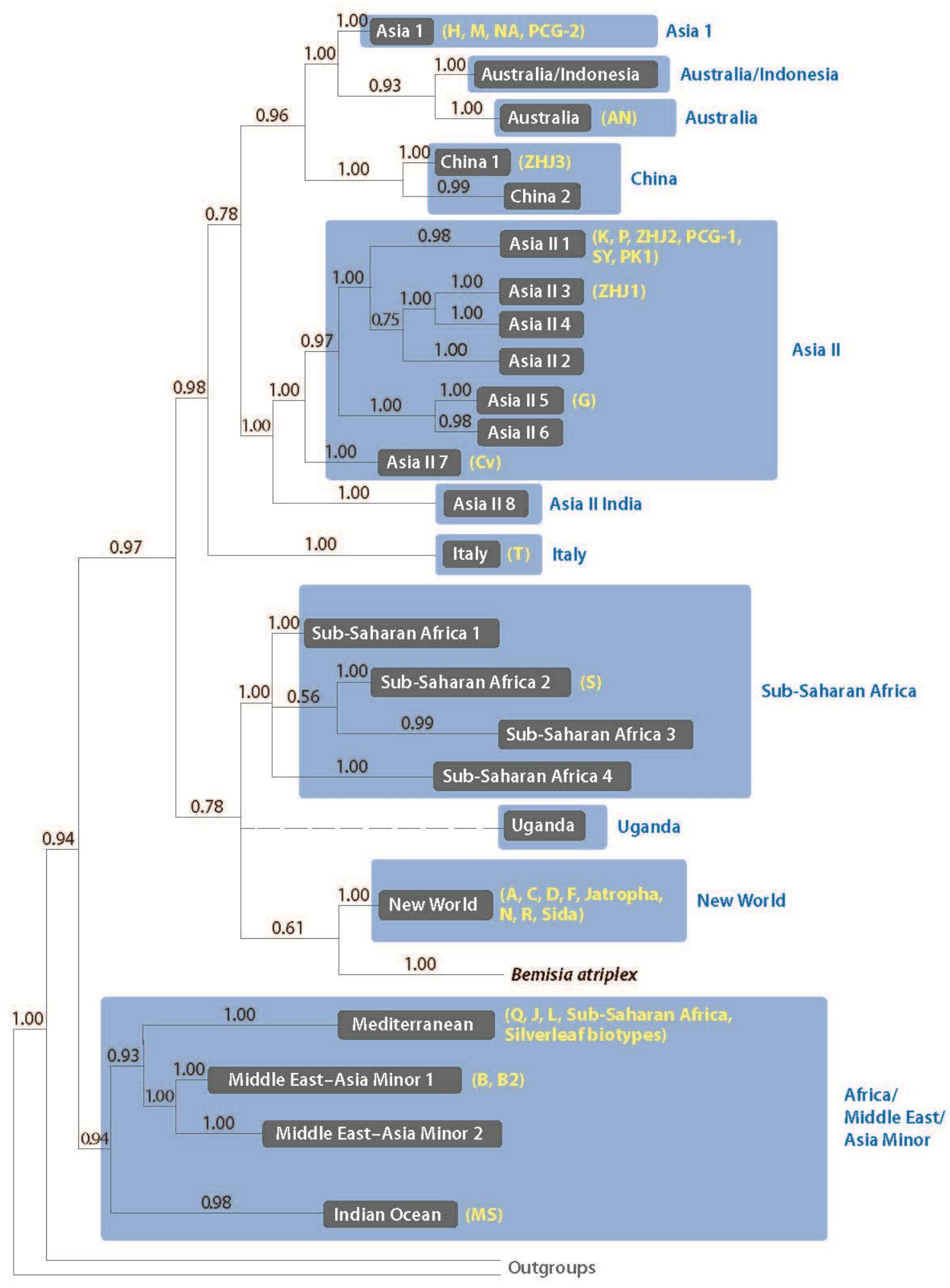

Figura 1: Estructura genética de Bemisia tabaci. (De Barro et al., 2011) 


\subsubsection{Morfología}

El huevo es elíptico e inicialmente de un tono amarillo blanquecino y según va evolucionando va adquiriendo un tono marrón-rojizo. La hembra coloca los huevos en posición vertical y generalmente en el envés de las hojas. Los huevos se hayan recubiertos por una secreción pulverulenta de color blanco. Miden unos 0,16 $\mathrm{mm}$ de longitud por unos 0,072 $\mathrm{mm}$ de diámetro (Gómez-Menor, 1945). En función de la especie de planta huésped los puede colocar de forma aislada o bien en grupo. En este último caso la hembra, tras clavar su estilete en la hoja y a la vez que se alimenta, gira alrededor de su estilete, el cual usa como eje de rotación, colocando así una hilera de huevos que tiene forma de circunferencia.

En los insectos exopterigotos (aquellos que tienen una metamorfosis simple o incompleta) los estados juveniles se denominan ninfas y no existe estado pupal. En la comunidad científica es corriente referirse a las ninfas de mosca blanca (y otros insectos como trips) como larvas y a la última fase de la N4 como pupa. Por facilidad de lectura en esta memoria en ocasiones se utilizan estos términos aunque técnicamente es incorrecto.

La L1 (larva de primer estadio) móvil o “crowler", es la que emerge del huevo. Esta larva posee un par de antenas, 6 patas funcionales y dos ojos simples de color rojo. Su cuerpo tiene forma elíptica y alargada y de color blanco-amarillento casi transparente. En su cuerpo pueden apreciarse dos manchas de color verde con forma oval que son los llamados micetomas. Esta larva tras emerger camina por la superficie hasta que encuentra una zona idónea y se fija.

La L1 fija, es la L1 móvil después de que ésta se fije a la superficie de la hoja. Cuando se fija repliega sus patas y antenas, clava su estilete bucal y empieza a alimentarse. También se produce un endurecimiento del exoesqueleto de la larva.

A la L1 fija la sucede la L2 (larva de segundo estadío), tras una muda. La L2 exteriormente es muy similar a la L1, diferenciándose únicamente en que la L2 es de un tamaño algo mayor.

La L3 (larva de tercer estadío) surge tras producirse una segunda muda. La L3 es de mayor tamaño que la L2 y de aspecto muy similar a esta última.

Finalmente, tras una tercera muda, aparece el último estadío larvario, la L4 o larva de cuarto estadío, que se diferencia del anterior estadío en que la L4 es de mayor tamaño. Según esta descripción podemos decir que los diversos estadíos larvarios por los que pasa B. tabaci en su desarrollo se diferencian básicamente en el tamaño de los sucesivos estadios, ya que exteriormente son muy similares. 
La pupa que es el estadío que sucede al de L4, ya sí presenta diversas modificaciones respecto al estadio anterior. Los ojos se vuelven compuestos y de color rojo. El cuerpo es de color amarillo y de forma más o menos elíptica. A ambos lados del cuerpo y en el interior de este, pueden verse dos bandas de color blanco que son las alas.

Tras el desarrollo de la pupa, el adulto emerge tras abandonar el exhuvio a través de una apertura en forma de $\mathrm{T}$ practicada en la parte posterior de ésta. Tras emerger el adulto tiene las alas replegadas, las cuales extiende en poco tiempo. El cuerpo del adulto es de color amarillo y las alas de color blanco. Cuando se encuentra en reposo mantiene las alas plegadas formando una especie de tejadillo (figura 2). También, después de la emergencia secreta una sustancia cérea con la cual recubre sus alas y parte de su cuerpo. Los ojos son compuestos y de color rojo. La hembra adulta generalmente es de mayor tamaño que el macho. Además se diferencia de este último en la forma del abdomen, ya que el de la hembra tiene una forma más o menos globosa y oval mientras que el del macho tiene una forma más apuntada.

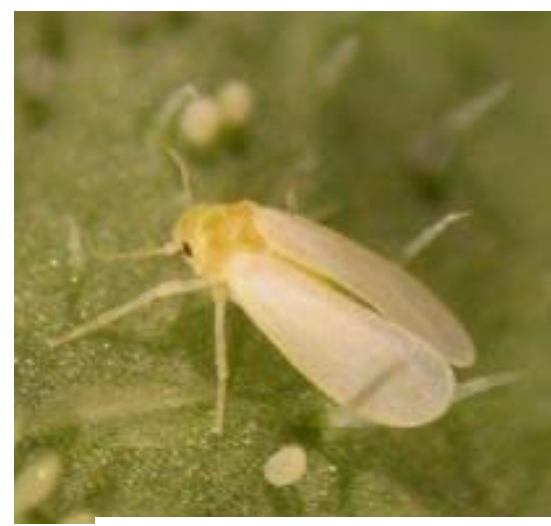

Figura 2. Bemisia tabaci

\subsubsection{Biología}

Como se ha podido comprobar en el apartado anterior B. tabaci a lo largo de su ciclo de vida pasa por etapas de desarrollo diferentes: huevo, cuatro estadios ninfales y adulto

Los apareamientos se producen transcurrido un breve periodo de tiempo después de la emergencia de los adultos. La reproducción puede ser bisexuada o partenogenética de tipo arrenotoca (Horowitz y Gerling, 1992; Perring et al., 1993). La proporción de sexos puede variar en función de las condiciones ambientales, de la estación del año, etc. 
Factores como la temperatura, la humedad y la abundancia y calidad del alimento van a condicionar la duración del desarrollo de esta mosca. En un experimento llevado a cabo con esta especie (Hendi et al., 1987) se obtuvieron los siguientes resultados (tabla 1):

Tabla 1.- Duración de las fases de desarrollo de $B$. tabaci a $30^{\circ} \mathrm{C}$ y $60 \%$ de $\mathrm{HR}$

\begin{tabular}{ll}
\hline Fase de desarrollo & Duración (días) \\
\hline Tiempo para una generación & 34 \\
\hline Huevo-Adulto & $17-27$ \\
\hline Pre-oviposición & $1-2$ \\
\hline Longevidad hembras & $8-43$ \\
\hline Longevidad machos & $3-13$ \\
\hline Fecundidad & 300 huevos/hembra \\
\hline
\end{tabular}

B. tabaci es capaz de completar en los meses más cálidos una generación en tan solo $12-14$ días, mientras que en los meses más fríos estos valores se incrementan hasta los 43 - 49 días (Rapisarda, 1990). De este modo, en áreas cálidas se produce un solapamiento de las generaciones, ya que esta especie se reproduce sin interrupción, pudiendo producirse hasta 11 generaciones por año.

Por otro lado también parece ser que el hospedante así como el estado sanitario de este influyen en la fecundidad de B. tabaci. El rango de temperaturas al cual puede desarrollarse y multiplicarse esta plaga es muy amplio, ya que puede realizar estos procesos en un intervalo de temperaturas que va desde los $16^{\circ} \mathrm{C}$ hasta los $34^{\circ} \mathrm{C}$. Los valores de los umbrales extremos de temperatura por debajo y por encima de los cuales no pueden realizar estos procesos son respectivamente 9 y $40^{\circ} \mathrm{C}$ (Sánchez et al., 1991). Los valores térmicos limitantes dependen también a su vez del estadío de desarrollo considerado y del hospedante vegetal (Powell y Bellows, 1992). De este modo, la L1 encuentra su valor térmico mínimo a $16,2{ }^{\circ} \mathrm{C}$ en calabacín y a $11,5{ }^{\circ} \mathrm{C}$ en el algodón. Por otro lado, el huevo tiene su mínimo térmico a $18,3{ }^{\circ} \mathrm{C}$ en el calabacín y a 15,8 en el algodón. Estos autores también señalaron que la supervivencia de esta especie se incrementa para temperaturas del orden de los $25-30{ }^{\circ} \mathrm{C}$ por encima de la que presenta a $20^{\circ} \mathrm{C}$. 


\subsubsection{Etología}

Durante el invierno, en cultivos al aire libre, B. tabaci tiende, en el caso de no mantenerse los cultivos (Stansly, 2002), a trasladarse a otros hospedantes secundarios donde pasa el invierno, generalmente en estadío de L4 o de pupa, ya que estos estadíos son los que presentan una menor mortalidad a bajas temperaturas (Horowitz y Gerling, 1992; Powell y Bellow, 1992). Estos hospedantes secundarios suelen ser plantas adventicias de porte herbáceo que se sitúan próximas a los cultivos. Una vez llega la primavera los adultos tienden a irse de nuevo hacia los cultivos, momento en el cual comienzan a detectarse poblaciones importantes. Los primeros focos de esta plaga suelen detectarse en los bordes de los cultivos. En este momento la mayor parte de los individuos de las poblaciones son hembras. A la vez que el cultivo se va desarrollando y van incrementándose las poblaciones de mosca blanca va aumentando también la proporción de machos, de este modo a final de campaña, aproximadamente al inicio del otoño, la proporción de machos es superior al 50 \% (Horowitz y Gerling, 1992).

En cultivos jóvenes la distribución espacial de B. tabaci en los diferentes estratos de la planta es irregular, ya que no existe una diferenciación muy acusada entre las hojas que aparecen en los diferentes estratos. En cultivos más desarrollados la distribución espacial en los diferentes estratos va a depender mucho del hospedante y más concretamente en el tipo de superficie que tienen sus hojas. Otro aspecto del comportamiento de B. tabaci es su tendencia, dentro de los cultivos protegidos, a desplazarse hacia las zonas más cálidas. Por tanto, encontraremos las mayores densidades de población en las zonas más cálidas de los invernaderos, y en función del hospedante, en uno u otro estrato del cultivo.

\subsubsection{Hospedantes}

Es una plaga extraordinariamente polífaga, ya que ha sido descrita sobre 420 especies de unas 74 familias botánicas diferentes. Dentro de estas se puede destacar (Mound y Halsey, 1978a):

- Asteráceas: Cártamo, gerbera, girasol lechuga, pataca.

- Convolvuláceas: Boniato

- Crucíferas: Brócoli, coles, coles de Bruselas, coliflor, nabo, rábano.

- Cucurbitáceas: Calabacín, calabaza, melón, pepino, sandía.

- Euforbiáceas: Mandioca, poinsettia.

- Labiadas: Albahaca, menta, orégano. 
- Fabáceas: Alfalfa, cacahuete, garbanzo, guisante, haba, judía, lenteja, soja.

- Malváceas: Abutilon, algodón, hibisco.

- Solanáceas: berenjena, pimiento, tabaco, tomate, patata.

Coloniza también un importante número de plantas espontáneas, entre las más frecuentes en los cultivos españoles destacan: Malva parviflora, Solanum nigrum, Datura stramonium, Chenopodium álbum, Sisymbrium irio, Senecio vulgaris, Sonchus oleraceus, Sonchus tenerrimus, Inula, Capsella bursapastoris (Muñiz, 2000; Muñiz, 1996, Alcázar et al., 1999; Lacasa et al., 1996).

\subsubsection{Daños}

B. tabaci es capaz de producir dos tipos de daños: directos e indirectos.

Los daños directos son provocados por la absorción de savia del floema, por parte de los diferentes estadios, de la planta huésped. Estos daños ocasionan una cierta pérdida de vigor en la planta que en última instancia pueden afectar a los rendimientos económicos.

Otro de los daños directos que provoca esta plaga es como consecuencia de la secreción de melaza. Los adultos, sobre todo las larvas segregan gran cantidad. La melaza es una sustancia compuesta por azúcares, monosacáridos, disacáridos y trisacáridos, cuya composición varía en función de la edad de la larva y se considera un subproducto de la actividad alimentaria de larvas y adultos. La melaza es excretada a través del ano, cayendo a la superficie de los vegetales. Es un medio de cultivo óptimo para el desarrollo de hongos tipo negrilla (Capnodium $s p p$.), que dificultan e incluso impiden la fotosíntesis en las superficies afectadas, produciéndose decoloraciones. Los productos manchados de melaza y negrilla pueden perder valor comercial y/o encarecer los costes al tener que ser lavados.

El daño indirecto que realiza esta mosca, y que sin duda es el más importante por las grandes pérdidas económicas que provoca en la agricultura, es la transmisión de virus. Se cree que $B$. tabaci es capaz de transmitir aproximadamente unos 300 virus fitopatógenos. Entre éstos cabe destacar el TYLCV (Tomato Yellow Leaf Curl Begomovirus) o virus del rizado amarillo o de la hoja en cuchara del tomate. Fue detectado por primera vez en España en cultivos de tomate de Murcia y Almería a final de verano de 1992 (Moriones et al., 1993). Posteriormente a su aparición, esta enfermedad se ha ido expandiéndose a otras áreas de cultivo de la península, incluso hasta Portugal (Louro et al., 1996). En la actualidad, el TYLCV es uno de los principales problemas fitopatológicos del cultivo del tomate en muchos países de la cuenca mediterránea, donde con frecuencia resulta ser un factor limitante para éste cultivo ya que 
puede originar la pérdida total de la producción, sobre todo en cultivos de final de verano y otoño, después de los periodos de altas temperaturas y humedades relativas bajas favorables para el desarrollo del vector (Moriones, 1996; Picó et al., 1996j; Sánchez-Campos et al., 1999).

\subsection{Métodos de control de Bemisia tabaci}

\subsubsection{Control biológico}

La aplicación del control biológico de moscas blancas en cultivos hortícolas y ornamentales está fuertemente influida por el clima, los ciclos de cultivo y las especies vegetales cultivadas. Hay una gran diversidad de parasitoides, depredadores y hongos entomopatógenos que son capaces de reproducirse y/o alimentarse sobre las diferentes especies de moscas blancas. En el caso de la Cuenca Mediterránea la fauna auxiliar asociada a los cultivos hortícolas, tanto en invernadero como al aire libre, y a los cítricos es muy rica y abundante, e hiberna al aire libre junto con el hospedador o la presa. Estos enemigos naturales pueden colonizar los cultivos conjuntamente con la plaga, lo que permite que el entorno suministre un aporte continuo de fauna útil a los cultivos. De hecho, la mayor parte de los enemigos naturales de moscas blancas que actualmente se están comercializando e inoculando en los invernaderos se han identificado en la Cuenca Mediterránea (Castañé et al. 2008).

Los parasitoides más comunes de las moscas blancas son himenópteros de la familia de los afelínidos y más concretamente de los géneros Encarsia, Eretmocerus y Cales. Las especies más importantes para Bemisia tabaci son: Encarsia formosa, E. pergandiella, E. tricolor, E. lutea, E. hispida, E. meritoria, E. sophia, E. inaron, E. noahi, E. guadelupae, Eretmocerus mundus, Er. eremicus, Cales noacki, Amitus spiniferus. (Gerling 1990; Gerling et al., 2001; Hernández-Suárez et al., 2003).

Los depredadores de moscas blancas incluyen coccinélidos, míridos, antocóridos, neurópteros, dípteros y fitoseidos (Soto y Garcia-Marí, 2000; Gerling et al., 2001; Avilla et al., 2004; Hoddle, 2004). Las especies más importantes para Bemisia tabaci son:

Ácaros: Amblyseius (Typhlodromips) swirskii

Coccinélidos: Clistotethus arcualus, Delphastus catalinae, Cryptolaemus monttrouzieri, Coccinella undecimpunctata $L$.

Dípteros: Coenosia attenuata, Acletoxenus formosus Loew

Antocóridos: Orius albidipennis, O. laevigatus, O. majusculus

Míridos: Macrolophus caliginosus, Nesidiocoris tenuis, Dicyphus tamaninii, D. errans

Neurópteros: Chrysoperla carnea, Conwentzia psociformis 
Como hongos podemos destacar Lecanicillium lecani, Paecilomyces fumosoroseus y Beauveria bassiana y como nematodos entomopatógenos se han hecho ensayos con Steinernema feltiae mostrando una eficacia relativamente elevada (Cuthbertson et al., 2007).

Actualmente, en el Sur de España el control biológico de la mosca blanca en el cultivo de pimiento se basa en la inoculación del parasitoide E. mundus y del fitoseido A. swirski, extendiéndose su aplicación a unas 6.000 ha. En tomate se emplea el control biológico en unas 1.400 ha de invernaderos (Van der Blom et al., 2008) y los enemigos naturales más ampliamente utilizados son E. mundus y los depredadores $N$. tenuis y, en menor medida, $M$. caliginosus. La instalación de ambos depredadores en el cultivo, sobre todo cuando las temperaturas van en descenso, es muy lenta y en algunos casos se inoculan conjuntamente con E. mundus (Van der Blom 2007, Nannini et al., 2006). Nesidiocoris tenuis es más abundante que M. caliginosus en estas zonas más cálidas, sin embargo debe tenerse en cuenta que este depredador es también fitófago y puede producir daños al cultivo sobre todo cuando no hay presas disponibles y las poblaciones son elevadas (Arnó et al. 2006b; Calvo et al., 2008; Sánchez, 2008).

La aplicación del control biológico en cultivos ornamentales también está en expansión. En cultivos de flor cortada, como la gerbera, se obtiene un buen control de B. tabaci mediante la inoculación del parasitoide E. mundus. En cambio, en cultivos en los que se comercializa toda la planta, como la poinsetia, sólo se obtienen buenos resultados cuando se inicia el cultivo con poblaciones muy bajas de la plaga y con pocos residuos de insecticidas sobre los esquejes, de forma que puedan comenzarse las sueltas de E. mundus desde el principio. El cultivo de la poinsetia se hace en invernaderos con calefacción lo que permite una buena acción del parasitoide. Sin embargo, debe tenerse en cuenta que cuando por necesidades del cultivo se baja la temperatura, la actividad del parasitoide disminuye y puede comprometerse el control de la plaga al final del cultivo. 


\subsubsection{Control químico}

Está basado en la aplicación de tratamientos con productos insecticidas.

\subsubsection{Principales grupos de insecticidas utilizados en el control químico de Bemisia}

\section{tabaci}

\section{$\underline{\text { Carbamatos }}$}

Son inhibidores de la acetilcolinesterasa (AchE). Los insecticidas carbamatos son ésteres del del ácido carbámico. El modo de acción es similar al de los fosforados, pero en este caso la reacción causa una carbamilación del grupo hidróxido serina (Sánchez, 2003).

Los carbamatos neutralizan la acetilcolinoesterasa, enzima encargada de destruir la acetilcolina que es un neurotransmisor que asegura la comunicación entre dos neuronas. Al no destruir la acetilcolina, se acumula en las sinapsis neuronales impidiendo la transmisión de mensajes nerviosos lo que acarrea la muerte del insecto. Ejemplo es el metomilo, que es un insecticida con actividad por vía sistémica y contacto. Se caracteriza por su efecto de choque y buena absorción foliar. Según la clasificación de los modos de acción de IRAC (Comité de acción para la resistencia a los insecticidas) pertenece al grupo $1 \mathrm{~A}$ Inhibidores de la acetilcolinesterasa.

\section{$\underline{\text { Piretroides }}$}

Los piretroides son sustancias químicas que se obtienen por síntesis y poseen una estructura muy parecida a las piretrinas. Los piretroides son un grupo de plaguicidas artificiales desarrollados para controlar preponderantemente las poblaciones de insectos plaga. Este grupo surgió como un intento por parte del hombre de emular los efectos insecticidas de las piretrinas naturales obtenidas del crisantemo, que se venían usando desde 1850.

$\mathrm{Su}$ acción, como casi todos los insecticidas, es a nivel sistema nervioso, generando una alteración de la transmisión del impulso nervioso. Típicamente son ésteres del ácido crisantemo, que tiene alto grado de lipofilia (soluble en grasas). Su efecto fundamental de debe a una modificación en el canal del sodio de la membrana nerviosa.

Para explicar el mecanismo de los piretroides distinguimos entre piretroides de tipo I: carentes de grupo alfa ciano en su molécula (aletrina, permetrina, tetrametrina, cismetrina,..) y piretroides de tipo II: poseen el grupo alfa ciano en su molécula (cipermetrina, deltametrina, 
fenvalerato, fenpropanato,..). Los compuestos de tipo I inducen picos múltiples de descargas en los nervios sensoriales, en los nervios motores y en las interneuronas dentro del sistema nervioso central, provocando convulsiones. Los compuestos de tipo II despolarizan el potencial de las membranas de los axones, esto reduce la amplitud del potencial de acción y lleva a la pérdida de excitabilidad eléctrica, provocando descoordinación. Estos efectos ocurren porque los piretroides prolongan la corriente que fluye por los canales de sodio al hacer más lento o al impedir el cierre de los canales. La duración de las corrientes de sodio modificadas para los compuestos de tipo I dura décimas o centésimas de milisegundos, mientras que las de tipo II duran algunos minutos o aún más.

En este grupo de insecticidas esta el alfa-cipermetrín, con actividad insecticida, no sistémico, con acción por contacto e ingestión. Según la clasificación de los modos de acción de IRAC pertenece al grupo 3A Moduladores del canal de sodio.

\section{$\underline{\text { Neonicotinoides }}$}

Los neonicotinoides son una familia de insecticidas que actúan en el sistema nervioso central de los insectos y con menor toxicidad en mamíferos.

El modo de acción de los neonicotinoides es similar al de los insecticidas derivados de la nicotina, que actúa en el sistema nervioso central. Son agonistas (sustancias capaces de unirse a un receptor celular y provocar una respuesta en la célula con el fin de estimular una función) del receptor nicotínico de la acetilcolina. Actúan por depolarización de la célula post-sináptica debido a la entrada de iones sodio y calcio. Activan el receptor nicotínico de la acetilcolina, pero lo hacen de manera persistente, ya que no son sensibles a la acción degradativa de la acetilcolinesterasa (Sánchez, 2003). En insectos, los neonicotinoides causan convulsiones, hiperexcitación y parálisis que llevan a la muerte, frecuentemente en pocas horas.

De este grupo son los insecticidas imidacloprid y tiametoxam, que según la clasificación de los modos de acción de IRAC pertenece al grupo 4A Agonistas del receptor nicotínico de la acetilcolina.

El imidacloprid es un insecticida sistémico y residual con actividad por contacto e ingestión, es absorbido por vía radicular y foliar. Los insectos tratados muestran inmediatamente los síntomas del envenenamiento con excitación y parálisis. Muestra actividad antialimentaria 
paralizando la acción de alimentarse a los insectos. Esta acción evita inmediatamente la transmisión de virus y controla el daño producido por los insectos. Posee actividad residual.

\section{$\underline{\text { Reguladores de crecimiento }}$}

Los reguladores del crecimiento de insectos (RCI) del tipo I y II son compuestos análogos o miméticos de las hormonas de la muda y juvenil. Actúan desequilibrando la concentración de las hormonas naturales durante los procesos de crecimiento y desarrollo normal entre estadios de las distintas plagas, provocando deformidades y la muerte por hambre. Así por otro lado, los inhibidores del desarrollo de insectos (IDI) del tipo III, interfieren con la formación de una nueva cutícula, ocasionando rompimiento o mal formaciones durante la muda, al inhibirse la síntesis de quitina, una sustancia que se encuentra solamente en los artrópodos, hongos y nematodos. Entre estos compuestos se encuentran los derivados de las benzoilureas.

Específicamente, los reguladores del crecimiento de insectos (RCI) afectan el crecimiento y desarrollo de los insectos-plaga como imitadores análogos de la hormona juvenil y como inhibidores de la síntesis de quitina. A los compuestos simuladores de la HJ (hormona juvenil) se les conocen por sus sinónimos como: juvenoides y juvenógenos. Ellos alteran el desarrollo inmaduro y la emergencia como adultos. Los inhibidores de la síntesis de quitina, (benzoilureas convencionales, buprofezin y ciromazina), afectan la formación de nuevos exoesqueletos durante la muda.

Dentro del grupo de los juvenoides está el piriproxifén que es un insecticida hormonal, con actividad por ingestión y contacto. Afecta a la fisiología de la morfogénesis, reproducción y embriogénesis de los insectos. Según la clasificación de modos de acción de insecticidas IRAC pertenece al grupo 7C Mimético de hormonas juveniles.

Y el buprofezín que es un insecticida con actividad por contacto, ingestión e inhalación. Perturba a la vez la formación de la quitina y el metabolismo de las prostaglandinas ligadas al proceso de regulación de la hidroxiecdisona. Según la clasificación de modos de acción de insecticidas IRAC pertenece al grupo 16 Inhibidores de la biosíntesis de la quitina, tipo 1, Homópteros. 


\section{Piridinazometrinas}

En este grupo está la pimetrozina, que es una piridinazometina sistémica con actividad insecticida selectiva, de contacto e ingestión, con acción específica contra homópteros. Se distribuye de manera acrópeta por el xilema; su transporte por el floema es muy débil. Posee actividad traslaminar. Se ha observado que actúa sobre los receptores neuronales del insecto, estimulando la liberación de serotonina en las fosas sinápticas. Los receptores de la serotonina, a su vez, se estimulan e influyen en las glándulas salivares. Los insectos afectados dejan de alimentarse poco después del tratamiento. Bloquea la penetración del estilete al iniciar la alimentación y no existe efecto de choque por lo que los insectos siguen activos pero no se pueden alimentar. Este bloqueo es irreversible y la muerte ocurre por hambre uno o pocos días después de la aplicación. Según la clasificación de modos de acción de insecticidas IRAC pertenece al grupo 9B Bloqueadores selectivos de la alimentación de homópteros.

\section{$\underline{\text { Piridazinonas }}$}

A este grupo pertenece el piridabén, insecticida y acaricida selectivo de contacto. Ofrece un control residual excepcionalmente largo, y acción inmediata en un amplio rango de temperaturas. No es sistémico ni traslaminar ni tiene actividad por inhalación por lo que debe pulverizarse muy bien la totalidad de la planta. Piridabén es un inhibidor metabólico que interrumpe el transporte de electrones en las mitocondrias en el Sitio 1. Según la clasificación de modos de acción de insecticidas IRAC pertenece al grupo $21 \mathrm{~A}$ acaricidas e insecticidas METI, inhibidores del transporte de electrones en el complejo mitocondrial I.

\section{$\underline{\text { Azadiractín }}$}

Insecticida botánico regulador del crecimiento que impide la muda por lo que los insectos mueren. Extraído del árbol del Neem. Actúa por contacto o por ingestión. Existen varias hipótesis sobre su modo de acción: interferencia con el sistema neuroendocrino que controla la síntesis de la ecdisona, responsable del proceso de la muda (inhibidor de la síntesis de quitina), y de la hormona juvenil y también la inhibición de la liberación de ecdisona de la glándula que la produce. Según la clasificación de modos de acción de insecticidas IRAC pertenece al grupo "un" Compuestos de modo de acción desconocido o incierto. 


\subsection{Resistencia a insecticidas}

\subsubsection{Definiciones y tipos}

La resistencia es definida como el desarrollo de la habilidad para tolerar dosis altas de tóxicos, los cuales resultarían letales a la mayoría de los individuos en una población normal de la misma especie. Según Crow (1960) es el cambio genético en respuesta a la selección (por plaguicidas). La OMS (Brown y Pal 1971) la define como el desarrollo de la habilidad en una raza de insectos para tolerar dosis de tóxicos que han probado ser letales a la mayoría de los individuos en una población normal de la misma especie.

Según la FAO (1970), es una respuesta disminuida de la población de una especie de animales o plantas a un plaguicida o agente de control como resultado de su aplicación. La FAO (1979) enmarca la resistencia como la capacidad desarrollada por una población determinada de insectos, al no ser afectada por la aplicación de insecticidas.

La resistencia corresponde a "la reducción en la susceptibilidad de una población y se evidencia mediante repetidos fallos en la efectividad de un producto, disminuyendo las expectativas de control al ser usado a la dosis recomendada para la plaga y donde los fallos por almacenamiento del producto, aplicación y factores climáticos poco frecuentes pueden ser eliminados" IRAC (Insecticide Resistance Action Committee).

Bajo el término de resistencia se engloban los siguientes tipos de resistencia: Resistencia cruzada (positiva o negativa): según Monge (1986), indica que la resistencia cruzada positiva puede ser definida como "la resistencia que se genera en los insectos a un determinado plaguicida y a otros que no se han aplicado, pero que tienen forma de acción o de detoxificación similares". Siendo la resistencia cruzada negativa lo contrario, cuando al aplicar un plaguicida aumenta la resistencia a éste pero disminuye a otros.

Este fenómeno de la resistencia cruzada se da cuando una plaga desarrolla resistencia a un producto, que al ser tratada intensamente con éste, adquiere un mecanismo de resistencia. Este mecanismo de resistencia puede otorgar resistencia a otros productos, que incluso nunca hayan sido utilizados contra esa plaga o esa población.

El caso típico corresponde al DDT y a los piretroides que a pesar de pertenecer a diferentes grupos químicos comparten el mismo modo de acción, pues ambos actúan sobre la velocidad de los canales iónicos quedando la membrana nerviosa alterada (efecto Knock Down o volteo). El desarrollo de la resistencia al volteo se produce por la expresión del gen Kdr. 
Resistencia múltiple: Se utiliza este término cuando dos mecanismos de resistencia o más están operando en el mismo insecto (Bisset, 2002). Según Silva et al. (2004), es la protección contra varios insecticidas no relacionados debido a la coexistencia de diferentes mecanismos de resistencia seleccionados de manera independiente. Un ejemplo es el de Musca domestica L., que ha desarrollado este tipo de resistencia en Dinamarca (Keiding, 1977) o el caso de Letinotarsa decemlineata Say que ha desarrollado resistencia a 38 insecticidas (Mota-Sánchez et al. 2002).

\subsubsection{Factores que influyen en la resistencia}

Según Gorghiou y Taylor (1986), los factores que predisponen a la resistencia a los insecticidas se pueden resumir en tres, genéticos, biológicos y operacionales. Dentro de los factores genéticos, el principal es la proporción inicial de genes de resistencia en la población. Los factores biológicos, presentan como elemento principal la naturaleza biológica de la especie (fertilidad, fecundidad, etc.) y los factores operacionales, implican principalmente, la naturaleza química del insecticida.

A continuación se describen los factores conocidos o sugeridos que influyen en la selección de resistencia a insecticidas en poblaciones de campo (Georghiou y Taylor 1977):

\section{A. Genéticos}

a. Frecuencia de genes de resistencia

b. Número de genes de resistencia

c. Dominancia de los genes de resistencia

d. Penetración, expresión e interacciones de los genes de resistencia

e. Historia de la selección con otros insecticidas

f. Magnitud de la integración del genoma resistente con los factores de la capacidad biótica.

B. Biológicos/Ecológicos

1. Bióticos

a. Duración de la generación

b. Descendencia por año

c. Monogamia/Poligamia, partenogénesis

2. De comportamiento/Ecológicos

a. Aislamiento, movilidad, migración 
b. Monofagia/Polifagia

c. Sobrevivencia fortuita, refugio

C. Operacionales

1. El insecticida

a. Naturaleza química del insecticida

b. Relación con los compuestos usados con anterioridad

c. Persistencia de los residuos, formulación

2. La aplicación
a. Umbral de aplicación
b. Umbral de selección
c. Estado biológico seleccionado
d. Modo de aplicación
e. Selección en espacios limitados
f. Selección alternada

\subsubsection{Mecanismos implicados en la resistencia a insecticidas}

Existen diferentes mecanismos en que las plagas pueden llegar a ser resistente a los plaguicidas:

- Resistencia de comportamiento. Consiste en la pérdida de susceptibilidad por cambio en el comportamiento del insecto frente a los repetitivos programas de control. No es un mecanismo tan importante, sin embargo contribuye en la disminución de la efectividad de la dosis letal del plaguicida. Esta habilidad puede producirse mediante un estímulo dependiente o independiente. El primero se evidencia cuando una plaga evita el contacto con la zona tratada con plaguicida (repelencia) y el estímulo independiente ocurre cuando la plaga abandona la zona tratada con el plaguicida hacia un área sin residuos (irritancia). Este mecanismo no confiere una resistencia real, ya que sería controlado si entrara en contacto con el producto, por eso se le llama pseudoresistencia.

- Resistencia a la penetración. Este mecanismo de resistencia se produce en un amplio rango de insecticidas. Consiste en una baja absorción del plaguicida debido a la modificación en la cutícula o en el tracto digestivo del insecto. Esta reducción en la penetración del 
insecticida se traduce en una menor absorción de la toxina en el cuerpo del insecto comparado con las poblaciones susceptibles.

- Resistencia metabólica. Los insectos tiene enzimas que degradan cualquier tóxico al que son expuestos. Estos enzimas de detoxificación también son los responsables de metabolizar los insecticidas a productos no tóxicos, más hidrófilos, y fácilmente excretables. La resistencia metabólica corresponde al mecanismo típico expresado por los insectos, rompiendo la estructura de los plaguicidas mediante el sistema enzimático pudiendo degradar un amplio espectro de plaguicidas. Es decir, las enzimas detoxificadoras son utilizadas para romper la invasión del plaguicida (toxina) en el cuerpo del insecto. El primer caso de resistencia metabólica citado correspondió al detectado en mosca doméstica con el uso de DDT (Wiesmann 1947)

Estudios de detoxificación en insectos revelan que la versatilidad en la adaptación de los insectos a su medio es provista por el fenómeno de inducción. Éste es un proceso en el cual un estímulo químico promueve la actividad del sistema de detoxificación mediante la producción de enzimas adicionales.

El insecticida sufre dentro del organismo del insecto una serie de reacciones mediante las cuales adquiere grupos funcionales que le permiten en una segunda fase, conjugarse con sustancias endógenas y dar como resultado compuestos más polares de menor solubilidad en lípidos y como consecuencia más fácilmente excretables. No siempre es necesario que el insecticida se transforme mediante reacciones de la primera fase, porque en su estructura puede poseer grupos funcionales que le permitan experimentar directamente las reacciones de la segunda fase (Sotolongo, 1988).

Existen tres clases de enzimas de detoxificación:

- Esterasas

- P450 monooxigenasas

- Glutatión S-transferasas

Estos sistemas enzimáticos metabolizan la materia activa del insecticida de diversos modos: hidrólisis (esterasas), oxidaciones (P450 monooxigenasas) y conjugaciones (Glutatión Stransferasas).

Esterasas: Las carboxilesterasas o esterasas constituyen una gran familia de enzimas que son responsables el metabolismo lipídico y de la detoxificación de xenobióticos, entre otras funciones. Las esterasas están implicadas en resistencia a organofosforados, carbamatos y 
piretroides debido a que son ésteres y pueden ser hidrolizados por esterasas. El aumento en actividad degradativa mediada por esterasas es un mecanismo de resistencia muy importante en organofosforados, a veces importante en piretroides y poco importante en carbamatos (Leclant, 1988). Dentro de las esterasas podemos diferenciar: carboxiestearasas, fosforotriestearasas, según produzcan hidrólisis de grupos carboxiester o fosforotriester (Bisset, 2002).

P450 mooxigenasas: El citocromo P-450 interviene fundamentalmente en reacciones de oxidación, también es capaz de catalizar reducciones, hidrataciones o hidrólisis. Salvo contadas excepciones, el P-450 requiere oxígeno molecular y NADPH para oxidar el substrato. Se trata de reacciones de monooxigenación en las que sólo uno de los átomos de oxígeno es incorporado en la molécula del substrato, mientras que el otro es reducido hasta agua. A los enzimas que catalizan este tipo de oxidaciones se les conoce como monooxigenasas u oxidasas de función mixta.

Las citocromo P450 constituyen un grupo numeroso de enzimas que se han asociado a resistencia metabólica (Feyereisen, 2005). Las P450 poseen una gran variedad de actividades enzimáticas (oxidasa, reductasa, isomerasa...), y son el producto de la traducción de los genes CYP (revisado por Feyereisen, 2011). Este grupo de enzimas presenta un pico de absorción a una longitud de onda de $450 \mathrm{~nm}$, característica que da nombre a esta familia proteica (Omura y Sato, 1964). Debido a su función de detoxificación, por oxidación de los xenobióticos, poseen un papel importante en el metabolismo de los insecticidas. Las P450 están implicadas en la resistencia frente a los principales grupos de insecticidas, tales como organofosforados, piretroides, etc.

Glutatión S-transferasas: conforman una familia de enzimas implicadas en la detoxificación de multitud de xenobióticos. Estas enzimas catalizan la unión de una molécula de glutatión al insecticida, dando lugar a un compuesto hidrosoluble que se excreta más fácilmente. Se clasifican de acuerdo con la reacción que catalizan como alquil, aril y epoxitransferasas (Terriere, 1984). Las transferasas del glutation son importantes en la detoxificación de organofosforados y proveen la forma más importante de resistencia metabólica al DDT a través de la dehidroclorinación.

- Resistencia por insensibilidad en el punto de acción. Corresponde al segundo mecanismo más común de resistencia y está referida al cambio en la estructura del sitio o al número de sitios donde el plaguicida causa toxicidad sobre el insecto. 
Generalmente, los insecticidas actúan en un sitio específico del insecto, habitualmente en el sistema nervioso del insecto (piretroides, organofosforados y carbamatos). El sitio de acción puede ser modificado por razas resistentes impidiendo la acción del insecticida. Como resultado, el insecto no será controlado mediante la aplicación de un plaguicida o sólo se afectarán los insectos más susceptibles.

Existen tres puntos principales de la acción de los insecticidas que son afectados por este mecanismo, en la mayoría de los casos el mecanismo involucra una sustitución de un simple aminoácido del sitio activo: la AchE (el blanco para los organofosforados y carbamatos) y los canales de $\mathrm{Na}+$ de la membrana de las células nerviosas (para algunos organoclorados y piretroides) y los receptores GABA (para los ciclodienos).

\section{$\underline{\text { Acetilcolinesterasa alterada }}$}

La AchE es el sitio activo de los organofosforados y carbamatos (Gepner y cols., 1978), los cuales se unen a la AchE, formando un compuesto fosforilado o carbamilado, el cual impide la función normal de la AchE que es la hidrólisis de la acetilcolina (Ac). La enzima (AchE) juega un papel importante en las funciones nerviosas. Esta molécula tiene como función específica catalizar la hidrólisis del neurotransmisor excitatorio Ac, lo cual hace que sea un componente clave para la sinápsis colinérgica en el sistema nervioso tanto de insectos, donde la Ac es el principal neurotransmisor (Toutant, 1989), como de todas aquellas especies que presentan este sistema como parte de su fisiología.

Algunos estudios sugieren como explicación para el mecanismo de insensibilidad del punto de acción, mutaciones puntuales simples o múltiples. Para el caso del locus AchE se demostró que un determinado número de mutaciones puntuales a este nivel provocaron afectación en la sensibilidad de la AchE cuando fue inhibida por OFs y carbamatos en M. domestica (Kozaki y cols., 2001).

\section{$\underline{\text { Receptores GABA (ácido amino butírico) }}$}

Los receptores GABA están localizados en los canales de los iones $\mathrm{Cl}^{-}$de la membrana nerviosa, los cuales controlan el flujo de estos iones a través de la misma. Ellos son receptores del neurotransmisor. Los ciclodienos, los cuales constituyen un subgrupo de los organoclorados, también afectan la función del nervio, pero por la unión con los receptores GABA. La resistencia a ciclodienos está asociada con el reemplazamiento de un simple aminoácido (alanina 302) de una subunidad del gen de resistencia a dieldrin (Rdl), que codifica para el receptor GABA. En los insectos resistentes a ciclodienos, el residuo alanina es 
reemplazado por residuos de serina o por glicina y esta mutación convierte al receptor GABA insensible a la unión con el insecticida. La alteración en los receptores GABA los hace insensible a los ciclodienos.

\section{Alteraciones en los canales de sodio $(\mathrm{Na}+)$}

El canal de $\mathrm{Na}+$ es el sitio fisiológico primario de acción de los insecticidas piretroides, DDT y sus análogos. La alteración del canal de sodio o la reducción de la afinidad de las proteínas del canal por el insecticida es un importante mecanismo de resistencia que confiere insensibilidad nerviosa y es además conocida como resistencia por knock down (gen kdr).

Los datos disponibles acerca del mecanismo del gen kdr provienen principalmente de estudios electrofisiológicos donde se observa que los insecticidas no alteran la función nerviosa. Los insecticidas piretroides y DDT interfieren con la velocidad de cierre de los canales iónicos quedando la membrana nerviosa excitada en forma permanente y produciendo lesiones primarias críticas, puntos de partida de cadenas de eventos que conducen a la muerte (Magin et al., 1985 y Leclant, 1988).

\subsection{Resistencia a insecticidas en Bemisia tabaci}

Como consecuencia de la exposición extensa a los insecticidas, B. tabaci ha desarrollado resistencia a una amplia gama de agentes de control químicos. La necesidad de una mayor diversidad de productos químicos para el control de mosca blanca en los programas de manejo de la resistencia ha dado lugar a la introducción de varios insecticidas con nuevos modos de acción, que no se ven afectadas por los mecanismos de resistencia a los organofosforados, por ejemplo, o piretroides.

La resistencia a imidacloprid se demostró por primera vez en B. tabaci en invernaderos en la región de Almería en el sur de España, pero también fue detectado en poblaciones de Italia y Alemania (Elbert y Nauen, 2000; Nauen et al., 2002), y en Arizona, pero a niveles más bajos (Li et al., 2001).

En el caso de los insecticidas reguladores del crecimiento, a pesar de tener un modo de acción único, han demostrado estar sujetos también a la resistencia por B. tabaci. Los cambios en la susceptibilidad a buprofezín y piriproxifén han sido bien documentados y, de forma similar a imidacloprid, se detectaron por primera vez en sistemas de producción intensiva, cerrados. La resistencia a buprofezín fue documentada por primera vez en poblaciones de B. tabaci recogidas en invernaderos de los Países Bajos, y en invernaderos de España e Israel (Cahill et 
al., 1996; Horowitz y Ishaaya, 1994), donde los cambios en la susceptibilidad se asociaron con aplicaciones repetidas del compuesto.

Piriproxifén se utilizó por primera vez en Israel en 1991, y al cabo de un año, se detectó un nivel relativamente alto de resistencia (> 500 veces) en poblaciones de B. tabaci recolectadas de un invernadero de rosas, donde las poblaciones habían sido expuestas a tres aplicaciones consecutivas (Horowitz y Ishaaya, 1994).

En el 2005, ya aparece publicado resistencias a alfa-cipermetrín en poblaciones recogidas en cultivos de berenjena en Grecia (Roditakis et al., 2005).

En carbamatos como metomilo, ya en los años 90 se observaron resistencia en poblaciones en Pakistán (Ahmad et al., 2010).

En poblaciones recogidas en invernaderos de Almería en 1994 se observaron resistencias a pimetrozina, a pesar que nunca se había usado (Elbert, N., y R. Nauen. 2000).

Actualmente, se pueden encontrar en la literatura casos en los que Bemisia tabaci ha presentado resistencias a más de 45 materias activas distintas, por esto es necesario implementar programas de control integrado y de manejo de la resistencia en Bemisia tabaci utilizando distintos sistemas de control e insecticidas con diferentes mecanismos de acción que permitan su sostenibilidad en el tiempo. 


\subsection{Bibliografía}

Ahmad, M., Arif, M., Naveed M. 2010. Dynamics of Resistance to organohosphate and carbamate insecticides in the cotton whitefly Bemisia tabaci (Hemiptera: Aleyrodidae) from Pakistan . journal of pesticide science, 83 409-420.

Alcázar, A.; Lacasa, A.; Guerrero, M. M.; Guirao, P. y Jordá, C. 1999. Hospedantes de Bemisia tabaci (Gennadius) y del Tomato Yellow Leaf Curl Virus en cultivos de tomate de Murcia. Resúmenes del 1 Congreso de Entomología Aplicada - VII Jornadas Cientificas de la SEEA. Almeria, 8-12 noviembre de 1999: 35 (Abstract).

Alemandri, V., De Barro, P., Bejerman, N., Arguello Caro, E.B., Dumon, AD., Mattio, M.F., Rodriguez, S.M., Truoli, G. (2012) Species within the Bemisia tabaci (Hemiptera: Aleyrodidae) complex in soybean and bean crops in Argentina. Journal of Economical Entomology, 105, 48- 53.

Alfaro, A. 1953. Aspecto fitopatológico del cultivo algodonero en Aragón. Boletines de Patología Vegetaly Entomología Agrícola, 20: 145-166.

Arnó, J.; Castané, C.; Riudavets, J.; Roig, J. y Gabarra, R. 2006. Characterization of damage to tomato plants produced by the zoophytophagous predator Nesidiocoris tenuis. OILB/WPRS Bull., 29 (4): 249-254.

Avilla, J.; Albajes, R.; Alomar, O.; Castane, C. y Gabarra, R. 2004. Biologícal control of whiteflies ín protected vegetable crops, pp. 171-184. En: R.G. Van Oriesche, K.M. Heinz y M.P. Parrella (editores) Biocontrol in protected culture. Ball Publishing, Batavia, Illinois, EE UU.

Bisset, J. 2002. Uso correcto de insecticidas: control de la resistencia. Rev Cubana Med Trop. 54(3): 202-219.

Blom, J. Van Der. 2007. Control de plagas en hortícolas protegidas: Almeria, el año de la transición. Horticultura 200: 36-43.

Blom, J. Van Der; Robledo, A.; Torres, S. y. Sánchez J.A. 2008. Control biológico de plagas en Almería: revolución verde después de dos décadas. Phytoma-España 198: 42-48.

Boykin L M, Shatters R G, Rosell R C, McKenzie C L, Bagnall R A, De Barro P J, Frohlich D R. 2007. Global relationships of Bemisia tabaci (Hemiptera: Aleyrodidae) revealed using Bayesian analysis of mitochondrial COI DNA sequence. Molecular Phylogenetics and Evolution, 44, 1306-1319. 
Broadbent AB, Foottit RG, Murphy GD. 1989. Sweetpotato whitefly Bemisia tabaci (Gennadius) (Homoptera: Aleyrodidae), a potential insect pest in Canada. Can. Entomol. 121:1027-28.

Brown, A. W. A. y Pal, K. 1971. Insecticide resistance in arthropods. In World Health Organization Monograph Series No. 38. Geneva, World Health Organization. P. 491.

Brown J. K., Frohlich D. R., Rosell R. C. 1995. The sweetpotato or silverleaf whiteflies: biotypes of Bemisia tabaci or a species complex? Annual Review of Entomology, 40, 511-534.

Cahill, M., Jarvis, W., Gorman, K., Denholm, I., 1996. Resolution of baseline responses and documentation ofresistanc e to buprofezin in Bemisia tabaci (Homoptera: Aleyrodidae). Bull. Entomol. Res. 86, 117-122.

Calvo, J.; Bolckmans, K.; Stansly, P. y Urbaneja, A. 2008. Predation by Nesidiocoris tenuis on Bemisia tabaci and Injury to Tomato. BioControl. En prensa. (DOI 10.1007/s10526-0089164-y).

Carnero, A.; Montesdeoca-Montesdeoca, M.; Pérez-Padrón, F.; Silverio-Núñez, A. y Rodríguez-López, P, 1990. Presencia de Bemisia tabaci (Gennadius) en cultivos comerciales de hortícolas y ornamentales en la isla de Tenerife (Islas Canarias). Cuadernos de Fitopatología, $4^{\circ}$ Trimestre: 176-180.

Castañé, C., Arnó, J., Beitia, F., Gabarra, R. 2008 Control biológico de moscas blancas, pp. 239-253. En J.A. Jacas \& A. Urbaneja (eds.) Control biológico de plagas agrícolas, M.V. Phytoma España, S.L., Valencia, España.

Cheek S, Macdonald O. 1994. Statutory controls to prevent the establishment of Bemisia tabaci in the United Kingdom. Pestic. Sci. 42:135-42

Crow, J. F. 1960. Genetics of insecticide resistance: general considerations. Miscelaneous Publication of the Entomological Society of America 2. 69-74.

Cuthbertson. A. G. S. Walters, K. F. A., Northing, P. y Luo, W. 2007. Efficacy of the entomopathogenic nematode, Steinernema feltiae, against sweetpotato whitefly B. tabaci (Homoptera: Aleyrodidae) under laboratory and glasshouse conditions. Bull. Entomo!. Res. 97(1): 9-14. 
De Barro, P.J. 2012. The Bemisia tabaci species complex: questions to guide future research. Journal of Integrative Agriculture, 11, 187- 196.

De Barro, P. and Ahmed, M.Z. 2011. Genetic networking of the Bemisia tabaci cryptic species complex reveals pattern of biological invasions. PLoS ONE, 6, e25579.

De Barro P J, Liu S S, Boykin L M, Dinsdale A B. 2011. Bemisia tabaci: a statement of species status. Annual Review of Entomology, 56, 1-19

De Barro, P.J., Trueman, J. W.H. and Frohlich, D.R. 2005. Bemisia argentifolii is a race of B. tabaci (Hemiptera: Aleyrodidae): the molecular genetic differentiation of B. tabaci populations around the world. Bulletin of Entomological Research, 95, 193- 203.

De La Rua, P., Ceni s, J.L., Simon, B., Cifuentes, D. and Martinez- Mora, C. 2006. New insights into the mitochondrial phylogeny of the whitetly Bemisia tabaci (Hemiptera : Aleyrodidae) in the Mediterranean Basin. Journal of Zoological Systematics and Evolutionary Research, 44, 25- 33.

Dinsdale A, Cook L, Riginos C, Buckley Y M, De Barro P J. 2010. Refined global analysis of Bemisia tabaci (Hemiptera: Sternorrhyncha: Aleyrodoidea: Aleyrodidae) mitochondrial cytochrome oxidase 1 to identify species level genetic boundaries. Annals of the Entomological Society of America, 103, 196-208.

Downie D. A. 2010. Baubles, bangles, and biotypes: A critical review of the use and abuse of the biotype concept. Journal of Insect Science, 10, 176.

Elbaz M, Lahav N, Morin S. 2010. Evidence for pre-zygotic reproductive barrier between the B and Q biotypes of Bemisia tabaci (Hemiptera: Aleyrodidae). Bulletin of Entomological Research, 100, 581-590.

Elbert, A., Nauen, R., 2000. Resistance of Bemisia tabaci (Homoptera: Aleyrodidae) to insecticides in southern spain with special reference to neonicotinoids. Pest Manage. Sci. 56, $60-64$.

Feyereisen, R. 2005. Insect cytochrome P450. In L. I. Gilbert, K. Iatrou, \& S. S. Gill (Eds.), Comprehensive Molecular Insect Science. 4: 1-77. Oxford, UK: Elsevier.

Feyereisen, R. 2011. Arthropod CYPomes illustrate the tempo and mode in P450 evolution. Biochim. Biophys. Acta. 1814: 19-28. 
Gennadius, P. 1889. Disease of the tobacco plantations in the Trikonia. The aleurodide of tobacco. Ellenike, Georgia, 5: 1-3.

Georghiou, G. P., y Taylor, C. E. 1986. Factors influencing the evolution of resistance. Pp. 157-169. In: National Research Council (ed). Pesticide resistance: Strategies and tactics for management. Acad. Press. Washington. D. C.

Georghiou, G. P., y Taylor, C. E. 1977. Genetic and biological influences in the evolution of insecticide resistance. J. Econ. Entomol. 70: 319-312.

Georghiou, G. P., y Taylor, C. E. 1977. Operational influences in the evolution of insecticide resistance. J. Econ. Entomol. 70: 653-658.

Gepner, J. I.; Hall, L. M. y Statelle, D.B. 1978. Insect acetylcholine receptors as a site of insecticide action. Nature, 70: 188-190.

Gerling, D. 1990. Natural enemies of whiteflies: predators and parasitoids, pp. 147-185. En: D. Gerling (editor) Whiteflies: their bionomics, pest status and management. Intercept, Andover, Hants, Reino Unido.

Gerling, D.; Alomar, O. y Arnó, J. 2001. Biological control of Bemisia tabaci using predators and parasitoids. Crop Prot. 20: 779- 799.

Gómez-Menor, J. 1945. Aleiródidos de interés agrícola. Boletines de Patología Vegetal y Entomología Agrícola, XIII: 161-198.

Gómez-Menor, J. 1943. Contribución al cocimiento de los Aleyródidos de España (Hem. Homóptera) $1^{a}$ nota. Eos, 19: 173-209.

Guirao, P., Beitia, F. and Cenis, J.L. 1997. Biotype determination of Spanish populations of Bemisia tabaci (Hemiptera: Aleyrodidae). Bulletin of Entomological Research, 87, 587- 593.

Guirao, P.; Cenis, J. L. y Beitia, F. 1996. Determinación de la presencia en España de biotipos de Bemisia tabaci (Gennadius). Phytoma España, 81 (Ago/sep): 30-34.

Hendi, A; M.J. AbdeL-Fattah, A. E-Sayed 1987. Biological study on the whitefly Bemisia tabaci (Genn) (Homoptera: Aleyrodidae). Bull. Soc. Ent. Egypte 65: 1984-1985.

Hernandez-Suárez, E., Carnero, A., Aguiar, A., Prinsloo, G.; Lasalle, J. y Polaszek, A. 2003. Parasitoids of whiteflies (Hymenoptera: Aphelinidae, Eulophidae, Platygastridae; Hemiptera: 
Aleyrodidae) from the Macaronesian archipelagos of Canary Islands, Madeira and the Azores. Syst. Biodivers. 1: 55-108.

Hoddle, M.S. 2004. Biological control of whiteflies on ornamental crops, pp. 149-170. En: R.G. Van Driesche, K.M. Heinz y M.P. Parrella (editores) Biocontrol in protected culture. Ball Publishing, Batavia, Illinois, EE UU.

Horowitz A. R. y Gerling, D. 1992. Seasonal variation of sex ratio in Bemisia tabaci on cotton in Israel. Environmental Entomology, 21 (3): 556-559.

Horowitz, A.R., Ishaaya, I., 1994. Managing resistance to insect growth regulators in the sweetpotato whitefly (Homoptera: aleyrodidae). J. Econ. Entomol. 87, 866-871.

Hu, 1.A., De Barro, P., Zhao, H., Wang, 1. , Nardi, F. and Liu, S.S. 2011. An extensive field survey combined with a phylogenetic analysis reveals rapid and widespread invasion of two alien whiteflies in China. PLoS ONE, 6, e16061.

Izquierdo, A. y Durán, M. 1967. Enfermedades y parásitos del tabaco en España. Boletines de Patología Vegetal y Entomología Agrícola, 30: 155-214.

Keiding J. 1977. Resistance in the housefly in Denmark and elsewhere, pp. 261-302. In: D.L.Watson, and A.W.A. Brow (eds). Pesticide management and insecticide resistance. Academic Press: New York, EUA.

Kozaki, T.; Shono, T. y Kono, Y. 2001. Fenitroxon insensitive acetylcholinesterases of the housefly, Musca domestica associated with point mutations. Insect. Biochem. Mol. Biol., 31: 991997.

Lacasa, A. y Contreras, J. 1995. Las plagas. En: F. Nuez (Eds.) El cultivo del tomate. Mundi-Prensa. Madrid. Pp. 386-467.

Lacasa, A.; Sánchez, J.; Gutiérrez, J.; Contreras, J.; Guirao, P.; Ros, C.; Molina, J.; Lorca, M. Y Hita, I. 1996. Dinámica poblacional de Bemisia tabaci (Gennadius) y evolución de la incidencia del TYLCV en cultivos de tomate en Murcia. En: J. L. Cenis (Eds.) El virus del rizado amarillo (boja en cuchara) del tomate (TYLCV) y su vector Bemisia tabaci. Jornadas $\mathrm{n}^{\circ} 8$. Región de Murcia. Consejería de Medio Ambiente Agricultura y Agua. Murcia. Pp. 35-46.

Leclant, F. 1988. Resistencia a los insecticidas y acaricidas. Información Técnica Económica Agraria, 77: 6-29. 
Li, A.Y., Dennehy, T.J., Li, S., Wigert, M.E., Zarborac, M., Nichols, R.L., 2001. Sustaining Arizona's fragile success in whitefly resistance management, In: Dugger, P. and Richter, D. (Eds.), Proceedings Beltwide Cotton Conferences. National Cotton Council, Memphis, TN, pp. 1108-1114.

Liu S S, Colvin J, De Barro P J. 2012. Species concepts as applied to the whitefly Bemisia tabaci systematics: how many species are there? Journal of Integrative Agriculture, 11, 176-186.

Louro, D., Noris, E.; Veratti, F. Y Accotto, G. P. 1996. First report of tomato yellow leaf curl virus in Portugal. Plant Disease, 80 (9): 1079 (Abstract).

Magnin, M.; Fournier, D. y Pasteur, N. 1985. Mécanismes physiologiques de la résistance des insects aux insecticides. Cahiers ORSTOM, Série: Entomologie Médicale et Parasitologie XXIII (4): 273-280.

Monge, L. A. 1986. Manejo Racional de Insecticidas. Resistencia y rotación. Editorial tecnológica de Costa Rica. Cartago, Costa Rica. p. 74.

Moriones, E. 1996. El virus del rizado amarillo del tomate (TYLCV): una nueva virosis en España. En: J. L. Cenis (Eds.) El virus del rizado amarillo (hoja en cuchara) del tomate (TYLCV) y su vector Bemisia tabaci. Jornadas $\mathrm{n}^{\circ}$ 8. Región de Murcia. Consejería de Medio Ambiente Agricultura y Agua. Murcia. Pp. 19-22.

Mota-Sánchez D.; Bills, P. S. y. Whalon, M. E. 2002. Arthropod resistance to pesticides: Status and overview. In: W.B.Wheeler (ed.). Pesticides in agriculture and the environment. MARCEL Dekker, Inc. N.Y.

Mound, L. A. y Halsey, S. H. 1978. Whitefly of the world. A systematic catalogue of the Aleyrodidae (Homoptera) with host plant and natural enemy data. British Museum (Natural History) and John Wiley and Sons. London. 340pp.

Muñiz, M. 2000. Host suitability of two biotypes of Bemisia tabaci on some common weeds. Entomologia Experiementalis et Applicata, 95 (1): 63-70.

Muñiz, M. 1996. Preferencias y reproducción de Bemisia tabaci en malas hierbas de invierno y en cultivos hortícolas de interés. En: J. L. Cenis (Eds.) El virus del rizado amarillo (hoja en cuchara) del tomate (TYLCV) y su vector Bemisia tabaci. Jornadas $\mathrm{n}^{\circ}$ 8. Región de Murcia. Consejería de Medio Ambiente Agricultura y Agua. Murcia. Pp. 55-59. 
Nannini, M.; Foddi, F.; Murgia, G.; Pisci R.; Sanna, F. y Spanedda, S. 2006. Alternative whitefly biocontrol options for greenhouse tomatoes. IOBC/WPRS Bull. 29 (4):65-70.

Nauen, R.; Stump, N. and Elbert, A. 2002. Toxicological and mechanistic studies on neonicotinoid cross resistance in Q-type Bemisia tabaci (Hemiptera: Aleyrodidae). Pest Management Science, 58 868-875.

Omura, T., \& Sato, R. 1964. The carbon monoxide-binding pigment of liver microsomes I. Evidence for its hemoprotein nature. J. Biol. Chem. 239: 2370-2378.

Perring, T.M.; Cooper, A. D.; Rodriguez, R. J.; Farrar, C. R. Y Bellows, T. S. 1993. Identification of a whitefly species by genomic and behavioral studies. Science, 259: 74-77.

Picó, B.; Diez, M. J. y Nuez, F. 1996. Viral diseases causing the greatest economic losses to the tomato crop. II. The tomato yellow leaf curl virus - a review. Scientia Horticulturae, 67 (34): 157-196.

Powell, D.A. y Bellows, T.S. 1992. Adult longevity, fertility and population growth rates for Bemisia tabaci (Genn.) (Homomoptera:Aleyrodidae) on two host plant species. J. Appl. Ent.; 113: 67-78.

Quaintance, A. L. 1900. Contribution towards a monograph of the American Aleurodidae. USDA, Tech. Ser. Bur. Entomol., 8: 9-64.

Quaintance, A. L. y Baker, A. C. 1914. Classification of the Aleyrodidae Part II. USDA, Tech. Ser. Bur. Entomol., 27: 95-109.

Rapisarda, C. 1990. La Bemisia tabaci vettore del TYLCV in Sicilia. Informatore Fitopatológico, 6: 27-31.

Roditakis, E., Roditakis, N.E., Tsagkarakou, A. 2005. Insecticide resistance in Bemisia tabaci (Homoptera: Aleyrodidae) populations from Crete. Pest Management Science, 61 577-582.

Russell, L. M. 1957. Synonyms of Bemisia tabaci (Gennadius) (Homoptera, Aleyrodidae). Bull. Brooklyn Entomol. Soc., 52: 122-123.

Sánchez-Campos, S., Navas-Castillo, J., Carnero, R.; Soria, C.; Díaz, J. A. y Morientes, E. 1999. Displacement of tomato yellow leaf curl virus TYLCV-Sr by TYLCV-Is in tomato epidemics in Spain. Phytopathology, 89 (11): 1038-1043. 
Sánchez, H. 2003. Manejo de insecticidas en ambientes urbanos. Pp 203-236. In Bases para el manejo racional de insecticidas. Silva, G., y R. Hepp [Eds]. 310 p.

Sánchez, J.A. 2008. Zoophytophagy in the plant bug Nesidiocoris tenuis. Forest Entomol. 10: $75-80$.

Sánchez, J.M.; Garijo, C., García, E.J. 1991. Moscas blancas, 37-52. En "Plagas de tomate: Bases para el control integrado”. M.A.P.A. Secretaría General Técnica. Madrid.

Silva, G.; Rodríguez, J. C y Bernal, J. S. 2004. Revisión de los fundamentos para el manejo de la resistencia a insecticidas/Acaricidas en Frutales. Rev. Frutícola, 25 (1): 27-33.

Soto, A. y F. Garcia-Marí. 2000. Las moscas blancas de citricos. http://www.seea.es/conlupa/mbeitricos/mbCitricos.htm (22/01/2008).

Sotolongo M. G. y Vidal A. N. 1988. Metabolismo y excreción de los compuestos extraños en: Elementos de Toxicología. La Habana: Editorial Pueblo y Educación; p. 11,12.

Stansly, P.; Urbaneja, A.; Beltran, D.; Calvo, J.; López, J.; Sánchez, E.; Klapwijk, J. y Bolkmans, K. 2002. Eretmocerus mundus: Control biológico de la mosca blanca Bemisia tabaci. FECOAM, 37: En prensa.

Sun D B, Xu J, Luan J B, Liu S S. 2011. Reproductive incompatibility between the B and Q biotypes of the whitefly Bemisia tabaci: genetic and behavioural evidence. Bulletin of Entomological Research, 101, 211-220.

Terriere, C. L. 1984. Induction of detoxification enzymes in insects. Ann. Rev. Entomol. 29: $71-78$

Toutant, J.P. 1989. Insect acetylcholinesterase: catalytic properties, tissue distribution and molecular forms. Progress in Neurobiology, 32: 423-446.

Wang P, Sun D B, Qiu B L, Liu S S. 2011. The presence of six cryptic species of the whitefly Bemisia tabaci complex in China as revealed by crossing experiments. Insect Science, 18, 67-77.

Wang X. W., Luan J. B., Li J. M., Bao Y. Y., Zhang C. X., Liu S. S. 2010. De novo characterization of a whitefly transcriptome and analysis of its gene expression during development. BMC Genomics, 11, 400. 
Wiesmann, R. 1947. Untersuchungen uber das physiologische verhalten von Musca domestica L.. verschiedener proveniezen. Schwei‡: Ent. Gesell. Mitt., 20 484-504.

Xu J, De Barro P J, Liu S S. 2010. Reproductive incompatibility among genetic groups of Bemisia tabaci supports the proposition that the whitefly is a cryptic species complex. Bulletin of Entomological Research, 100, 359-366. 


\section{OBJETIVOS}

La importancia económica y la expansión a nivel mundial de la plaga Bemisia tabaci hace que sea necesario el desarrollo de unas estrategias de control efectivas. Para ello es necesario un buen conocimiento de las herramientas de las que disponemos para combatirla. Los insecticidas es una de esas herramientas y lo primero es determinar la efectividad que presentan las materias activas de los diversos grupos, así como sus resistencias cruzadas y los mecanismos de la resistencia implicados. Para intentar avanzar en este sentido se han planteado los siguientes objetivos:

\section{Objetivo general:}

Determinar el estado actual de la resistencia a insecticidas de Bemisia tabaci, conocer la resistencia cruzada existente entre los insecticidas de uso más común para el control de la mosca, y revelar cuales son los mecanismos que están involucrados en la detoxificación de insecticidas en poblaciones de campo provenientes de invernaderos de uso hortícola del sureste español.

Para alcanzar esta finalidad se propusieron los siguientes objetivos concretos:

1. Evaluar los niveles de resistencia en ninfas en poblaciones de campo de B. tabaci biotipo Q, en el sureste de España a los insecticidas más representativos que se usan en su control.

2. Determinar la existencia de resistencia cruzada entre dos neonicotinoides y la pimetrocina en poblaciones de campo de Bemisia, tanto en estado adulto como en ninfas.

3. Conocer los mecanismos implicados en la resistencia del acaricida METI piridabén en poblaciones de campo de Bemisia y seleccionadas en laboratorio.

4. Determinar la existencia de resistencia cruzada de tres reguladores del crecimiento, azadiractín, buprofecín y piriproxifén, entre sí y con insecticidas de otros grupos. Y revelar cuales son los mecanismos implicados en la detoxificación del insecticida utilizando poblaciones seleccionadas en laboratorio. 


\section{MATERIAL Y MÉTODOS GENERALES}

El material y métodos de esta tesis consiste por un lado en el necesario para la recogida y cría de la mosca y por otro el de los bioensayos.

El material necesario para la cría de las poblaciones de Bemisia tras la recogida en campo lo forman tanto unas jaulas de cría como el material vegetal libre de tratamientos insecticidas, que se detallan a continuación.

\subsection{Jaulas de cría}

Las jaulas que se utilizan para la cría y mantenimiento de ensayos, se hacen utilizando bandejas de polipropileno negras (57 cm de largo, $42 \mathrm{~cm}$ de fondo y $9 \mathrm{~cm}$ de alto), a las que se le fija mediante bridas una estructura de malla plástica. Las medidas de la jaula una vez montada son $52 \mathrm{~cm}$ de alto, $57 \mathrm{~cm}$ de largo y $42 \mathrm{~cm}$ de fondo. Sobre esta estructura se coloca una funda de malla anti-trips realizada a medida, dotada de una gran cremallera que se utiliza para el riego y la introducción y extracción tanto de material vegetal como de insectos. La estructura con la malla se coloca a su vez sobre otra bandeja negra cuya función es sujetar la tela y evitar la salida de los individuos.
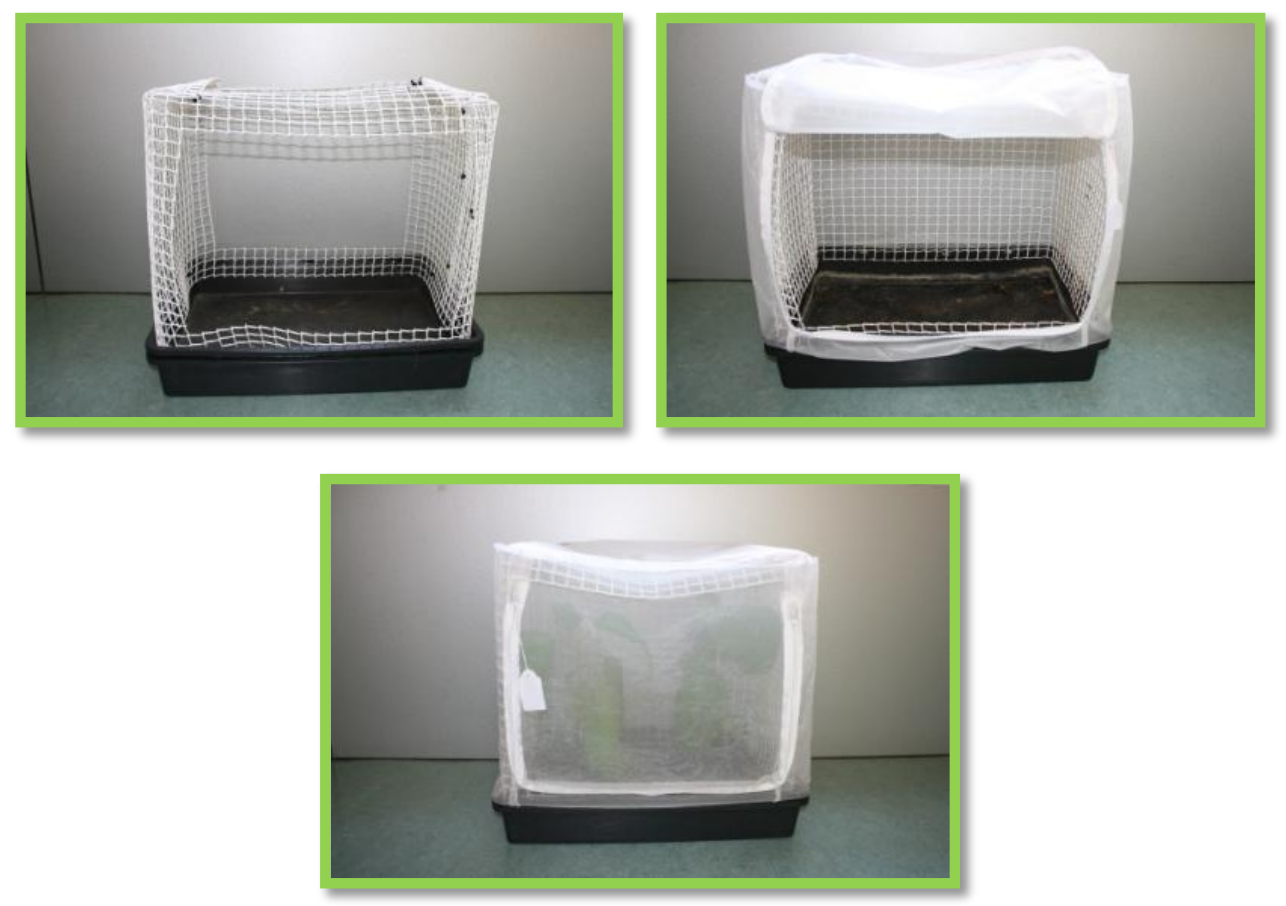

Figura 1. Paso a paso del montaje de una jaula de cría y vista final. 


\subsection{Material vegetal}

En unas cámaras de cultivo del laboratorio de Protección de Cultivos de la Finca Experimental Tomás Ferro que pertenece a la ETSIA, se siembran semanalmente semillas de algodón, berenjena, pepino y pimiento para obtener plantas suficientes para asegurar la cría y la realización de bioensayos durante todo el año. Nunca se aplica tratamiento insecticida, salvo en el caso extraordinario de invasión de alguna plaga. En ese caso, se elimina todo el material vegetal de la cámara en cuestión, se trata con un desinfectante (Oromyzys, cuya materia activa es diclorvos 20\%), y se vuelve a introducir el material vegetal. En cada una de las cuatro cámaras de las que se dispone, hay planta de diferentes estados vegetativos, para evitar perder todo el material vegetal en caso de contaminación.

\subsection{Insectos}

Los individuos son recogidos intentando cubrir la mayor superficie del invernadero, para obtener una muestra representativa de la población original, evitando recolectar de los bordes de la parcela, donde la inmigración y los tratamientos de parcelas contiguas puedan influir sobre la población.

La población sensible de referencia (LAB-S) fue recogida en Murcia, en agosto del 2006, en un invernadero de pimiento que no había sido expuesto a tratamientos insecticidas al menos los 5 años previos, ya que se dedicaba a la cría de enemigos naturales de mosca blanca. Se trataba de invernadero con un sistema de cierre que impedía la inmigración de insectos.

\subsubsection{Poblaciones de campo}

Se han utilizado poblaciones de campo recogidas en las provincias de Murcia y Almería (Tabla 1 y Figura 2). Se obtuvieron a lo largo del año 2006: MU-A, MU-MA, MU-MI, ALBA, AL-MO, AL-PA, de las que se conocen los niveles de resistencia para los insecticidas más comúnmente utilizados para el control de B. tabaci en el sureste español (Fernández et al., 2009). 
Tabla 1. Origen de las poblaciones recogidas

\begin{tabular}{c|ccccc}
\hline Población & Localidad & Provincia & Hospedante & Año & Biotipo \\
\hline LAB-S & Águilas & Murcia & Pimiento & 2006 & Q \\
MU-A & Águilas & Murcia & Tomate & 2006 & Q \\
AL-BA & Balanegra & Almería & Pimiento & 2006 & Q \\
MU-MI & Mirador & Murcia & Pimiento & 2006 & Q \\
MU-MA & Mazarrón & Murcia & Tomate & 2006 & Q \\
AL-MO & La Mojonera & Almería & Pimiento & 2006 & Q \\
AL-PA & El Ejido & Almería & Pimiento & 2006 & Q \\
\hline
\end{tabular}

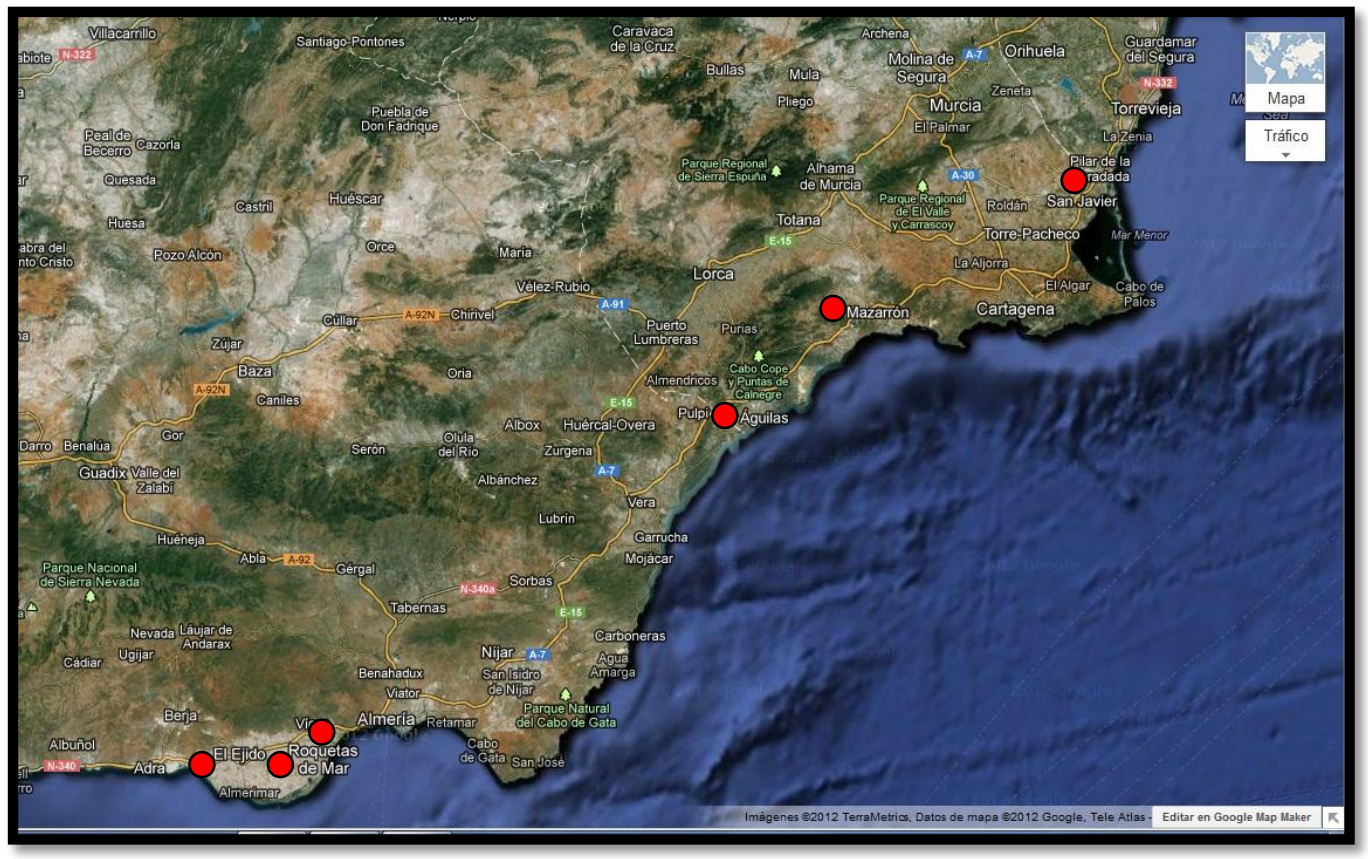

Figura 2. Origen de las poblaciones recogidas 
En todos los casos, se recogieron adultos directamente de las hojas, utilizando un aspirador entomológico de mano, a pilas. Inmediatamente después de ser aspirados, los adultos de $B$. tabaci, se pasan a las jaulas de cría, en las que previamente se introduce planta de algodón, pimiento, berenjena y/o pepino sin ningún tipo de tratamiento insecticida (Figura 3).
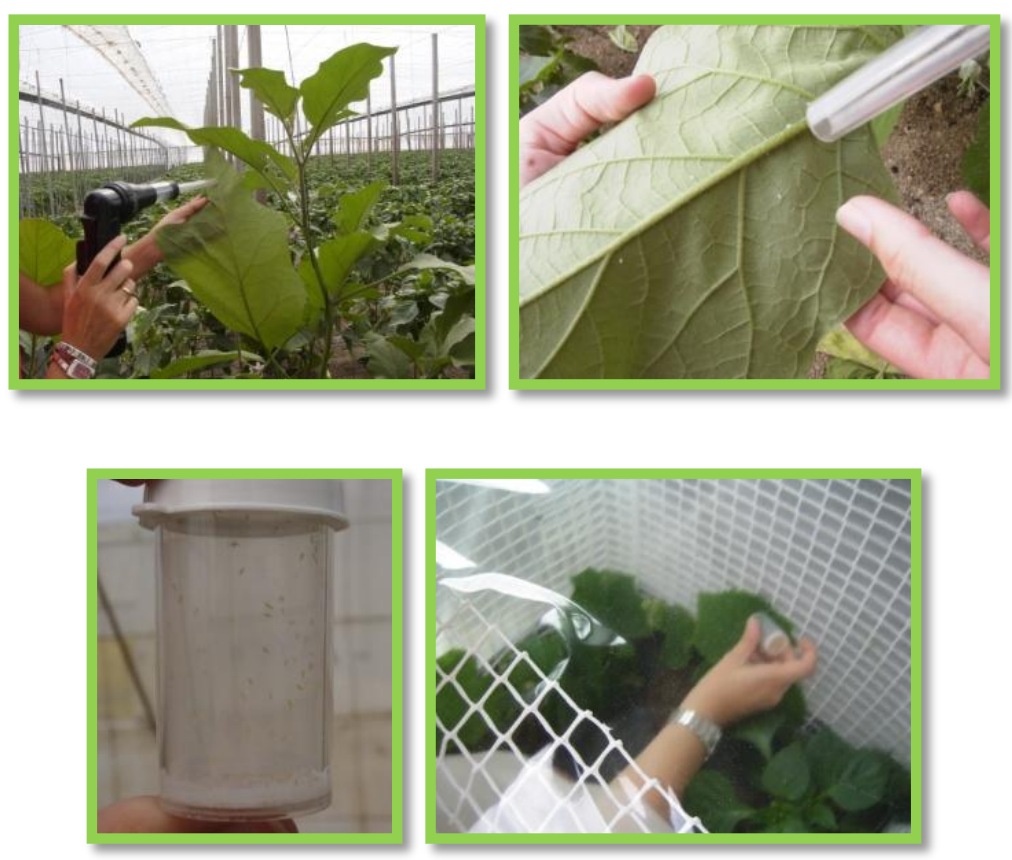

Figura 3. Recogida de poblaciones en campo

Para su cría y mantenimiento, todas las poblaciones se almacenan en una cámara de cultivo del grupo de investigación de Protección de Cultivos en la ETSIA, con unas condiciones de $25 \pm 2{ }^{\circ} \mathrm{C}, 60 \% \mathrm{HR}$ y fotoperiodo 16 horas luz: 8 horas oscuridad. También se crea una copia de cada una de las poblaciones que se mantiene en laboratorio, con las mismas condiciones.

$\mathrm{Al}$ inicio de la cría, antes de empezar a realizar bioensayos, se caracterizaron los biotipos de todas las poblaciones, por PCR-RFLP, mediante amplificación por PCR de un fragmento del gen mitocondrial citocromo oxidasa I, seguido de restricción con la enzima Tru9I (Bosco et al., 2006), siendo todas de biotipo Q. 


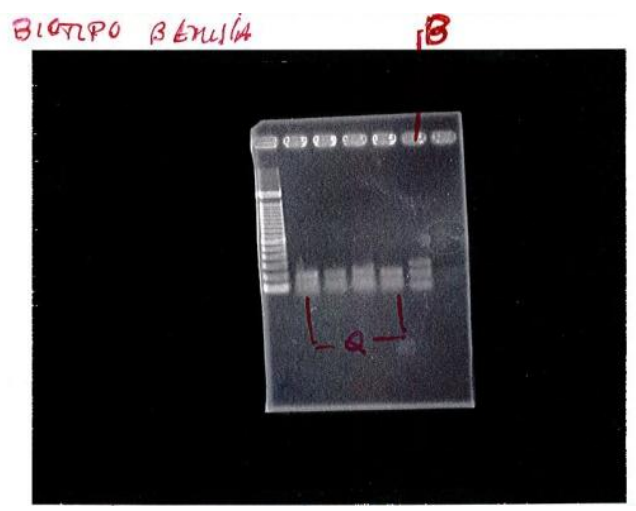

Figura 4. Resultado de la electroforesis en gel de acrilamida

Las poblaciones MU-A y MU-MA fueron recogidas de invernaderos cercanos, en las poblaciones de Águilas y Mazarrón respectivamente, zonas de cultivo de tomate de la Región de Murcia, el 9 de marzo del 2006, al principio de la temporada.

La población MU-MI se recogió en el Campo de Cartagena el 15 de septiembre de 2006, es decir al final de la campaña, en un invernadero de pimiento en control químico con una alta presión insecticida. En este invernadero se realizaron 27 tratamientos insecticidas a lo largo de los 9 meses del ciclo de cultivo, de los cuales 11 fueron específicos para el control de mosca blanca (1 con piriproxifén, 2 con imidacloprid, 4 con azadiractín y 4 con piridabén). Fue difícil encontrar esta población, ya que más del 95\% de la superficie de invernaderos de esta zona utiliza el control biológico casi exclusivamente.

Las tres poblaciones de Almería, AL-BA, AL-MO, AL-PA, fueron recogidas en la zona de producción intensiva, que cuenta con unas 30.000 ha de invernaderos, donde se practicaba casi exclusivamente el control químico de manera muy intensiva, con al menos una aplicación insecticida por semana. AL-BA y AL-PA, se recolectaron el 18 de enero del 2006 (a mitad del ciclo de cultivo), mientras que AL-MO se recogió el 20 de septiembre de 2006 (principio de la campaña siguiente).

\subsubsection{Poblaciones seleccionadas}

Con el paso de los años, hemos conseguido obtener poblaciones resistentes a diferentes insecticidas. Este proceso, es largo y tedioso, por ello aún no se han conseguido a todos los insecticidas que deseamos.

El proceso se lleva a cabo de la siguiente manera. En primer lugar se parte de individuos sensibles y caracterizados, en nuestro caso, de la población sensible de referencia (LAB-S), 
que sabemos son sensibles a los insecticidas que se utilizan para el control de B. tabaci en la zona o no muestran diferencias significativas con la población más sensible.

Se fundan 8 nuevas poblaciones a partir de la cría de LAB-S que tenemos en el laboratorio. Una vez que cada una de las poblaciones ya está establecida, se realizan 5 tratamientos sucesivos con dosis ascendentes, dejando entre ellos suficiente tiempo como para permitir la multiplicación de los individuos supervivientes. Una vez terminado este ciclo de 5 tratamientos ascendentes, que en lo sucesivo llamaremos ciclo de selección, se lleva a cabo un bioensayo completo de ninfas (6 dosis y un control) con "su insecticida", para determinar si se ha conseguido alcanzar o no cierto nivel de resistencia al insecticida en cuestión. En caso afirmativo, la población se considera seleccionada y se le realizará un tratamiento de recuerdo una vez al año para mantener en el tiempo el nivel de resistencia adquirido. En caso negativo, se realizará un nuevo ciclo de selección, esta vez de sólo 3 tratamientos.

Tabla 2. Estado de las selecciones de las poblaciones de Bemisia.

\begin{tabular}{|c|c|c|c|c|}
\hline & & LAB-S & SELECCIONADA & \\
\hline Insecticida & $\begin{array}{c}\text { Dosis } \\
\text { Campo } \\
\text { (ppm) }\end{array}$ & CL50 $\left(\mathrm{mg} \mathrm{L}^{-1}\right)(95 \% \mathrm{LC})$ & CL50 $\left(\mathrm{mg} \mathrm{L}^{-1}\right)(95 \% \mathrm{LC})$ & FR50 \\
\hline Alfa-cipermetrín & 40 & $141,19(40,29-255,59)$ & $557,71(251,749-807,665)$ & 4 \\
\hline Azadiractín & 48 & $2,65(0,53-6,55)$ & $102,65(62,11-197,62)$ & 39 \\
\hline Buprofecín & 200 & $8,73(4,45-14,38)$ & $830,11(371,56-2325,13)$ & 95 \\
\hline Imidacloprid & 150 & $15,19(1,29-81,08)$ & $12,95(5,27-24,79)$ & 1 \\
\hline Pimetrozina & 300 & $29,2(3,2-107,4)$ & $72499,18(21651,78-23208173)$ & 2483 \\
\hline Piridabén & 200 & $0,34(0,21-0,51)$ & $36,55(18,05-61,35)$ & 108 \\
\hline Piriproxifén & 75 & $20,86(13,77-30,37)$ & $2333,89(1052,3-7916,9)$ & 112 \\
\hline Tiametoxam & 50 & $17,95(8,12-34,38)$ & $77,85(52,51-112,45)$ & 4 \\
\hline
\end{tabular}

Hasta el momento se han conseguido seleccionar poblaciones resistentes a azadiractín, buprofecín, pimetrozina, piridabén y piriproxifén, que se han denominado como R-AZA, R-BU, R-PIME, R-PIB, R-PIX. Seguimos con el proceso de selección al resto de insecticidas.

\subsection{Insecticidas}

Para realizar los bioensayos y las posteriores poblaciones resistentes, se han utilizado los insecticidas que se usan habitualmente en el sureste español para el control de mosca 
blanca (Figura 5 y Tabla 3). Éstos son: alfa-cipermetrín, azadiractín, buprofecín, imidacloprid, metomilo, pimetrozina, piridabén, piriproxifén y tiametoxam, algunos ya en desuso como buprofecín y metomilo, que dejaron de estar autorizados en 2009, pero que en su momento se utilizaban. En todos los casos, se utilizan diluciones de los insecticidas en agua destilada a la que se le añade el mojante Tween 20, salvo en los ensayos con ciantraniliprol, puesto que el método de bioensayo realizado es de absorción sistémica.

Tabla 3. Insecticidas utilizados

\begin{tabular}{|c|c|c|c|c|c|}
\hline & & GRUPO IRAC & $\begin{array}{c}\text { NOMBRE } \\
\text { COMERCIAL }\end{array}$ & MATERIA ACTIVA & $\begin{array}{c}\text { CASA } \\
\text { COMERCIAL }\end{array}$ \\
\hline Metomilo * & $1 \mathrm{~A}$ & Carbamatos & LANNATE $20 \mathrm{~L}$ & Metomilo $20 \%$ & DuPont Ibérica \\
\hline $\begin{array}{c}\text { Alfa } \\
\text { cipermetrín }\end{array}$ & $3 \mathrm{~A}$ & Piretroides & FASTAC & $\begin{array}{c}\text { Alfa cipermetrin } 10 \% \\
{[\mathrm{EC}]}\end{array}$ & BASF \\
\hline Imidacloprid & $4 \mathrm{~A}$ & Neonicotinoides & CONFIDOR $20 \mathrm{LS}$ & Imidaclorpid $20 \%$ [SL] & Bayer CropScience \\
\hline Tiametoxam & $4 \mathrm{~A}$ & Neonicotinoides & ACTARA & $\begin{array}{c}\text { Tiametoxam } 25 \% \\
\text { [WG] }\end{array}$ & Syngenta Agro \\
\hline Piriproxifén & $7 \mathrm{C}$ & $\begin{array}{l}\text { Miméticos de la } \\
\text { hormona juvenil }\end{array}$ & JUVINAL $10 \mathrm{EC}$ & Piriproxifen $10 \%[\mathrm{EC}]$ & Kenogard \\
\hline Pimetrozina & $9 \mathrm{~B}$ & $\begin{array}{l}\text { Bloqueadores } \\
\text { selectivos de la } \\
\text { alimentación }\end{array}$ & PLENUM & $\begin{array}{c}\text { Pimetrozina } 50 \% \\
\text { [WG] }\end{array}$ & Syngenta Agro \\
\hline Buprofecín * & 16 & $\begin{array}{c}\text { Inhibidores de la } \\
\text { biosíntesis de quitina, } \\
\text { tipo } 1\end{array}$ & APPLAUD & Buprofecin 25\% [WP] & Syngenta Agro \\
\hline Piridabén & $21 \mathrm{~A}$ & Acaricidas METI & SANMITE & Piridaben $20 \%$ [WP] & BASF \\
\hline Azadiractín & $\mathrm{UN}$ & $\begin{array}{c}\text { Modo de acción } \\
\text { desconocido o incierto }\end{array}$ & ALIGN & Azadiractín 3,2\% [EC] & Sipcam Iberia \\
\hline
\end{tabular}

* Dejaron de estar autorizados en 2009
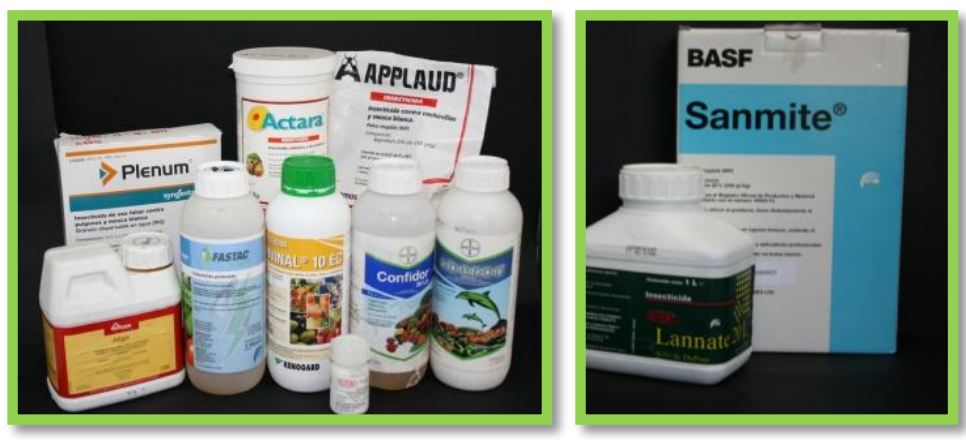

Figura 5. Insecticidas utilizados 


\subsection{Mantenimiento de poblaciones}

Una vez a la semana, todas las jaulas de cría de las poblaciones se riegan, y en aquellas que es necesario se introduce planta limpia. Del mismo modo, si hay alguna planta seca o muy estropeada por la mosca se elimina, para evitar que en la jaula haya demasiadas macetas que incrementen la humedad relativa de la jaula e impidan la introducción de nueva planta.

Como ya se ha mencionado, las jaulas se mantienen en una cámara climática y una copia en el laboratorio, en la Figura 6 puede verse la distribución en ambos casos.
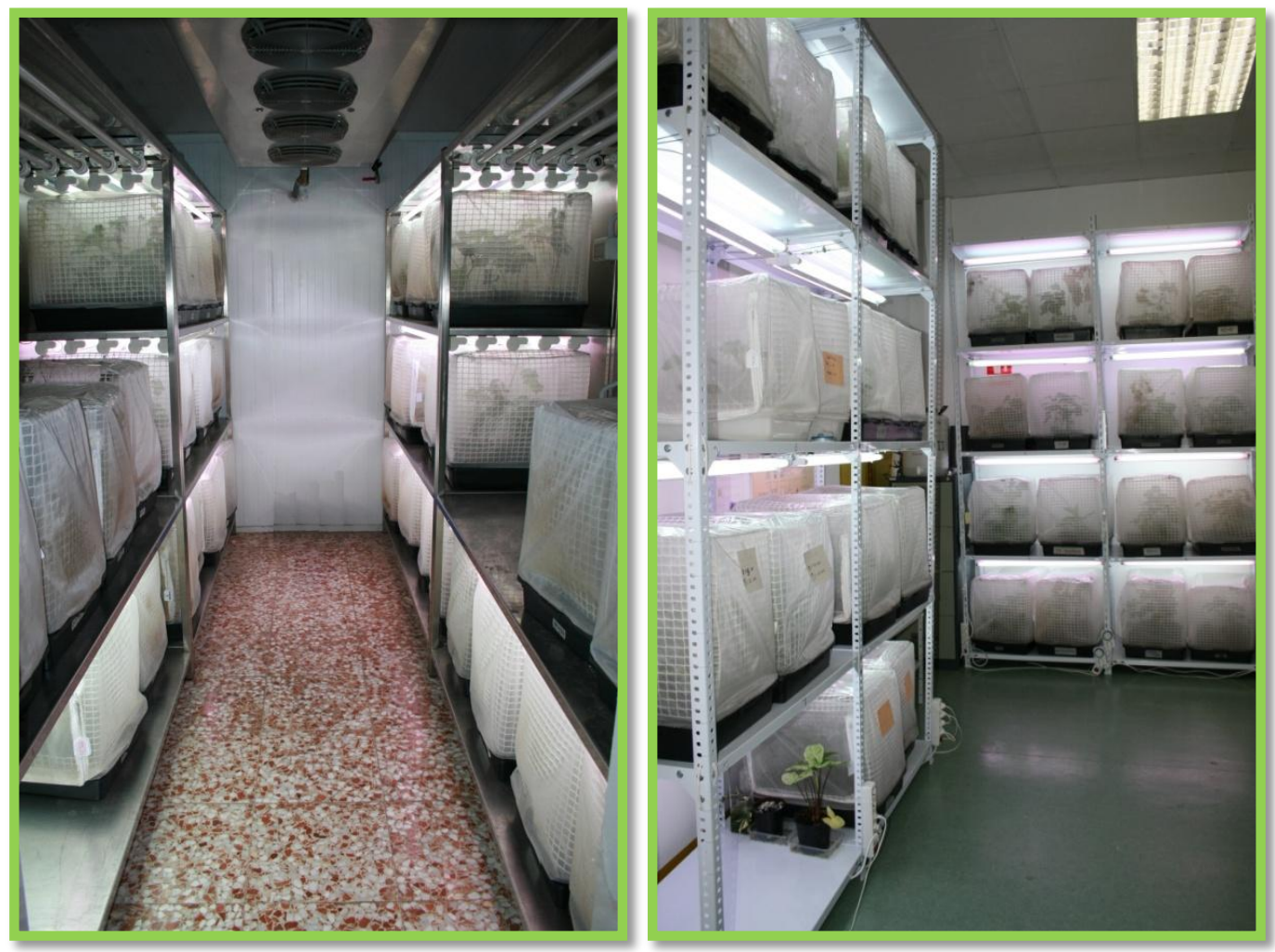

Figura 6. Distribución de las jaulas de cría en la cámara climática y en laboratorio

\subsection{Bioensayos}

A continuación se detallan los diferentes tipos de bioensayo que se realizan, dependiendo del insecticida utilizado y del estado de desarrollo de la mosca.

En todos los casos, se utiliza $\mathrm{CO}_{2}$ de uso alimentario para adormecer a las moscas e introducirlas en las cajas correspondientes (Figura 7). 


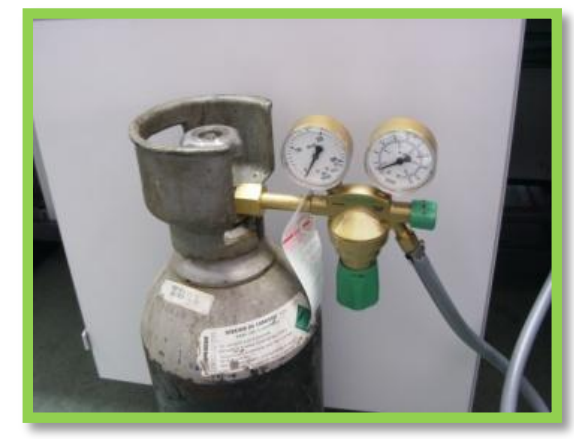

Figura 7. $\mathrm{CO}_{2}$ de uso alimentario

\subsubsection{Material empleado}

Hay una serie de material que es común para varios tipos de ensayo. En primer lugar, se describe y en cada bioensayo sólo se mencionará.

\subsubsection{Caja-pinza}

Las cajas-pinza se utilizan para los ensayos de huevos y ninfas. Se hacen cortando tubos de centrífuga de $50 \mathrm{~mL}$ a unos $4 \mathrm{~cm}$ de la rosca. Se lija ligeramente la zona del corte para que no queden imperfecciones. En un lado, en sentido vertical se le fija con pegamento una pinza para el pelo metálica con una pata doblada y cortada a medida, de manera que una de ellas queda paralela al tubo y la otra perpendicular por la parte lijada. A la parte perpendicular, se le pega un círculo de polipropileno negro de $1 \mathrm{~mm}$ de grosor, y $4 \mathrm{~cm}$ de diámetro. Para que sea lo más estanco posible y haga vacío al conectar la caja-pinza al aspirador, se rodea con burlete de goma. Por otro lado, a las tapas de los tubos se les hace un agujero de unos $2 \mathrm{~cm}$ de diámetro, sobre el que se pega una malla metálica de espesor suficiente como para permitir la ventilación e impedir que se escapen los individuos confinados en la caja-pinza (Figura 8). 


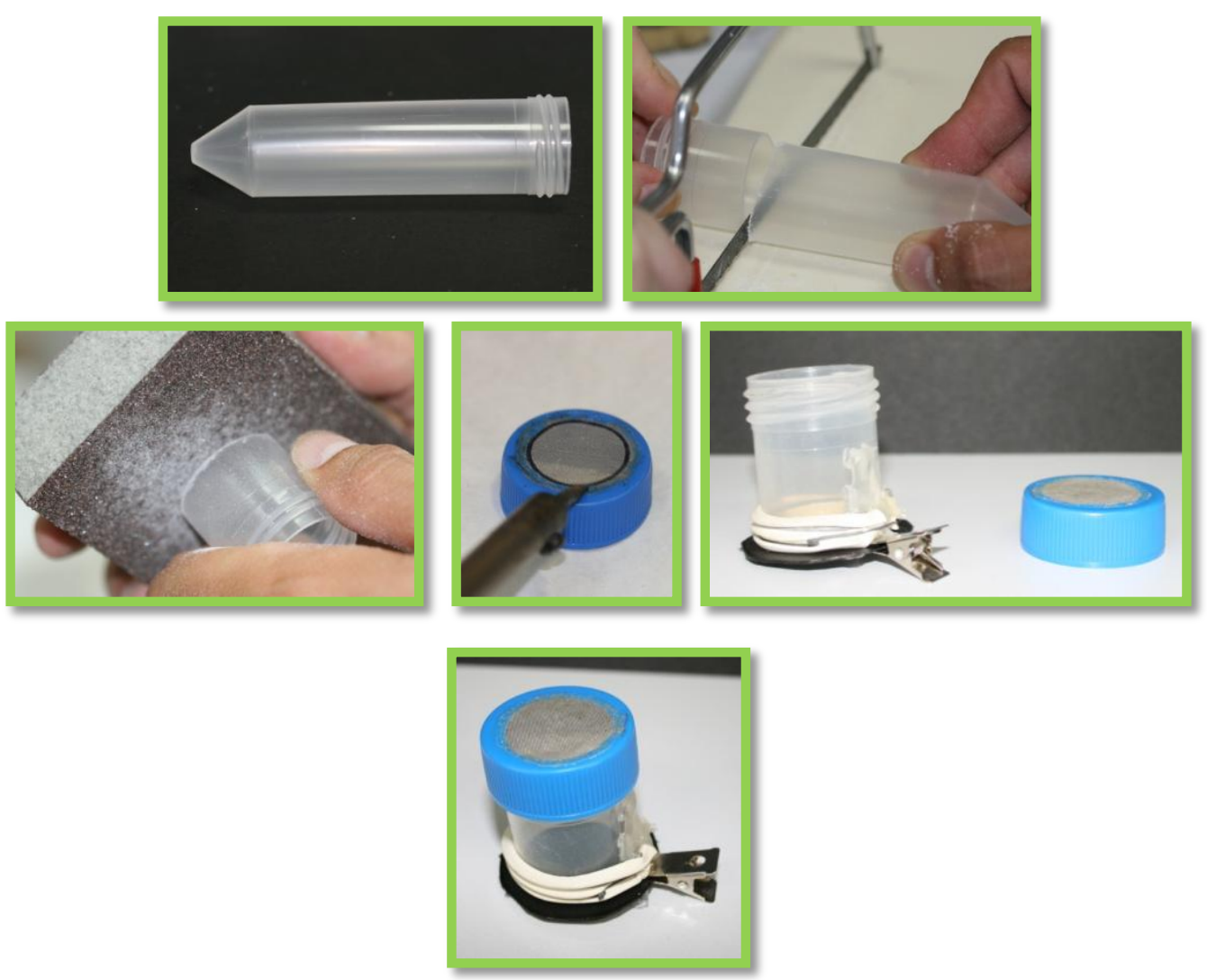

Figura 8. Paso a paso del montaje de una caja-pinza y vista final

\subsubsection{Caja adultos}

Para los ensayos de adultos, se utilizan cajas redondas de polipropileno transparente, de 28 mm de diámetro (Figura 9). En las paredes de la base, se hacen tres agujeros para favorecer la ventilación. También se tapan con malla metálica.
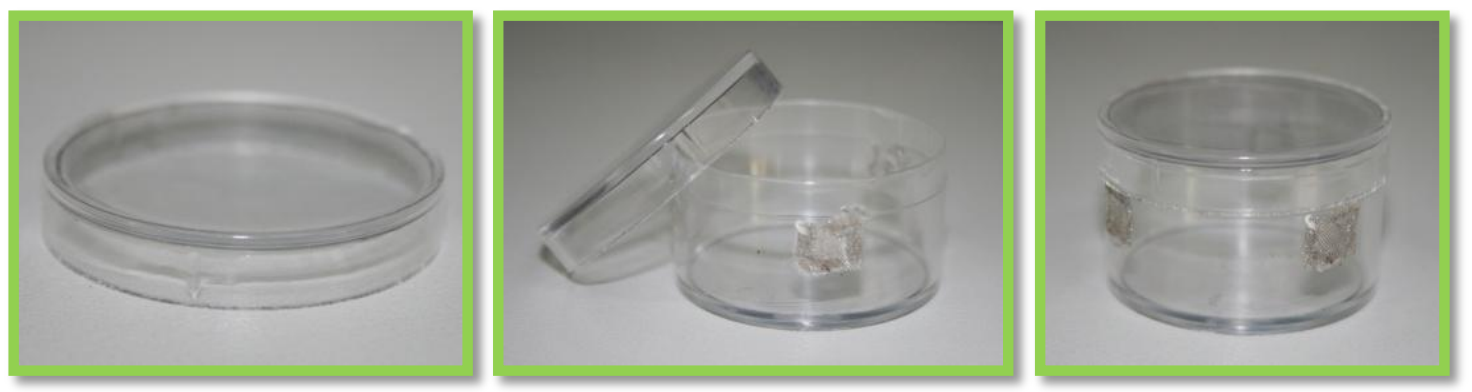

Figura 9. Vista de la caja y la tapa utilizada para bioensayo de adultos. 


\subsubsection{Bioensayo de huevos}

Este tipo de bioensayo se realiza cuando utilizamos el piriproxifén, puesto que es el único de los insecticidas elegidos, que actúa como ovicida.

La metodología es la siguiente (Figura 11):

Se utilizan plántulas de algodón de unos 20 o $25 \mathrm{~cm}$ de altura, con unas 4 hojas verdaderas. A una de las hojas más jóvenes se le fija una caja-pinza sujeta mediante un palito de madera, con unas 40 hembras adultas en su interior, de manera que los individuos queden en el envés de la hoja y se mantiene durante 24 horas. Transcurrido este periodo de tiempo, se procede al desmontaje del ensayo, se quita la caja-pinza y se aspira la mosca. Una vez libre de adultos, a cada planta se le asigna un número y se observa en la lupa binocular. Con un rotulador permanente de $0,05 \mathrm{~mm}$ de grosor, se van marcando uno por uno los huevos hasta llegar a un máximo de 30.

Una vez marcadas las 21 plantas que se utilizan para cada bioensayo (6 dosis más un control y 3 repeticiones para cada una), se reparten por dosis, de manera que el número de huevos en cada repetición sea lo más homogéneo posible (sólo en los casos en los que no se alcanzan los 30 huevos/hoja)

Se separan las plantas que se tratan con cada dosis, se preparan las 6 dosis necesarias y el control, todas ellas con agua destilada y mojante (Tween 20) en proporción 1:1000, y se procede al tratamiento. Éste se lleva a cabo introduciendo por completo la hoja con los huevos durante 10 segundos en la dosis correspondiente. Al sacarla se deja que gotee el exceso de líquido y se dejan secar al aire entre 30 y 60 minutos.
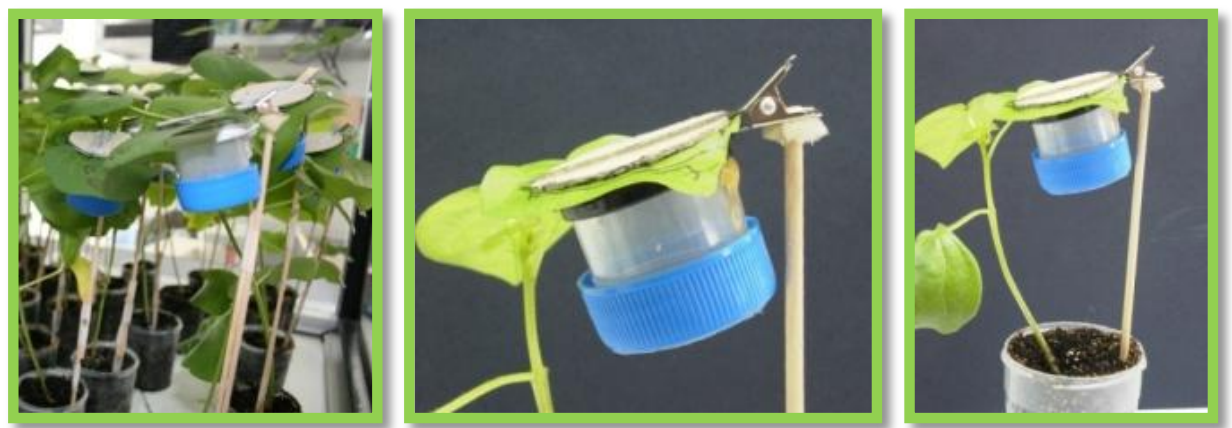

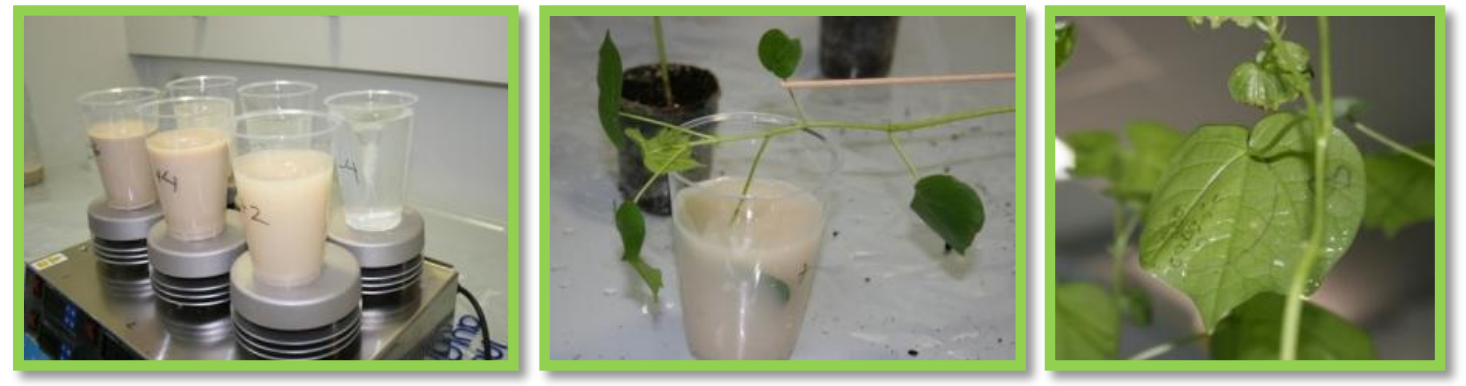

Figura 11. Montaje y tratamiento del bioensayo de huevos de Bemisia.

Transcurrido ese periodo de tiempo, una vez que las plantas están secas, se introducen en una jaula de malla como las que se utilizan para la cría, que se mantendrá en el laboratorio $\left(25 \pm 2^{\circ} \mathrm{C}, 60 \%\right.$ HR y fotoperiodo 16 horas luz: 8 horas oscuridad) hasta el momento del conteo de la mortalidad, día 14 desde que se inició el bioensayo, momento en el que los huevos vivos han evolucionado y ya se observan ninfas N2. Por ello en el conteo, se consideran individuos vivos aquellos que se encuentran en estado N2 y muertos tanto los huevos muertos como aquellos que a pesar de tener buen aspecto aún no han eclosionado, debido a que ha pasado el tiempo suficiente para su desarrollo (Figura 12).
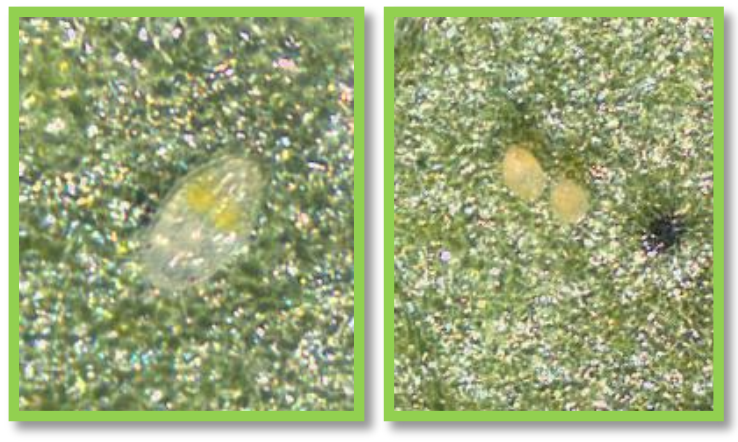

Figura 12. Ninfa N2 y huevo sin eclosionar

\subsubsection{Bioensayo de ninfas}

$\mathrm{Al}$ igual que en los ensayos de huevos (Figura 11), se utilizan plántulas de algodón de unos 20 ó $25 \mathrm{~cm}$ de altura, con unas 4 hojas verdaderas. A una de las hojas más jóvenes se le fija una caja-pinza sujeta mediante un palito de madera, con unas 40 hembras adultas en su interior, de manera que los individuos queden en el envés de la hoja y se mantiene durante 48 horas.

Transcurrido este periodo de tiempo, se procede al desmontaje del ensayo, se quita la cajapinza y se aspira la mosca. A cada planta se le asigna un número y se introduce en una jaula 
de malla como las que se utilizan para la cría, que se mantendrá en el laboratorio durante 12 días.

Transcurrido este tiempo, suficiente para alcanzar el estadío N2, se observa cada planta en la lupa binocular, y con un rotulador permanente se van marcando una por una las ninfas N2 hasta llegar a un máximo de 30 (Figura 13).

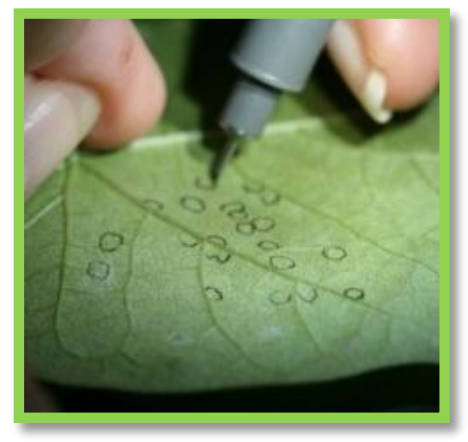

Figura 13. Marcado de ninfas en hoja de algodón

Una vez marcadas las 21 plantas que se utilizan para cada bioensayo (6 dosis más un control y 3 repeticiones para cada una), se reparten por dosis, de manera que el número de ninfas en cada repetición sea lo más homogéneo posible (sólo en los casos en los que no se alcanzan los 30 ninfas/hoja)

Se separan las plantas que se tratan con cada dosis, se preparan las 6 dosis necesarias y el control, todas ellas con agua destilada y mojante, y se procede al tratamiento. Éste se lleva a cabo introduciendo por completo la hoja con las ninfas durante 10 segundos en la dosis correspondiente. Al sacarla se deja que gotee el exceso de líquido y se dejan secar al aire entre 30 y 60 minutos.

Transcurrido ese periodo de tiempo, una vez que las plantas están secas, se introducen en la jaula en la que estaban antes de tratamiento, y se mantienen de nuevo en el laboratorio hasta el momento del conteo de la mortalidad, día 30 desde que se inició el bioensayo. Se ha fijado este periodo de tiempo, porque en estudios previos se ha visto que en las condiciones de nuestro laboratorio es el tiempo necesario para que todos los huevos lleguen al menos a estado de pupa. Por ello, en el conteo, se consideran como individuos vivos aquellos que se han desarrollado hasta llegar a estado de pupa, y también los exuvios (el adulto ya ha emergido). Por otro lado, se consideran muertos los huevos no eclosionados, y tanto las ninfas muertas como aquellas ninfas que a pesar de tener buen aspecto aún no han llegado a estado de pupa (Figura 14). 

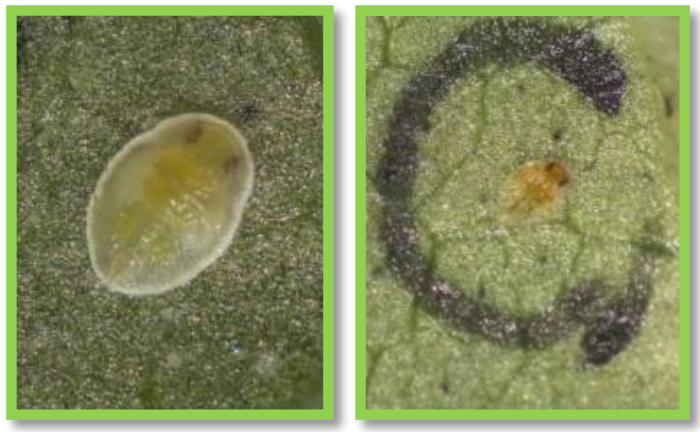

Figura 14. Pupa y ninfa muerta

\subsection{4.- Bioensayo de adultos}

Así como los ensayos de huevos y ninfas son casi idénticos, sólo variando los periodos de tiempo, el de adultos cambia totalmente la metodología utilizada (Figura 15).
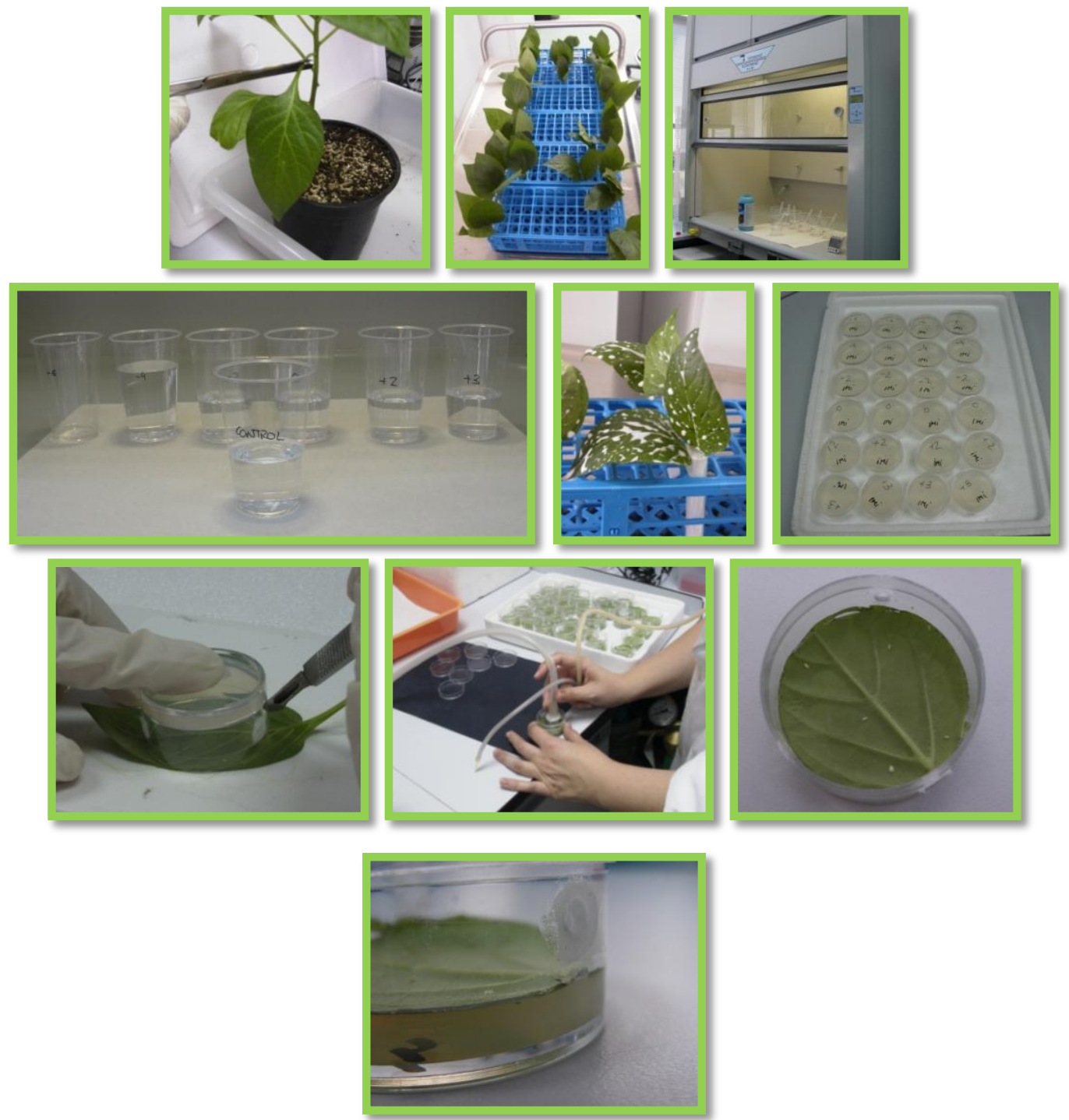

Figura 15. Bioensayo de adultos de Bemisia. 
En este caso, se utilizan las cajas de polipropileno transparentes antes descritas (Figura 9). En cada una de ellas se colocan $5 \mathrm{~mL}$ de agar al 2\% (preparado con agua destilada).

Mientras el agar se enfría y se solidifica, se cortan hojas de pimiento (libres de residuos insecticidas) lo suficientemente grandes como para cubrir la superficie de la caja, y se colocan en agua. A continuación se procede a preparar las dosis del insecticida y el control. $\mathrm{Al}$ igual que en los ensayos antes descritos, también se utiliza mojante. En este caso, como el número de individuos por repetición es menor, se realizan 4 repeticiones.

Una vez preparadas las dosis, se tratan las hojas de igual modo, sumergiendo la totalidad de la hoja en la dosis correspondiente. Se deja escurrir el exceso de líquido e inmediatamente se ponen separadas por dosis, con el peciolo en un tubo de plástico de $5 \mathrm{~mL}$ con agua en gradillas, para mantener el estado turgente de la hoja el máximo tiempo posible. Transcurridos unos 30-60 minutos, en cuanto están totalmente secas, se procede al montaje del ensayo.

Se coloca en la superficie de agar, un disco de hoja de pimiento cortado a medida, con el envés hacia arriba. Sobre él se colocan 10 hembras adultas y se cierra la caja. Transcurridos unos minutos, se le da la vuelta a la caja, de manera que la mosca quede en su posición habitual, es decir, en el envés de la hoja y boca abajo.

Todas las cajas se colocan en una bandeja con rejilla, para evitar la condensación y permanece en condiciones de laboratorio hasta el momento de la lectura, 24, 48 o 72 horas después, dependiendo del modo de acción del insecticida utilizado. En este caso se cuentan individuos vivos y muertos.

\subsubsection{Selección de poblaciones}

Por último, otro tipo de tratamiento que se lleva a cabo es el de selección. Se hace para inducir la resistencia en laboratorio. Como se explicó en el apartado de poblaciones seleccionadas (3.3.2.), se parte de una población sensible (LAB-S) a la que se le hacen sucesivos tratamientos con dosis crecientes. Entre ellos, se deja pasar el tiempo suficiente para la recuperación de la población. 
El día del tratamiento de selección se prepara la dosis del insecticida deseado con agua y mojante, esta vez en un pulverizador de mano. Se trata planta limpia hasta punto de goteo, y se deja secar dentro de la cámara de gases (Figura 23).

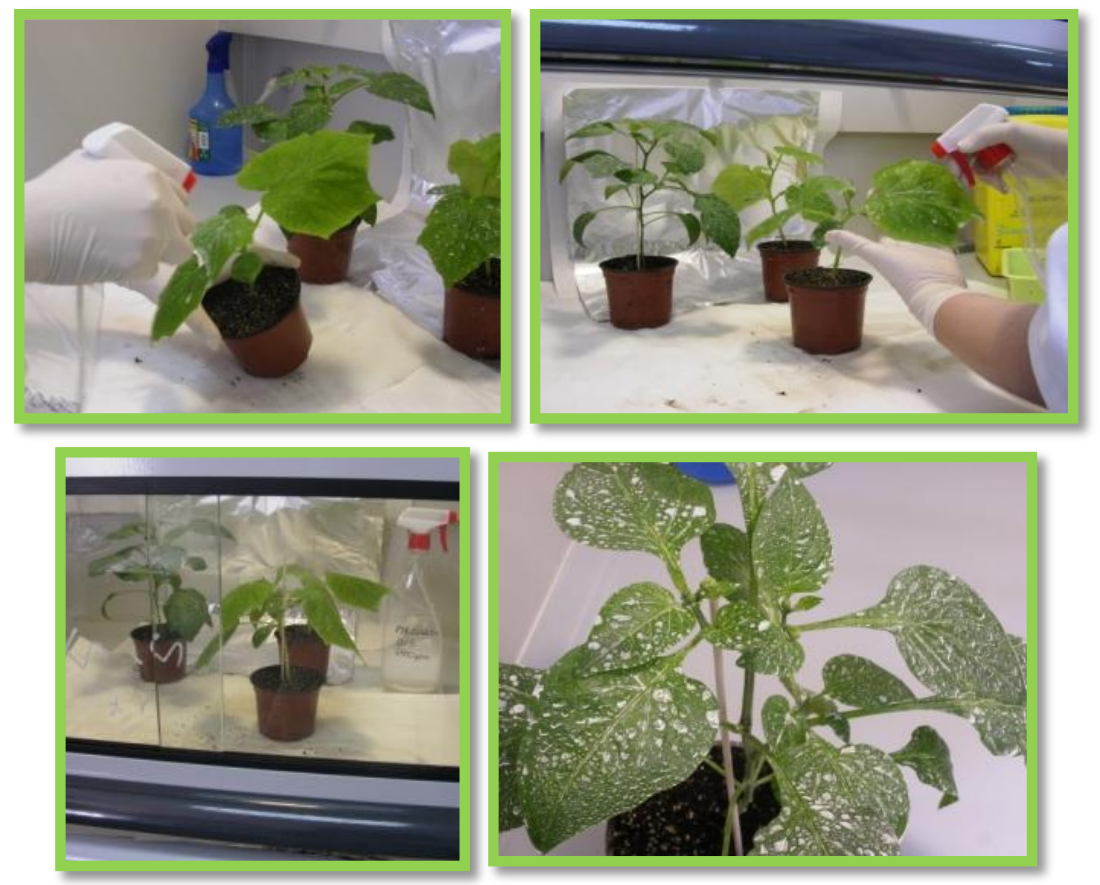

Figura 16. Tratamiento de selección de poblaciones de Bemisia.

Mientras el material vegetal recién tratado se seca, se procede al vaciado de las jaulas. Éstas se sacan de la cámara y con la ayuda de un aerógrafo, se van soplando los adultos de mosca, de modo que nos quede la mayor cantidad de mosca dentro de la jaula, y podamos sacar sólo las plantas con ninfas y huevos.

Una vez que se ha secado la planta nueva tratada, se introduce en las jaulas, de manera que las moscas que se han quedado dentro sin planta tengan de nuevo material vegetal donde posarse y realizar de nuevo las puestas.

Por otra parte, las plantas con puestas que hemos sacado, se llevan a la cámara de gases y se tratan también a punto de goteo. Una vez secas se vuelven a introducir en sus jaulas.

En el caso de las poblaciones resistentes a imidacloprid y tiametoxam, como en nuestros ensayos previos se vio que la resistencia al insecticida sólo expresaba sobre adultos (Nauen et al., 2008), la selección se hace en dos veces. En primer lugar se sopla la mosca igual que en el resto de las selecciones, y a esos adultos que quedan en la jaula se les pone, una vez que se ha secado, planta nueva tratada con la dosis elegida del insecticida, para que se multipliquen y criar sólo los supervivientes. Por otro lado, las plantas que se sacan con 
huevos y larvas, se introducen esta vez en jaulas nuevas. Cuando estos adultos emergen, son tratados de igual modo.

\subsubsection{Bioensayos de sinergistas}

Este tipo de bioensayos se realizan para poder determinar que posibles mecanismos están implicados en la resistencia a insecticidas. Se basan en añadir un producto que por sí sólo no tiene efecto plaguicida, pero sin embargo cuando se le añade a los insecticidas, éstos incrementan su actividad. Los sinergistas utilizados en este estudio fueron el butóxido de piperonilo (PBO) y el S,S,S tributil fosforotritioato (DEF). El PBO es un inhibidor del citocromo P450 y el DEF inhibe las esterasas.

La metodología de estos bioensayos es similar a los de ninfas descritos anteriormente. Se diferencian en que dos horas antes de ser tratadas las plantas con el insecticida se realiza un tratamiento con el sinergista. Todas las plantas son tratadas con una única dosis subletal y se deja un control para asegurarnos que realmente el sinergista por sí sólo no tiene efecto sobre Bemisia. El resto del bioensayo sigue los pasos de un bioensayo de ninfas. 


\subsection{Bibliografía}

Fernández, E., Gravalos, C., Haro, P. J., Cifuentes, D., y Bielza, P. 2009. Insecticide resistance status of Bemisia tabaci Q-biotype in south-eastern Spain. Pest management science, 65(8), 885-891.

Bosco D, Loria A, Sartor C and Cenis JL 2006. PCR-RFLP identification of Bemisia tabaci biotypes in theMediterranean Basin. Phytoparasitica 34:243-251.

Nauen R, Bielza P, Denholm I and Gorman K, (2008). Age-specific expression of resistance to neonicotinoid insecticides in the whitefly, Bemisia tabaci. PestManag Sci 64:11061110. 


\section{Capítulo 1}

Estado de la resistencia a insecticidas de Bemisia tabaci biotipo $Q$ en el sureste de España

Publicado en la revista Pest Management Science 65 (8): 885-891 en 2009. "Insecticide resistance status of Bemisia tabaci Q-biotype in south-eastern Spain” 


\section{Resumen}

Bemisia tabaci Gennadius, biotipo Q, ha desarrollado fácilmente resistencia a insecticidas de numerosas clases. Los estudios realizados en el área mediterránea son necesarios para aclarar el estado de la resistencia y los patrones de resistencia cruzada en este biotipo de mosca blanca invasiva. Fueron determinados los niveles de resistencia en ninfas de siete poblaciones de B. tabaci biotipo Q en el sureste de España a los insecticidas más representativos.

Seis poblaciones presentaron niveles bajos a moderados de resistencia a alfa-cipermetrín (con un factor de resistencia de 0,2 a 1,7), azadiractina (0,2 a 7), buprofecín (11 a 59), imidacloprid (1 a 15), metomilo (3 a 55), pimetrocina (3 a 273), piridabén (0,9 a 9), piriproxifén $(0,7 \mathrm{a}$ 15) y tiametoxam $(0,4$ a 11) en comparación con una población de referencia contemporánea española biotipo Q $\left(\mathrm{CL}_{50}=141,2 ; 2,7 ; 8,7 ; 15,2 ; 19,9 ; 29,2 ; 0,34\right.$; 20,9 y $17,9 \mathrm{mgL}^{-1}$, respectivamente). Una sola población obtenida de un invernadero sujeto a un uso intensivo de insecticidas mostró niveles más altos de resistencia al mismo grupo de compuestos $(107,31,1164,3,52,2181,9,19$ y 20 respectivamente). Piridabén fue extremadamente eficaz contra todas las poblaciones de ninfas, con valores $\mathrm{CL}_{50}$ significativamente inferiores de las dosis de aplicación recomendadas.

A diferencia de lo publicado anteriormente, existen altas tasas de eficacia para las numerosos clases de insecticidas contra las poblaciones de B. tabaci biotipo Q de estas regiones de agricultura intensiva del sureste de España. Esto probablemente refleja las reducciones recientes y significativas en la exposición a insecticidas que han resultado de una mayor penetración de las tecnologías de manejo integrado de plagas y estrategias antiresistencia. Sin embargo, la presencia continuada de los genes de resistencia también sugiere que una reversión a niveles altos de exposición al insecticida podría dar lugar a una rápida selección para la resistencia. 


\section{Introducción}

La mosca blanca del tabaco, Bemisia tabaci Gennadius (Homoptera: Aleyrodidae), es una de las plagas de insectos agrícolas más perjudiciales. Causa pérdidas por alimentación directa, perjudicando la calidad del producto a través de la excreción de melaza, y actuando como vector de geminivirus de plantas. Algunos de estos virus son de gran importancia económica, tales como el virus del rizado amarillo o de la hoja en cuchara del tomate (TYLCV).

En muchos sistemas agrícolas a nivel mundial, B. tabaci ha desarrollado altos niveles de resistencia contra varias clases químicas de insecticidas, incluyendo los hidrocarburos clorados, organofosfatos, carbamatos, piretroides, reguladores del crecimiento de insectos y neonicotinoides (Palumbo et al. 2001, Horowitz et al. 2005 y Nauen y Denholm 2005).

Se han descrito varios biotipos de B. tabaci. El más extendido es el biotipo B (Costa y Brown 1991), pero en el sur de Europa, coexiste con el biotipo Q (Guirao et al 1997). El biotipo Q, el primero caracterizado en España (Guirao et al 1997), es originario de la región mediterránea, y se ha convertido en el biotipo predominante en la Península Ibérica desde el año 2000 (Simón et al. 2007). El biotipo Q se ha descubierto más ampliamente en la cuenca mediterránea (Horowitz et al. 2005, Brown 2000, Nauen et al. 2002, Simón et al. 2003 y Horowitz et al. 2003), China (Zhang et al. 2005), Japón (Ueda y Brown 2006), México, Estados Unidos y Guatemala (Brown 2009).

El biotipo Q está resultando especialmente invasivo, especialmente en los productos vegetales importados, y es motivo de preocupación debido principalmente a su amplia gama de mecanismos de resistencia que afectan tanto a los nuevos como a los grupos de insecticidas convencionales (Horowitz et al. 200, Nauen y Denholm 2005, Zhang et al. 2005, Dennehy et al. 2005).

Sin embargo, la mayoría de los estudios de resistencia de mosca blanca biotipo $Q$ se han llevado a cabo a partir de un número limitado de poblaciones recolectadas en España hace unos años. Los problemas de resistencia son a veces muy localizados, y las generalizaciones respecto a la resistencia a los insecticidas que dependen de conjuntos de datos limitados deben evitarse (Elbert y Nauen 2000). Por lo tanto, el examen de una amplia gama de poblaciones de campo contemporáneos en el área mediterránea es esencial para aclarar el 
estado de la resistencia y los patrones de resistencia cruzada en este biotipo de mosca blanca invasiva.

Además, son poco frecuentes los bioensayos con insecticidas en ninfas de Bemisia tabaci, a pesar del hecho de que todos los estados están presentes de manera continua durante la plaga y los estados inmaduros representan claramente una gran proporción del total de la población de mosca blanca. De hecho, la diferencia en la resistencia entre los diferentes estados del ciclo de la mosca blanca ha sido publicada recientemente (Nauen et al. 2008).

El objetivo de este estudio fue determinar los niveles de resistencia de siete poblaciones de B. tabaci biotipo Q de Almería y Murcia (sureste de España) a los insecticidas más representativos para el control de mosca blanca: alfa-cipermetrín, azadiractina, buprofecín, imidacloprid, metomilo, pimetrocina, piridabén, piriproxifén, y tiametoxam. 


\section{Material y Métodos}

\subsection{Poblaciones de Bemisia tabaci}

Las poblaciones utilizadas fueron una población sensible de referencia (LAB-S) recogida en un invernadero sin tratamientos químicos en la zona de Murcia y seis poblaciones de diferentes zonas de Murcia y Almería que ya han sido descritas en el capítulo de material y métodos. Se detallan a continuación en la tabla 1.

Tabla 1. Poblaciones de Bemisia tabaci.

\begin{tabular}{c|cccc} 
Poblaciones & Localización & Cultivo & Año & Biotipo \\
\hline LAB-S & Murcia & Pimiento & 2006 & Q \\
\hline MU-A & Murcia & Tomate & 2006 & Q \\
MU-MA & Murcia & Tomate & 2006 & Q \\
MU-MI & Murcia & Pimiento & 2006 & Q \\
AL-BA & Almería & Pimiento & 2006 & Q \\
AL-MO & Almería & Pimiento & 2006 & Q \\
AL-PA & Almería & Pimiento & 2006 & Q \\
\hline
\end{tabular}

\subsection{Insecticidas}

Los siguientes insecticidas formulados fueron los que se utilizaron para los bioensayos: alfa-cipermetrín $100 \mathrm{~g} \mathrm{~L}^{-1} \mathrm{CE}$ (Fastac $10 \mathrm{CE}, \mathrm{BASF}$, Sevilla, España), azadiractina $32 \mathrm{~g} \mathrm{~L}^{-1}$ CE (Align; Sipcam Inagra, Valencia, España), buprofezín $250 \mathrm{~g} \mathrm{~kg}^{-1}$ WP (Aplaudd, Syngenta Agro, Madrid, España), imidacloprid $200 \mathrm{~g} \mathrm{~L}^{-1}$ SL (Confidor 20LS, Bayer CropScience, Valencia, España), metomilo $200 \mathrm{~g} \mathrm{~L}^{-1}$ SL (Lannate $20 \mathrm{~L}$, Iberica DuPont, Barcelona, España), pimetrocina $250 \mathrm{~g} \mathrm{~kg}^{-1} \mathrm{WP}$ (Plenum $25 \mathrm{WP}$, Syngenta Agro, Madrid, España), piridaben $200 \mathrm{~g} \mathrm{~kg}^{-1}$ WP (Sanmite; BASF, Sevilla, España), piriproxifén $100 \mathrm{~g} \mathrm{~L}^{-1}$ CE (Juvinal 10 CE; Kenogard, Barcelona, España) y tiametoxam $250 \mathrm{~g} \mathrm{~kg}^{-1}$ WG (Actara 25 WG, Syngenta Agro, Madrid, España). Se prepararon diluciones seriadas de los compuestos formulados con agua desionizada que contiene $1 \mathrm{~mL} \mathrm{~L}^{-1}$ de Tween 20 (como un humectante no iónico) en el día del bioensayo.

\subsection{Bioensayos de ninfas y huevos}

Ver capítulo 2 de Material y Métodos (Apartado 3.6.2. y 3.6.3.). 


\subsection{Análisis de datos}

Cuando fue necesario, los datos del bioensayo fueron corregidos por la mortalidad del control (Abbott 1925).). Los datos se analizaron utilizando el programa POLO-PC para el análisis probit (Russell et al. 1977). Se calcularon las concentraciones que causan una mortalidad del 50\% $\left(\mathrm{CL}_{50}\right)$ y sus límites fiduciales al 95\%. También se calcularon los factores de resistencia a nivel de $\mathrm{CL}_{50}\left(\mathrm{FR}_{50}\right)$ como la relación entre la $\mathrm{CL}_{50}$ de la población y la $\mathrm{CL}_{50}$ de la población de referencia. Las dosis de campo de los insecticidas utilizadas en este estudio fueron las más altas tasas recomendadas por el fabricante. 


\section{Resultados y discusión}

Los resultados del análisis probit se muestran en la tabla 2. LAB-S fue la población más susceptible (o no significativamente diferente de la más susceptible) para alfa-cipermetrín, azadiractina, buprofecín, imidacloprid, metomilo, pimetrocina, piridabén, piriproxifén y tiametoxam.

Este estudio reveló variaciones en el nivel de resistencia a los insecticidas en $B$. tabaci biotipo Q recogida en el sureste de España, ejemplificada por la comparación entre las poblaciones MU-A y MU-MA. Estas poblaciones se obtuvieron de invernaderos en dos lugares cercanos (Águilas y Mazarrón, respectivamente) en el área de la producción de tomate de Murcia. La principal diferencia entre ambas ha sido el cambio en la estrategia para el control de mosca blanca en la localidad de Águilas (MU-A) hace varios años. La población MU-A fue la población de campo más susceptible de las que se ensayaron (o no significativamente diferente de la más susceptible) para alfa-cipermetrín, azadiractina, buprofecín, imidacloprid, piridabén, piriproxifén y tiametoxam. Esta población sólo mostró resistencia a metomilo y pimetrocina. En contraste, la población MU-MA fue significativamente más resistente a la azadiractina, buprofecín, imidacloprid y tiametoxam. Es posible que la estrategia sin tratamientos de insecticidas y el énfasis en el control biológico haya contribuido a los bajos niveles de resistencia evidentes en la población de MU-A.

La población MU-MI se recogió en un invernadero bajo control químico intensivo en el área de producción de pimiento de Murcia (Campo de Cartagena), un área en la que más del 95\% de la superficie del invernadero está bajo el control biológico, prácticamente sin ningún tratamiento insecticida. Esta práctica ha dado lugar a niveles de resistencia más bajos en las plagas con problemas de resistencia severos tales como Frankliniella occidentalis (Pergande) (Bielza et al. 2008). Sin embargo, la población MU-MI mostró los niveles más altos de resistencia, siendo la población más resistente (o no significativamente diferente de la más resistente) para todos los insecticidas aparte de imidacloprid y tiametoxam. Por lo tanto, parecería que una alta presión de selección en un invernadero en particular puede mantener altos factores de resistencia, incluso en un entorno de bajo uso de insecticidas. 
Tabla 2. Toxicidad a diferentes insecticidas para la población sensible (LAB-S) y poblaciones de campo de Bemisia.

\begin{tabular}{|c|c|c|c|c|}
\hline Insecticida & Población & Pendiente $( \pm \mathrm{ET})$ & CL50 (mg L $\left.{ }^{-1}\right)(95 \%$ LC) & FR50 \\
\hline \multirow[t]{7}{*}{ Alfa-cipermetrín } & LAB-S & $1,27( \pm 0,19)$ & $141,2(40,3-255,6)$ & 1 \\
\hline & MU-A & $0,56( \pm 0,10)$ & $236,4(90,6-780,3)$ & 1,7 \\
\hline & MU-MA & $0,38( \pm 0,06)$ & $62,3(7,7-1619,3)$ & 0,44 \\
\hline & MU-MI & $0,39( \pm 0,06)$ & $106,7(48,5-294,7)$ & 0,76 \\
\hline & AL-BA & $0,63( \pm 0,08)$ & $28,3(6,2-89,1)$ & 0,20 \\
\hline & AL-MO & $0,61( \pm 0,08)$ & $63,9(24,1-157,9)$ & 0,45 \\
\hline & AL-PA & $0,61( \pm 0,07)$ & $37,5(10,1-120,6)$ & 0,27 \\
\hline \multirow[t]{7}{*}{ Azadiractín } & LAB-S & $0,88( \pm 0,10)$ & $2,7(0,5-6,6)$ & 1 \\
\hline & MU-A & $0,88( \pm 0,09)$ & $0,6(0,1-1,3)$ & 0,2 \\
\hline & MU-MA & $0,92( \pm 0,09)$ & $5,4(1,7-13,0)$ & 2 \\
\hline & MU-MI & $1,26( \pm 0,27)$ & $82,7(36,5-166,7)$ & 31 \\
\hline & AL-BA & $0,78( \pm 0,08)$ & $4,0(1,7-7,5)$ & 1,5 \\
\hline & AL-MO & $1,50( \pm 0,18)$ & $18,5(11,5-26,4)$ & 7 \\
\hline & AL-PA & $0,75( \pm 0,10)$ & $0,8(0,0-3,0)$ & 0,3 \\
\hline \multirow[t]{7}{*}{ Buprofecín } & LAB-S & $1,66( \pm 0,17)$ & $8,7(4,4-14,4)$ & 1,0 \\
\hline & MU-A & $0,89( \pm 0,07)$ & $96,2(64,2-143,3)$ & 11 \\
\hline & MU-MA & $0,89( \pm 0,08)$ & $389,6(253,6-649,3)$ & 45 \\
\hline & MU-MI & $0,62( \pm 0,09)$ & $10159,0(2157,8-1389658,3)$ & 1164 \\
\hline & AL-BA & $0,49( \pm 0,06)$ & $125,1(31,9-519,9)$ & 14 \\
\hline & AL-MO & $1,56( \pm 0,22)$ & $390,4(127,4-724,5)$ & 45 \\
\hline & AL-PA & $0,59( \pm 0,13)$ & $518,1(115,3-1723,0)$ & 59,4 \\
\hline \multirow[t]{7}{*}{ Imidacloprid } & LAB-S & $0,60( \pm 0,07)$ & $15,2(1,3-81,1)$ & 1,0 \\
\hline & MU-A & $1,74( \pm 0,19)$ & $53,4(16,0-110,5)$ & 3 \\
\hline & MU-MA & $1,14( \pm 0,15)$ & $190,5(119,1-318,5)$ & 12 \\
\hline & MU-MI & $0,96( \pm 0,10)$ & $47,4(6,7-206,6)$ & 3 \\
\hline & AL-BA & $1,02( \pm 0,14)$ & $14,9(2,0-35,2)$ & 1 \\
\hline & AL-MO & $0,85( \pm 0,12)$ & $81,5(36,0-168,2)$ & 5 \\
\hline & AL-PA & $0,83( \pm 0,13)$ & $228,9(82,4-1017,5)$ & 15 \\
\hline \multirow[t]{7}{*}{ Metomilo } & LAB-S & $0,62( \pm 0,06)$ & $19,9(7,5-52,6)$ & 1 \\
\hline & MU-A & $0,85( \pm 0,09)$ & $1101,1(558,4-3293,5)$ & 55 \\
\hline & MU-MA & $0,46( \pm 0,07)$ & $199,1(47,4-3652,3)$ & 10 \\
\hline & MU-MI & $1,62( \pm 0,20)$ & $1030,8(405,5-1843,6)$ & 52 \\
\hline & AL-BA & $0,52( \pm 0,06)$ & $68,3(27,8-262,2)$ & 3 \\
\hline & AL-MO & $0,42( \pm 0,06)$ & $589,6(170,8-7211,6)$ & 30 \\
\hline & AL-PA & $0,52( \pm 0,07)$ & $109,3(36,9-467,8)$ & 5 \\
\hline \multirow[t]{7}{*}{ Pimetrocina } & LAB-S & $1,03( \pm 0,09)$ & $29,2(3,2-107,4)$ & 1 \\
\hline & MU-A & $3,05( \pm 0,531)$ & $7973(5163,4-10529)$ & 273 \\
\hline & MU-MA & $0,56( \pm 0,063)$ & $96,3(27,9-220,2)$ & 3 \\
\hline & MU-MI & $0,71( \pm 0,076)$ & $2181,2(670,5-8595,4)$ & 75 \\
\hline & AL-BA & $0,49( \pm 0,058)$ & $210,7(45,4-612,3)$ & 7 \\
\hline & AL-MO & $0,43( \pm 0,082)$ & $213,2(17,4-1035,9)$ & 7 \\
\hline & AL-PA & $0,38( \pm 0,072)$ & $157,6(29,6-485,6)$ & 5 \\
\hline \multirow[t]{7}{*}{ Piridabén } & LAB-S & $0,98( \pm 0,11)$ & $0,34(0,21-0,51)$ & 1 \\
\hline & MU-A & $0,93( \pm 0,10)$ & $0,32(0,02-1,09)$ & 0,9 \\
\hline & MU-MA & $0,72( \pm 0,08)$ & $0,47(0,01-2,30)$ & 1,4 \\
\hline & MU-MI & $1,85( \pm 0,31)$ & $2,95(0,96-5,01)$ & 9 \\
\hline & AL-BA & $1,01( \pm 0,07)$ & $0,88(0,61-1,26)$ & 3 \\
\hline & AL-MO & $0,60( \pm 0,07)$ & $0,76(0,13-2,43)$ & 2 \\
\hline & AL-PA & $1,07( \pm 0,11)$ & $3,08(1,40-5,67)$ & 9 \\
\hline
\end{tabular}




\begin{tabular}{c|cccc|}
\hline \multirow{3}{*}{ Piriproxifén } & LAB-S & $0,98( \pm 0,10)$ & $20,9(13,8-30,4)$ & 1,0 \\
& MU-A & $0,92( \pm 0,07)$ & $25,9(16,2-40,7)$ & 1,2 \\
\cline { 2 - 4 } & MU-MA & $1,03( \pm 0,08)$ & $15,4(7,5-28,3)$ & 0,7 \\
& MU-MI & $0,91( \pm 0,10)$ & $402,4(274,0-634,3)$ & 19 \\
& AL-BA & $1,17( \pm 0,09)$ & $117,1(73,5-196,9)$ & 6 \\
& AL-MO & $1,00( \pm 0,08)$ & $322,2(167,0-805,4)$ & 15 \\
& AL-PA & $1,19( \pm 0,12)$ & $243,3(118,7-547,9)$ & 12 \\
\hline \multirow{7}{*}{ Tiametoxam } & LAB-S & $1,87( \pm 0,16)$ & $17,9(8,1-34,4)$ & 1 \\
& MU-A & $0,88( \pm 0,149)$ & $47,4(3-116,4)$ & 11 \\
& MU-MA & $2,06( \pm 0,319)$ & $201,1(104,3-301,9)$ & 1,1 \\
& MU-MI & $0,82( \pm 0,08)$ & $20(8,8-38,6)$ & 3 \\
& AL-BA & $1,01( \pm 0,144)$ & $51,4(13,7-176,4)$ & 0,37 \\
& AL-MO & $0,84( \pm 0,097)$ & $6,6(0,55-19,6)$ & 4 \\
\hline
\end{tabular}

\subsection{Alfa-cipermetrín}

Alfa-cipermetrín es un piretroide sintético actual de cuarta generación que actúa sobre el sistema nervioso central, afectando a la transmisión de los impulsos nerviosos.

Los valores obtenidos de la $\mathrm{CL}_{50}$ para las poblaciones variaron entre 28,3 y 236,4 $\mathrm{mg} \mathrm{L}^{-1}$ (tabla 2), no habiendo diferencias significativas con la población sensible de referencia (LAB-S) siendo su $\mathrm{CL}_{50}$ de $141,2 \mathrm{mg} \mathrm{L}^{-1}$. En ninguno de los casos el factor de resistencia fue mayor de 2. MU-A fue la población en la que se obtuvo el valor más elevado a pesar de considerarse una de las poblaciones más sensibles a la mayoría de los insecticidas.

Aunque no existen diferencias significativas, cabe destacar el valor elevado que presenta la población de referencia y la mayoría de las poblaciones de campo, siendo muy superior a la dosis recomendada en campo para alfa-cipermetrín $\left(40 \mathrm{mg} \mathrm{L}^{-1}\right)$.

En la literatura, todos los estudios encontrados fueron referidos a adultos de B. tabaci, no pudiendose comparar con nuestros datos, ya que se realizaron sobre ninfas. Así que realizamos los bioensayos con adultos para alfa-cipermetrín, obteniendo unos valores de la $\mathrm{CL}_{50}$ de 7,6 a $195,8 \mathrm{mg} \mathrm{L}^{-1}$ para las poblaciones de campo y 18,3 $\mathrm{mg} \mathrm{L}^{-1}$ para la población sensible de referencia (Tabla 3). Aunque el rango de valores es menor que el obtenido para las ninfas, no hay una diferencia significativa entre ellos. 
Tabla 3. Toxicidad a alfa cipermetrín para la población sensible (LAB-S) y poblaciones de campo de Bemisia en estado adulto.

\begin{tabular}{c|cccc}
\hline Insecticida & Población & Pendiente $( \pm$ ET $)$ & CL50 $(\mathrm{mg}$ L-1 $)(95 \%$ LC) & FR50 \\
\hline Alfa Cipermetrín & LAB-S & $1,417( \pm 0,33)$ & $18,3(4,2-33,7)$ & 1 \\
& MU-A & $0,688( \pm 0,11)$ & $7,6(1,8-19,8)$ & 0,4 \\
& MU-MA & $1,014( \pm 0,15)$ & $12,5(5,5-23,1)$ & 0,7 \\
& MU-MI & $1,465( \pm 0,39)$ & $195,8(88,1-339)$ & 11 \\
& AL-BA & $0,761( \pm 0,23)$ & $61,3(20,9-192,9)$ & 3 \\
& AL-MO & $0,958( \pm 0,12)$ & $27,2(14,3-48,9)$ & 1,5 \\
& AL-PA & $0,957( \pm 0,27)$ & $111,5(33,4-226,3)$ & 6 \\
\hline
\end{tabular}

Si ahora vemos lo encontrado en la bibliografía, en Grecia entre 2002 y 2003 los valores de la $\mathrm{CL}_{50}$ de las poblaciones recolectas estuvieron en el rango de 0,08 a $17,1 \mathrm{mg} \mathrm{L}{ }^{-1}$, exceptuando una población con $130 \mathrm{mg} \mathrm{L}^{-1}$, que fue recolectada de un invernadero que había sido tratada aproximadamente con 20 aplicaciones con piretroides, neonicotinoides, organofosforados y carbamatos (Roditakis et al. 2005). Pero, dos años más tarde en 2005, otro estudio en Grecia, donde se recolectaron 53 poblaciones de B. tabaci biotipo Q, los valores variaron de 19,1 a >1000 $\mathrm{mg} \mathrm{L}^{-1}$ (Roditakis et al. 2008). Por otro lado, en China, las poblaciones biotipo Q recolectadas entre 2008 y 2009 presentaron valores de 23,2 a $632 \mathrm{mg}$ $\mathrm{L}^{-1}$ (Wang et al. 2010). Todos estos bioensayos tuvieron la misma población de referencia con un valor de la $\mathrm{CL}_{50}$ de $1,6 \mathrm{mg} \mathrm{\textrm {L } ^ { - 1 }}$.

Por lo tanto nuestras poblaciones de campo respondieron de manera similar a las descritas en la literatura, no siendo incluso tan resistentes como las descritas para Grecia.

\subsection{Azadiractina}

Azadiractina, un tetranortriterpenoide similar a los esteroides, derivado de los árboles de neem, es un fuerte antialimentario y un insecticida regulador del crecimiento para una gran variedad de plagas, incluyendo moscas blancas (Coudriet et al. 1985 y Schmutterer 1990). Además, puede causar una mortalidad significativa, particularmente en ninfas (Kumar y Poehling 2007). Esta toxicidad directa es el único efecto medido con los bioensayos presentes.

Existe una falta de estudios previos sobre la resistencia a la azadiractina en B. tabaci. Aunque la susceptibilidad a la azadiractina varió hasta 138 veces entre las poblaciones 
actuales, ésta aparentemente no compromete su rendimiento en el campo. A excepción de MU-MI, los valores de las $\mathrm{CL}_{50}$ estarían por debajo de la dosis de campo (48 mg L ${ }^{-1}$ ). La única población que mostró un nivel de resistencia moderada fue de MU-MI, que se obtuvo de un invernadero tratado 4 veces con azadiractina en los últimos 4 meses. Estos datos pueden subestimar el rendimiento en el campo de la azadiractina, ya que no tienen en cuenta su acción múltiple, tales como la disrupción de la muda y la reducción del crecimiento, el desarrollo y la oviposición.

\subsection{Buprofecín}

El regulador del crecimiento de insectos buprofecín es una tiadiazina, y su efecto principal es interferir en la deposición de quitina durante la muda y así causar la muerte ninfal durante la ecdisis (Cahill et al. 1996). El valor de $\mathrm{CL}_{50}\left(8,7 \mathrm{mg} \mathrm{L}^{-1}\right)$ de la población de referencia (LAB-S) para buprofecín está dentro de los valores publicados de la línea base de referencia de susceptibilidad. Los valores de la $\mathrm{CL}_{50}$ de la línea base de poblaciones de mosca blanca para las regiones productoras de algodón de Pakistán, Israel y Arizona, sin exposición previa a buprofecín, fueron de $0,5 \mathrm{mg} \mathrm{L}^{-1}$ (Cahill et al. 1996), 6,4 $\mathrm{mg} \mathrm{L}^{-1}$ (Horowitz y Ishaaya 1992) y 6,8-8,0 $\mathrm{mg} \mathrm{L}^{-1}$ (Yasui et al. 1997), respectivamente. Antes del uso generalizado de buprofecín en California y Arizona, los valores de $\mathrm{CL}_{50}$ de las poblaciones de mosca blanca de campo variaron de 0,03 a $37,1 \mathrm{mg} \mathrm{L}^{-1}$ (Toscano et al. 2001). Poblaciones de campo de Israel mostraron valores de $\mathrm{CL}_{50}$ de 5,8-29,9 mg $\mathrm{L}^{-1}$ (Horowitz y Ishaaya 1992 y 1994). Estos valores son similares a los publicados para las poblaciones de Almería recogidos en 1994 (Cahill et al. 1996), que van desde 0,87 hasta $15,8 \mathrm{mg} \mathrm{L}^{-1}$.

Los valores de $\mathrm{CL}_{50}$ para las poblaciones de campo fueron significativamente mayores de lo que hasta ahora estaba publicado, incluso para la población más susceptible, MU-A (96 mg $\mathrm{L}^{-1}$ ). Estas diferencias pueden deberse en parte al método de bioensayo: en este trabajo se utilizaron ninfas de 15 días de edad, mientras que en estudios anteriores se usaban ninfas de 7-9 días de edad. Sin embargo, algunas de las poblaciones presentes eran muy resistentes, especialmente la población MU-MI ( $\left.\mathrm{CL}_{50} 10.160 \mathrm{mg} \mathrm{L}^{-1}\right)$. Esta población fue seleccionada fuertemente con otros insecticidas, pero curiosamente no había recibido ninguna aplicación de buprofecín durante la temporada de cultivo. 


\subsection{Imidacloprid}

Imidacloprid, el primer insecticida comercialmente disponible de la clase neonicotinoides, ha sido utilizado intensamente para combatir B. tabaci en el sureste de España desde 1993, y las poblaciones de mosca blanca biotipo Q de Almería fueron el primer ejemplo de la resistencia de la plaga a neonicotinoides (Cahill et al. 1996).

El seguimiento de la resistencia en B. tabaci a imidacloprid en España se inició en 1994 y 1995 (Cahill et al. 1996), sólo 1-2 años después de su introducción en el mercado, cuando aún no se habían observado signos de reducción de control en campo (Elbert y Nauen 2000), mostrando un rango de valores de $\mathrm{CL}_{50}$ de 35 a $57 \mathrm{mg} \mathrm{L}^{-1}$ (Cahill et al. 1996 y Nauen et al. 2002). Estos valores son superiores a los de otros biotipos y las poblaciones susceptibles de referencia. Sin embargo, se obtuvieron antes del uso generalizado de imidacloprid en Almería, por lo que podrían ser considerados como los datos de referencia de susceptibilidad para las poblaciones de B. tabaci biotipo Q españolas. Nuestra población sensible de referencia mostró un valor de la $\mathrm{CL}_{50}$ similar a aquellas poblaciones en las que se bioensayaron adultos por inmersión foliar $\left(58 \mathrm{mg} \mathrm{L}^{-1}\right.$ ) (Nauen et al. 2008) y por lo tanto, probablemente representa un fenotipo casi susceptible.

En la bibliografía, todos los estudios que se han realizado para la resistencia a imidacloprid se han hecho sobre adultos de B. tabaci, pero un estudio relativamente reciente revela que el segundo estado ninfal es de 4 a 10 veces más sensible que los adultos a imidacloprid (Nauen et al. 2008). En ese estudio, la población de referencia que se utilizó fue la misma, con un valor de $\mathrm{CL}_{50}$ de $58 \mathrm{mg} \mathrm{L}^{-1}$ para adultos y $15 \mathrm{mg} \mathrm{L}^{-1}$ para ninfas. El presente estudio documenta las respuestas de los estados inmaduros de B. tabaci para más poblaciones. Aunque alguna población fue menos susceptible al imidacloprid que la población de referencia, esta resistencia puede ser insuficiente para comprometer la eficacia de las aplicaciones de campo. Excepto para las poblaciones MU-MA y AL-PA, los valores de $\mathrm{CL}_{50}$ del resto de las poblaciones estaban por debajo de la dosis de campo (150 $\left.\mathrm{mg} \mathrm{L}^{-1}\right)$. La resistencia expresada en los estados inmaduros no es lo suficientemente potente para comprometer las dosis de aplicación recomendadas para imidacloprid. Estos resultados pueden explicar el pobre control observado sobre adultos de poblaciones de campo de mosca blanca, mientras que los neonicotinoides son todavía ampliamente utilizados para el control de mosca blanca en el sureste de España. 
La resistencia cruzada en $B$. tabaci, se extiende a través de los principales insecticidas neonicotinoides comerciales (imidacloprid, tiametoxam y acetamiprid), como ya se ha publicado anteriormente (Elbert y Nauen 2000, Nauen et al. 2002, Rauch y Nauen 2003 y Prabhaker et al. 2005). Por lo tanto, la hipótesis que sugieren estos resultados para el imidacloprid (especifico del estado del desarrollo y buen control de ninfas) se puede extender a otros compuestos actualmente comprometidos por el mismo mecanismo de resistencia, aunque, es necesaria más investigación.

\subsection{Metomilo}

El metomilo es el carbamato más utilizado contra B. tabaci, por lo general dirigido a los adultos. Los bajos valores de la $\mathrm{CL}_{50}$ para algunas poblaciones (LAB-S, AL-BA, MU-MA y AL-PA) en comparación con la dosis de campo $\left(500 \mathrm{mg} \mathrm{L}^{-1}\right)$, muestran que este carbamato también es eficaz contra los estados inmaduros, por lo que no tiene por qué ser considerado simplemente como un adulticida.

Existe una cantidad limitada de trabajos publicados para la resistencia a carbamatos en $B$. tabaci, pero ninguna documenta toxicidad para ninfas (Bielza et al. 2000, Kranthi et al. 2001 y ElKady y Devine 2003). Los niveles de resistencia mostrados por B. tabaci a metomilo varió de 3 a 55 veces. Curiosamente, la población más resistente fue MU-A, a pesar de su alta susceptibilidad a los insecticidas ensayados. Sin embargo, la población multirresistente MU-MI fue también resistente metomilo. Estos resultados sugieren una falta de resistencia cruzada con otros insecticidas, incluso con organofosforados (ElKady y Devine 2003).

\subsection{Pimetrocina}

La pimetrocina, una azometina piridina, representa una clase química de insecticidas con una notable selectividad para los insectos chupadores, como los áfidos y moscas blancas, debido a su acción sistémica (Kristinsson 1994; Wyss y Bolinger 1997). Es un agente de control de B. tabaci que altera el comportamiento de alimentación, lo que lleva a la inanición y muerte (Ausborn et al. 2005 y Harrewijn y Kayser 1997).

Las poblaciones de campo bioensayadas con pimetrocina presentaron unos valores de la $\mathrm{CL}_{50}$ entre 157,6 y $7973 \mathrm{mg} \mathrm{L}^{-1}$. Sólo presentaron diferencias significativas con la población 
de referencia $\left(29,17 \mathrm{mg} \mathrm{L}^{-1}\right)$ las poblaciones MU-A y MU-MI, siendo los factores de resistencia 273 y 75 respectivamente. En este caso, al igual que ocurre con el metomilo, la población más susceptible a los otros insecticidas fue la más resistente a pimetrocina, presentando también resistencia la población multirresistente MU-MI.

En la literatura, al igual que pasa con otros insecticidas, todos los datos publicados son en estudios realizados sobre adultos de mosca blanca. Se han encontrado datos en ninfas de Trialeurodes vaporariorum (mosca blanca de los invernaderos) (Karatolos et al. 2010), que al ser una mosca blanca cabe esperar que los mecanismos de resistencia sean similares, pudiendo comparar ambos resultados. $\mathrm{El}$ rango de valores de la $\mathrm{CL}_{50}$ para T. vaporariorum fue de 78 a $213 \mathrm{mg} \mathrm{L}^{-1}$, no habiendo diferencias significativas con la mayoría de nuestras poblaciones.

Por lo tanto, excepto en dos poblaciones, el resto no presenta una resistencia significativa a pimetrocina.

Las poblaciones de campo presentan una $\mathrm{CL}_{50}$ cercana o superior $\left(158-7973 \mathrm{mg} \mathrm{L}^{-1}\right)$ a la dosis de campo $\left(250 \mathrm{mg} \mathrm{L}^{-1}\right)$. Por tanto no parece que este compuesto sea muy efectivo en ninfas en las poblaciones españolas (biotipo Q), sin embargo, si lo es en adultos, como se verá en el capítulo 2.

\subsection{Piridabén}

Piridabén es un acaricida que pertenece al grupo inhibidor mitocondrial de transporte de electrones (METI). Es activo frente a todas las etapas de ácaros fitófagos y algunos insectos, como la mosca blanca (Hirata et al 1995). Piridabén se utiliza comúnmente para el control de Bemisia en España.

Hay una completa falta de estudios previos sobre la resistencia de piridabén en B. tabaci. Todos los valores $\mathrm{CL}_{50}$ publicados en este estudio $\left(0,3-3,1 \mathrm{mg} \mathrm{L}^{-1}\right)$ son significativamente más bajos que la dosis de campo de $200 \mathrm{mg} \mathrm{L}^{-1}$. Además, las poblaciones MU-MI y AL-PA significativamente más tolerantes que la de referencia, sólo fueron 9 veces más resistentes, quedando aún muy lejos del valor de la dosis recomendada. Estos resultados documentan el estado actual de alta susceptibilidad a piridabén de las poblaciones de B. tabaci en el sureste de España, y demuestran una falta de resistencia cruzada con los compuestos examinados que fueron afectados por la resistencia. 


\subsection{Piriproxifén}

Piriproxifén, una hormona mimética juvenil, es un potente regulador de crecimiento de insectos que suprime la eclosión de los huevos de B. tabaci y también afecta a las ninfas, causando la mortalidad antes de la emergencia de adultos. Aunque los niveles de resistencia a piriproxifén se han publicado en poblaciones de campo de biotipos B y Q de B. tabaci de diversas áreas del mundo (Horowitz 2005, Toscano et al. 2001 y Ma et al. 2007), la resistencia a piriproxifén en poblaciones españolas biotipo $Q$ no ha sido documentada previamente. Para piriproxifén, los valores de la $\mathrm{CL}_{50}$ de las presentes poblaciones de campo variaron de 15 a $402 \mathrm{mg} \mathrm{L} \mathrm{L}^{-1}$. Estas poblaciones no son tan susceptibles a piriproxifén como la población biotipo Q recogida en Almería en 1994, ALM-1 ( CL $_{50} 0,002$ $\mathrm{mg} \mathrm{L^{-1 }}$ ) (Horowitz et al. 2003). Las respuestas de las poblaciones más susceptibles (LAB-S, MU-A y MU-MA), con valores de $\mathrm{CL}_{50}$ entre 15,4 y 25,9 $\mathrm{mg} \mathrm{L}^{-1}$, fueron similares a los publicados previamente para poblaciones resistentes a piriproxifén biotipo Q (Horowitz 2005 y Devine et al. 1999).

Además, los valores de las $\mathrm{CL}_{50}$ de las poblaciones más resistentes presentes variaron entre 117 y $402 \mathrm{mg} \mathrm{L}^{-1}$, siendo éstos los valores más altos jamás publicados. Por lo tanto, las poblaciones biotipo Q españolas mostraron una tolerancia a piriproxifén mayor que en otras áreas, probablemente debido a la selección para la resistencia. En el área de cultivo de tomate de Murcia, los agricultores continúan con el uso de piriproxifén para lograr un control aceptable de B. tabaci, además los valores de la $\mathrm{CL}_{50}$ de las poblaciones recogidas en ellos (MU-A y MU-MA) están por debajo de la dosis de campo $\left(75 \mathrm{mg} \mathrm{L}^{-1}\right)$.

Horowitz et al. (2003) demostraron una relación empírica entre la resistencia a piriproxifén y la presencia del biotipo Q. De manera similar, el biotipo Q fue vinculado con una alta resistencia y resistencia cruzada a los neonicotinoides (Nauen et al. 2002, Rauch y Nauen 2003). En las zonas donde múltiples biotipos coexisten, aplicaciones de piriproxifén y/o neonicotinoides pueden ser capaces de seleccionar el biotipo Q debido a su mayor resistencia a insecticidas (Horowitz et al. 2005). Los datos de las mosca blanca españolas biotipo Q presentados aquí son consistentes con estudios previos; la resistencia a imidacloprid y piriproxifén fue en general mayor que la documentada para otros biotipos e incluso la población sensible que se utilizó como referencia (Horowitz et al. 2005, Toscano et al. 2001, Cahill et al. 1996, Nauen et al. 2002, Ma et al. 2007). 


\subsection{Tiametoxam}

Pertenece a la subclase tianicotinilos de la segunda generación de neonicotinoides. Es agonista del receptor nicotínico de la acetilcolina y afecta a las sinapsis del sistema nervioso central de los insectos (Cahill and Denholm 1999). Las $\mathrm{CL}_{50}$ de las poblaciones de campo $\left(6,56\right.$ - 201,07 $\left.\mathrm{mg} \mathrm{L}^{-1}\right)$ no presentaron diferencias significativas con la población sensible de referencia $\left(17,95 \mathrm{mg} \mathrm{L}^{-1}\right)$, a excepción de la población MU-MA. El factor de resistencia obtenido varió de 0,37 a 11 . Presentando por tanto una resistencia baja para la mayoría de las poblaciones.

Los datos que se han encontrado en la bibliografía de la resistencia a tiametoxam son en adultos, siendo éstos mucho más elevados que los obtenidos para nuestras poblaciones. En poblaciones recogidas en 2002 en Israel el factor de resistencia fue de 26 a 651 (Horowitz et al. 2004), en China en 2008 fue de 29 a 1200 (Wang et al. 2010) y de 28,2 a >166 en otro trabajo. (Luo et al. 2010). Esto puede ser debido, que al igual que pasa en el imidacloprid, que la resistencia es especifica del estado de desarrollo y en este caso la expresan los adultos.

\subsection{Resistencia cruzada}

Aunque hay una significativa resistencia a buprofecín en todas las poblaciones de campo analizadas y sólo dos poblaciones presentan resistencia a azadiractín, se observó una correlación significativa $(\mathrm{r}=0,98, \mathrm{P}<0,01)$ entre los valores de $\mathrm{CL}_{50}$ para estos compuestos. Esto podría indicar la presencia de resistencia cruzada entre estos dos insecticidas. La población multirresistente (MU-MI) se pulverizó 4 veces con azadiractín en los 4 meses anteriores a su recogida, pero no recibió ninguna aplicación con buprofecín durante el ciclo de cultivo. La alta resistencia demostrada en esta población para ambos compuestos apoya esta teoría. Serían necesarios más estudios para confirmar esta implícita resistencia cruzada entre azadiractín y buprofecín, sin embargo, debido a sus diferentes modos de acción, un mecanismo común de detoxificación puede proporcionar la explicación más probable. También se encontró una correlación entre imidacloprid y tiametoxam $(\mathrm{r}=0,80, \mathrm{P}=0.03)$, esto se discutirá en el capítulo 2. La ausencia de correlación entre la resistencia a buprofecín y piriproxifén en $B$. tabaci ya se ha sido descrito previamente (Horowitz y Ishaaya 1992 y Toscano et al. 2001). De manera similar, se ha observado resistencia cruzada entre piriproxifén y neonicotinoides en trabajos anteriores 
(Ishaaya et al 2005). Tampoco se observa una correlación entre los dos neonicotinoides (imidacloprid y tiametoxam) aunque su resistencia cruzada ha sido descrita (Elbert A y Nauen 2000 y Nauen et al. 2002). Sin embargo, si se observan los datos, las poblaciones con las $\mathrm{CL}_{50}$ por debajo de $100 \mathrm{ppm}$ coinciden en ambos insecticidas al igual que ocurre con las poblaciones con las $\mathrm{CL}_{50}$ más altos, menos la población AL-PA. Entre pimetrocina y metomilo se ha observado una correlación significativa $(\mathrm{r}=0,78, \mathrm{P}<0.05)$, lo que podría significar una resistencia cruzada entre estos dos insecticidas. Aunque no se ha encontrado bibliografía al respecto, cabe pensar que B. tabaci podrían tener el mismo mecanismo de resistencia para detoxificar ambos insecticidas, pero para poder confirmar esto sería necesario realizar más estudios. 


\section{Conclusiones}

Hay una gran preocupación por la propagación de la mosca blanca biotipo Q en muchos países, como EE.UU. (Dennehy et al. 2005), China (Ma et al. 2007) e Israel (Horowitz et al. 2005). En algunas situaciones el desplazamiento de biotipos B por biotipos Q, bajo alta presión de insecticida, puede ser debido a la mayor resistencia a los insecticidas en biotipos Q (Pascual y Callejas 2004). La invasión de mosca blanca biotipo Q podría poner en peligro el manejo de la resistencia a insecticidas (MRI), con graves consecuencias para el control de B. tabaci. España tiene una larga historia de problemas de resistencia en los cultivos de hortalizas que implican a B. tabaci y especies coexistentes como el trips F. occidentalis (Bielza 2008).

Este estudio muestra el estado de la resistencia de la mosca blanca biotipo Q presente en el sureste de España a los insecticidas utilizados para su control. Aparte de una población recogida al final de la temporada (MU-MI) en un invernadero intensivamente tratado con insecticida, las poblaciones B. tabaci biotipo Q no mostraron una resistencia fuerte y amplia. Aunque este estudio presenta niveles de resistencia a algunos compuestos más altos que los de los otros biotipos de mosca blanca (biotipo B), en particular para imidacloprid y piriproxifén, las poblaciones de mosca blanca biotipo Q españolas mostraron unos valores del factor de resistencia bajos a moderados en comparación con la población de referencia española biotipo Q (LAB-S).

Los presentes resultados indican que la resistencia en biotipos $\mathrm{Q}$ puede reducirse si se alivian las presiones de selección a través de la implementación de una estrategia de MRI, como se observa en la población MU-A. Sin embargo, el establecimiento de la resistencia localizada también fue demostrada por la población MU-MI. Además, no se detectó resistencia cruzada entre los insecticidas con diferentes modos de acción, a pesar de la posibilidad de que exista resistencia cruzada entre azadiractín y buprofecín como se puso de relieve anteriormente. El uso sensato de insecticidas es esencial dado el potencial demostrado por B. tabaci biotipo Q de desarrollar resistencia a los insecticidas. 


\section{Bibliografía}

Abbott WS 1925. A method for computing the effectiveness of an insecticide. $J$ Econ Entomol 18:265-267.

Ausborn J, Wolf H, Mader W and Kayser H 2005.The insecticide pymetrozine selectively affects chordotonal mechanoreceptors. J Exp Biol 208:4451-4466.

Bielza P 2008. Insecticide resistance management strategies against the western flower thrips, Frankliniella occidentalis. Pest Manag Sci 64:1131-1138.

Bielza P, Conesa E, Lacasa A and Contreras J 2000. Modificación del método de las placas adhesivas amarillas para bioensayos de insecticidas en Bemisia tabaci (Gennadius) (Homoptera: Aleyrodidae). Boletín Sanidad Vegetal Plagas 26:731-738.

Bielza P, Quinto V, Grávalos C, Fernández E and Abellán J, 2008. Impact of production system on the development of insecticide resistance in Frankliniella occidentalis (Thysanoptera: Thripidae). J Econ Entomol 101:1685-1690.

Bosco D, Loria A, Sartor C and Cenis JL 2006. PCR-RFLP identification of Bemisia tabaci biotypes in theMediterranean Basin. Phytoparasitica 34:243-251.

Brown JK (2000). Molecular markers for the identification and global tracking of whitefly vector-begomovirus complexes. Virus Res 71:233-260.

Brown JK, 8 April 2009. The Bemisia tabaci Complex: Genetic and Phenotypic Variability Drives Begomovirus Spread and Virus Dispersification. [Online]. Available: http://www.apsnet.org/online/feature/btabaci

Cahill, M., and I. Denholm. 1999. Managing resistance to chloronicotinyl insecticides: rhetoric or reality?, pp. 253-270. In I. Yamamoto and J. Casida (eds.), Neonicotinoid insecticides and the nicotinic acetylcholine receptor. Springer, Tokyo.

Cahill M, Gorman K, Day S, Denholm I, Elbert A and Nauen R 1996. Baseline determination and detection of resistance to imidacloprid in Bemisia tabaci (Homoptera: Aleyrodidae). Bull Entomol Res 86:342-349. 
Cahill M, Jarvis W, Gorman K and Denholm I 1996. Resolution of baseline responses anddocumentationof resistance to buprofezin in Bemisia tabaci (Homoptera: Aleyrodidae). Bull Entomol Res 86:117-122.

Costa HS and Brown JK 1991.Variation in biological characteristics and esterase patterns among populations of Bemisia tabaci, and the association of one population with silver leaf symptom induction. Entomol Exp Appl 61:211-219

Coudriet DL, Prabhaker N and Meyerdirk DE 1985. Sweet-potato whitefly (Homoptera, Aleyrodidae) - effects of neem-seed extract on oviposition and immature stages. Environ Entomol 14:776-779.

Dennehy TJ,DeGain BA, Harpold VS, Brown JK, Morin S and Fabrick JA 2005. New challenges to management of whitefly resistance to insecticides in Arizona. University of Arizona Cooperative Extension Vegetable Report.

Devine GJ, Ishaaya I, Horowitz AR and Denholm I, 1999. The response of pyriproxyfenresistant and susceptible Bemisia tabaci Genn. (Homoptera: Aleyrodidae) to pyriproxyfen and fenoxycarb alone and in combination with piperonyl butoxide. Pestic Sci 55:405-411.

Elbert A and Nauen R 2000. Resistance of Bemisia tabaci (Homoptera: Aleyrodidae) to insecticides in southern Spain with special reference to neonicotinoids. PestManag Sci 56:60_ 64.

ElKady HandDevine GJ 2003. Insecticide resistance in Egyptian populations of the cottonwhitefly, Bemisia tabaci (Hemiptera: Aleyrodidae). Pest Manag Sci 59:865-871.

Guirao P, Beitia F and Cenis JL 1997. Biotype determination of Spanish populationsofBemisiatabaci (Hemiptera:Aleyrodidae). BullEntomol Res 87:587-593.

Guthrie F, Denholm I and Devine GJ, 2003. Biological evaluation of spiromesifen against Bemisiatabaci and anassessmentof resistance risk, ProcBCPCInternlConf CropSciTechnol,BCPC, Farnham, Surrey, UK, pp. 795-800.

Harrewijn P and Kayser H 1997. Pymetrozine, a fast-acting and selective inhibitor of aphid feeding; in situ studies with electronic monitoring of feeding behaviour. Pestic Sci 49:130140. 
Hirata K, Kawamura Y and Kudi Mand Igarashi H 1995. Development of a new acaricide, pyridaben. J Pestic Sci 20:177-179.

Horowitz AR, Denholm I, Gorman K, Cenis JL, Kontsedalov S and Ishaaya I, 2003. Biotype Q of Bemisia tabaci identified in Israel. Phytoparasitica 31:94-98.

Horowitz AR, Gorman K, Ross G and Denholm I 2003. Inheritance of pyriproxyfen resistance in the whitefly, Bemisia tabaci (Q biotype). Arch Insect Biochem Physiol 54:177-186.

Horowitz AR and Ishaaya I 1994. Managing resistance in insect growth regulators in the sweet-potato whitefly (Homoptera, Aleyrodidae). J Econ Entomol 87:866-871.

Horowitz AR and Ishaaya I 1992. Susceptibility of the sweet-potatowhitefly (Homoptera, Aleyrodidae) to buprofezin during the cotton season. J Econ Entomol 85:318-324.

Horowitz, A.R., S. Kontsedalov, and I. Ishaaya. 2004. Dynamics of Resistance to the Neonicotinoids Acetamiprid and Thiamethoxam in Bemisia tabaci (Homoptera: Aleyrodidae). Journal of Economic Entomology, 97(6) 2051-2056.

Horowitz AR, Kontsedalov S, Khasdan V and Ishaaya I. 2005. Biotypes B and Q of Bemisia tabaci and their relevance to neonicotinoid and pyriproxyfen resistance. Arch Insect Biochem Physiol 58:216-225.

Ishaaya I, Kontsedalov S and Horowitz AR 2005. Biorational insecticides: mechanism and cross-resistance. Arch Insect Biochem Physiol 58:192-199.

Karatolos, N.; Denholm, I.; Williamson, M.; Nauen, R. y Gorman, K. 2010. Incidence and characterisation of resistance to neonicotinoid insecticides and pymetrozine in the greenhouse whitefly, Trialeurodes vaporariorum Westwood (Hemiptera: Aleyrodidae) Pest Manag Sci; 66: 1304-1307.

Kranthi KR, Jadhav DR, Wanjari RR, Ali SS and Russell D 2001. Carbamate and organophosphate resistance in cotton pests in India, 1995 to 1999. Bull Entomol Res 91:3746.

Kristinsson, H. 1994. Pymetrozine: A new insecticide. In Advances in the Chemistry of Insect Control III, pp. 85-102. Cambridge: The Royal Society of Chemistry. 
Kumar P and Poehling HM 2007. Effects of azadirachtin, abamectin, and spinosad on sweetpotato whitefly (Homoptera: Aleyrodidae) on tomato plants under laboratory and greenhouse conditions in the humid tropics. J Econ Entomol 100:411-420.

Luo, C. Jones, C.M., Devine, G., Zhang, F., Denholm, I., and Gorman, K. 2010. Insecticide resistance in Bemisia tabaci biotype Q (Hemiptera: Aleyrodidae) from China. Crop Protection, 29 429-434.

Ma DY, Gorman K, Devine G, Luo WC and Denholm I 2007. The biotype and insecticide-resistance status of whiteflies, Bemisia tabaci (Hemiptera: Aleyrodidae), invading cropping systems in Xinjiang Uygur Autonomous Region, northwestern China. Crop Prot 26:612-617.

Nauen R, Bielza P, Denholm I and Gorman K 2008. Age-specific expression of resistance to neonicotinoid insecticides in the whitefly, Bemisia tabaci. PestManag Sci 64:1106-1110.

Nauen R and Denholm I 2005. Resistance of insect pests to neonicotinoide insecticides: current statusandfutureprospects. ArchInsectBiochem Physiol 58:200-215.

Nauen R, Sorge D, Sterner A and Borovsky D 2002. TMOF-like factor controls the biosynthesis of serine proteases in the larval gut of Heliothis virescens. Arch Insect Biochem Physiol 49:65.

Nauen R, Stumpf N and Elbert A 2002. Toxicological and mechanistic studies on neonicotinoid cross resistance in Q-type Bemisia tabaci (Hemiptera: Aleyrodidae). PestManag Sci 58:868-875.

Palumbo JC, Horowitz AR and Prabhaker N, 2001.Insecticidal control and resistance management for Bemisia tabaci. Crop Prot 20:739-765.

Pascual S and Callejas C, 2004. Intra- and interspecific competition between biotypes B and Q of Bemisia tabaci (Hemiptera: Aleyrodidae) from Spain. Bull Entomol Res 94:369-375.

Prabhaker N, Castle S, Henneberry TJ and Toscano NC, 2005. Assessment of crossresistance potential to neonicotinoid insecticides in Bemisia tabaci (Hemiptera: Aleyrodidae). Bull Entomol Res 95:535-543. 
Rauch $\mathrm{N}$ and Nauen R 2003. Identification of biochemical markers linked to neonicotinoid cross resistance in Bemisia tabaci (Hemiptera: Aleyrodidae). Arch Insect Biochem Physiol 54:165176.

Russell RM, Robertson JL and Savin NE 1977. POLO - a new computer program for probit analysis. Bull Entomol Soc Am 23:209-213.

Schmutterer H, 1990. Properties and potential of natural pesticides from the neem tree, Azadiracbta indica. Annu Rev Entomol 35:271-297.

Simon B, Cenis JL and De la Rua P 2007. Distribution patterns of the Q and B biotypes of Bemisia tabaci in the Mediterranean Basin based on microsatellite variation. Entomol Exp Appl124:327-336.

Simon B, Cenis JL, Demichelis S, Rapisarda C, Caciagli P and Bosco D 2003. Survey of Bemisia tabaci (Hemiptera: Aleyrodidae) biotypes in Italy with the description of a new biotype (T) from Euphorbia characias. Bull Entomol Res 93:259-264

Toscano NC, Prabhaker N, Castle SJ and Henneberry TJ 2001. Inter-regional differences in baseline toxicity of Bemisia argentifolii (Homoptera: Aleyrodidae) to the two insect growth regulators, buprofezin and pyriproxyfen. J Econ Entomol 94:1538-1546

Ueda S and Brown JK 2006. First report on the biotype Q of Bemisia tabaci in Japan bymitochondrial cytochrome oxidase I sequence analysis. Phytoparasitica 34:405-411.

Wang, Z., Yan, H., Yang, Y., Wu, Y. 2010. Biotype and insecticide resistance status of the whitefly Bemisia tabaci from China. Pest Management Science 66:1360-1366.

Wyss, P. and Bolinger, M. 1997. Translocation of pymetrozine in plants. Pestic. Sci. 50, 195202.

Yasui M, Ellsworth PC, Lublinkhof J and Comer D, 1997. Monitoring whitefly susceptibility to Applaud, in Cotton, a College of Agriculture Report. Series P-108, ed. by Silvertooth JC. College of Agriculture, University of Arizona, Tuscon, AZ, pp. 257-264.

Zhang LP, Zhang YJ, Zhang WJ, Wu QJ, Xu BY and Chu D, 2005. Analysis of genetic diversity among different geographical populations and determination of biotypes of Bemisia tabaci in China. JAppl Entomol 129:121-128. 


\section{Capítulo 2}

Resistencia cruzada entre neonicotinoides y pimetrocina en poblaciones de Bemisia tabaci en adultos y ninfas 


\section{Resumen}

La mosca blanca Bemisia tabaci (Gennadius) es una de las plagas más importantes en cultivos hortícolas y ornamentales en todo el mundo. El uso de insecticidas para su control es una práctica habitual, lo que ha dado lugar a que se desarrollen resistencias a los principales grupos de insecticidas. También surgen las resistencias cruzadas, observándose con frecuencia entre compuestos del mismo grupo, y aunque entre compuestos de distintos grupos es impredecible por tener estructuras y modos de acción diferentes también están surgiendo.

Seis poblaciones de campo se bioensayaron con los neonicotinoides imidacloprid y tiametoxan, y con pimetrocina. Las poblaciones presentaron resistencia cruzada entre los neonicotinoides pero no con la pimetrocina, tanto en ninfas como en adultos. Los resultados obtenidos para cada insecticida fueron diferentes en ninfas que en adultos. Siendo más elevados para los neonicotinoides en adultos y contrariamente en ninfas para la pimetrocina.

Estudios demuestran que existe una resistencia cruzada entre neonicotinoides y pimetrocina y que la sobreexpresión del citocromo P450 monooxigenasa es capaz de metabolizar ambos compuestos, pero nuestros resultados sugieren un mecanismo alternativo para la pimetrocina. Igualmente, se confirma que la expresión de la resistencia para estos insecticidas es en función del estado de desarrollo de Bemisia tabaci. 


\section{Introducción}

La mosca blanca del tabaco Bemisia tabaci, es una plaga polífaga que causa graves pérdidas tanto en cultivos hortícolas como en ornamentales a nivel mundial (Brown et al. 1995; Oliveira et al. 2001; Boykin et al. 2007). B. tabaci ha demostrado ser particularmente propensa a desarrollar resistencia a la mayoría de los grupos de insecticidas utilizados para su control como organofosforados, carbamatos, piretroides, insecticidas reguladores del crecimiento y neonicotinoides (Cahill et al 1996, Elbert y Nauen 2000, Ahmad et al 2002 y Cahill et al 1995). La resistencia a imidacloprid y a otros neonicotinoides se observó por primera vez en poblaciones de mosca blanca biotipo Q recolectadas en Almería en España en 1994 (Cahill et al 1996, Nauen y Denholm 2005, Nauen et al 2002 y Rauch y Nauen 2003). Los insecticidas neonicotinoides, como el imidacloprid y el tiametoxam, son mundialmente utilizados desde hace 20 años y tienen una enorme importancia económica en la protección de cultivos (Rao et al. 2011, Liu et al. 2007, McKenzie et al. 2012, Roditakis et al. 2009). Son agonistas del receptor nicotínico de la acetilcolina (Tomizawa et al. 1995) y afectan al sistema nervioso produciendo excitación y parálisis del insecto (Tomizawa et al 1995

En las poblaciones de mosca blanca de Almería, en 1994, se observó también por primera vez resistencia a pimetrocina (Elbert y Nauen 2000). La pimetrocina, una piridina azometina, es otro agente de control de la mosca blanca no relacionado con los neonicotinoides con un modo de acción único, altera el comportamiento de alimentación y causa la muerte de los insectos por inanición (Harrewijn y Kayser 1997; Peric y Marcic 2007; Castle et al. 2009). Su modo de acción exacto es desconocido, pero en algunas poblaciones de B. tabaci la resistencia a neonicotinoides se ha asociado con la resistencia a la pimetrocina debido a la sobre-expresión de un citocromo P450 monoxigenasa CYP6CM1 (Karunker et al. 2008), aparentemente capaz de desintoxicar ambos tipos de insecticidas (Gorman et al. 2010).

La resistencia cruzada ocurre cuando la resistencia a un compuesto también confiere protección contra otros. Es más común entre los miembros de un mismo grupo químico (intragrupo), que están por lo general estrechamente relacionados tanto estructural como funcionalmente. Ejemplos de resistencia cruzada intragrupo encontramos en bibliografía para los grupos de insecticidas más importantes, incluyendo piretroides, organofosforados y neonicotinoides (Prabhaker et al. 2005, Sivasupramaniam et al. 1997, Kranthi et al. 2001). 
Sin embargo, la resistencia cruzada puede darse entre insecticidas estructuralmente diferentes y con distintos modo de acción (intergrupo).

El objetivo de este estudio es determinar si existe resistencia cruzada entre dos insecticidas neonicotinoides (imidacloprid y tiametoxam), y la pimetrocina en poblaciones de campo Bemisia tabaci biotipo Q y poblaciones seleccionadas en laboratorio, tanto en adultos como en ninfas. 


\section{Material y Métodos}

\subsection{Poblaciones de Bemisia tabaci}

Las poblaciones utilizadas fueron una población sensible de referencia (LAB-S) recogida en un invernadero sin tratamientos químicos en la zona de Murcia y seis poblaciones de diferentes zonas de Murcia y Almería que ya han sido descritas en el capítulo de material y métodos. Se detallan a continuación en la tabla 1.

Tabla 1. Poblaciones de Bemisia tabaci.

\begin{tabular}{c|cccc} 
Poblaciones & Localización & Cultivo & Año & Biotipo \\
\hline LAB-S & Murcia & Pimiento & 2006 & Q \\
\hline MU-A & Murcia & Tomate & 2006 & Q \\
MU-MA & Murcia & Tomate & 2006 & Q \\
MU-MI & Murcia & Pimiento & 2006 & Q \\
AL-BA & Almería & Pimiento & 2006 & Q \\
AL-MO & Almería & Pimiento & 2006 & Q \\
AL-PA & Almería & Pimiento & 2006 & Q \\
\hline
\end{tabular}

\subsection{Insecticidas}

Los siguientes insecticidas formulados fueron los que se utilizaron para los bioensayos: imidacloprid $200 \mathrm{~g} \mathrm{~L}^{-1}$ SL (Confidor 20LS, Bayer Crop-Science, Valencia, España), pimetrocina $250 \mathrm{~g} \mathrm{~kg}^{-1}$ WP (Plenum $25 \mathrm{WP}$, Syngenta Agro, Madrid, España), y tiametoxam $250 \mathrm{~g} \mathrm{~kg}^{-1}$ WG (Actara $25 \mathrm{WG}$, Syngenta Agro, Madrid, España). Se prepararon diluciones seriadas de los compuestos formulados con agua desionizada que contiene $1 \mathrm{~mL} \mathrm{~L}^{-1}$ de Tween 20 (como un humectante no iónico) en el día del bioensayo.

\subsection{Bioensayos de ninfas y adultos}

Ver capítulo 2 de Material y métodos generales (Apartados 3.6.3. y 3.6.4).

\subsection{Selección de poblaciones}

Ver capítulo 2 de Material y métodos generales (Apartado 3.6.5.). 


\subsection{Análisis de datos}

Cuando fue necesario, los datos del bioensayo fueron corregidos por la mortalidad del control (Abbott 1925). Los datos se analizaron utilizando el programa POLO-PC para el análisis probit (Russell et al. 1977). Se calcularon las concentraciones que causan una mortalidad del 50\% $\left(\mathrm{CL}_{50}\right)$ y sus límites fiduciales al 95\%. También se calcularon los factores de resistencia a nivel de $\mathrm{CL}_{50}\left(\mathrm{FR}_{50}\right)$ como la relación entre la $\mathrm{CL}_{50}$ de la población y la $\mathrm{CL}_{50}$ de la población de referencia. Las dosis de campo de los insecticidas utilizadas en este estudio fueron las más altas tasas recomendadas por el fabricante. 


\section{Resultados y discusión}

Los resultados obtenidos del análisis probit para los bioensayos de ninfas de las poblaciones de campo con los insecticidas se muestran en la tabla 2. La población sensible de referencia LAB-S fue la población más sensible tanto para los neonicotioides, imidacloprid y tiametoxam, como para la pimetrocina. No habiendo diferencias significativas de la sensible con la mayoría de las poblaciones para los neonicotinoides (variando el factor de resistencia para imidacloprid de 0,98 a 15,1 y para tiametoxam de 0,37 a 11,2), pero sí en el caso de la pimetrocina (su factor de resistencia varió de 3,3 a $273,3)$.

Tabla 2. Toxicidad de imidacloprid, tiametoxam y pimetrocina para la población sensible (LABS) y poblaciones de campo de Bemisia en ninfas.

\begin{tabular}{|c|c|c|c|c|}
\hline Insecticida & Población & Pendiente $( \pm$ ET $)$ & 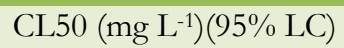 & FR50 \\
\hline \multirow[t]{7}{*}{ Imidacloprid } & LAB-S & $0,60( \pm 0,07)$ & $15,2(1,3-81,1)$ & 1 \\
\hline & MU-A & $1,74( \pm 0,19)$ & $53,4(16,0-110,5)$ & 3 \\
\hline & MU-MA & $1,14( \pm 0,15)$ & $190,5(119,1-318,5)$ & 12 \\
\hline & MU-MI & $0,96( \pm 0,10)$ & $47,4(6,7-206,6)$ & 3 \\
\hline & AL-BA & $1,02( \pm 0,14)$ & $14,9(2,0-35,2)$ & 1 \\
\hline & AL-MO & $0,85( \pm 0,12)$ & $81,5(36,0-168,2)$ & 5 \\
\hline & AL-PA & $0,83( \pm 0,13)$ & $228,9(82,4-1017,5)$ & 15 \\
\hline \multirow[t]{7}{*}{ Tiametoxam } & LAB-S & $1,87( \pm 0,16)$ & $17,9(8,1-34,4)$ & 1 \\
\hline & MU-A & $0,88( \pm 0,149)$ & $47,4(3-116,4)$ & 3 \\
\hline & MU-MA & $2,06( \pm 0,319)$ & $201,1(104,3-301,9)$ & 11 \\
\hline & MU-MI & $0,82( \pm 0,08)$ & $20(8,8-38,6)$ & 1,1 \\
\hline & AL-BA & $1,01( \pm 0,144)$ & $51,4(13,7-176,4)$ & 3 \\
\hline & AL-MO & $0,84( \pm 0,097)$ & $6,6(0,55-19,6)$ & 0,4 \\
\hline & AL-PA & $0,68( \pm 0,061)$ & $119(52,0-340)$ & 7 \\
\hline \multirow[t]{7}{*}{ Pimetrocina } & LAB-S & $1,03( \pm 0,09)$ & $29,2(3,2-107,4)$ & 1 \\
\hline & MU-A & $3,05( \pm 0,531)$ & $7973(5163,4-10529)$ & 273 \\
\hline & MU-MA & $0,56( \pm 0,063)$ & $96,3(27,9-220,2)$ & 3 \\
\hline & MU-MI & $0,71( \pm 0,076)$ & $2181,2(670,5-8595,4)$ & 75 \\
\hline & AL-BA & $0,49( \pm 0,058)$ & $210,7(45,4-612,3)$ & 7 \\
\hline & AL-MO & $0,43( \pm 0,082)$ & $213,2(17,4-1035,9)$ & 7 \\
\hline & AL-PA & $0,38( \pm 0,072)$ & $157,6(29,6-485,6)$ & 5 \\
\hline
\end{tabular}


Los datos de las $\mathrm{CL}_{50}$ de las poblaciones para imidacloprid y tiametoxan muestran que entre ambos insecticidas existe resistencia cruzada, ya que no hay diferencias significativas, excepto para la población AL-MO. Observándose una correlación significativa entre los valores $(r=0,80, P=0.03)$. Esto ya fue demostrado por primera vez por Elbert y Nauen en el año 2000 con poblaciones del sur de España.

Contrariamente, no existe una correlación significativa entre imidacloprid y pimetrocina, al igual que ocurre entre el tiametoxam y la pimetrocina. Por tanto no hay resistencia cruzada entre estos dos neonicotinoides con la pimetrocina. Varios autores argumentan que la resistencia a los neonicotinoides está fuertemente asociada con la resistencia a la pimetrocina (Qiong et al 2012, Nauen et al 2013). Y que por lo tanto B. tabaci tiene el mismo y único mecanismo de resistencia para los neonicotinoides como para la pimetrocina. Nuestros resultados no confirman esa hipótesis, al igual que lo publicado por Gorman et al (2010), donde las poblaciones seleccionadas para tiametoxan sí mostraban resistencia cruzada con pimetrocina, pero cuando la población era seleccionada para pimetrocina no había resistencia cruzada con los neonicotinoides.

Para confirmar nuestros resultados se seleccionó a partir de la población sensible de referencia LAB-S una población resistente a pimetrocina, R-PIME. Esta población se bioensayó con los tres insecticidas, pimetrocina, imidacloprid y tiametoxam en estado de ninfa. Los valores obtenidos de la $\mathrm{CL}_{50}$ se muestran en la tabla 3 a continuación.

Tabla 3. Toxicidad de imidacloprid, tiametoxam y pimetrocina para la población sensible (LABS) y la población seleccionada para pimetrocina de Bemisia tabaci en estado de ninfa.

\begin{tabular}{c|cccc}
\hline Insecticida & Población & Pendiente $( \pm$ ET $)$ & CL50 $\left(\mathrm{mg} \mathrm{L}^{-1}\right)(95 \%$ LC) & FR50 \\
\hline Imidacloprid & LAB-S & $0,60( \pm 0,07)$ & $15,2(1,3-81,1)$ & 1 \\
& R-PIME & $0,96( \pm 0,10)$ & $12,5(5,5-23,4)$ & 0,82 \\
\hline Tiametoxam & LAB-S & $1,87( \pm 0,16)$ & $17,9(8,1-34,4)$ & 1 \\
& R-PIME & $1,44( \pm 0,18)$ & $33,4(10,5-66,2)$ & 1,87 \\
\hline Pimetrocina & LAB-S & $1,03( \pm 0,09)$ & $29,2(3,2-107,4)$ & 1 \\
& R-PIME & $0,98( \pm 0,15)$ & $72499,2(21651,8-23208173,1)$ & 2483 \\
\hline
\end{tabular}


En primer lugar cabe destacar el elevado valor obtenido para la pimetrocina, siendo por tanto una población muy resistente con un factor de resistencia de 2483. Los valores obtenidos para imidacloprid (12,5 ppm) y tiametoxam $(33,4 \mathrm{ppm})$ muestran que no existe una resistencia cruzada con pimetrocina, siendo sus factores de resistencia de 0,82 y 1,87 respectivamente. Esto reafirma la existencia de un mecanismo de resistencia distinto para la pimetrocina. Es decir, al menos hay dos mecanismos implicados en su resistencia.

Los datos presentados hasta ahora, se realizaron sobre ninfas de B. tabaci, a continuación en la tabla 4 se muestra los datos obtenidos para los bioensayos realizados a adultos sobre la población sensible y las poblaciones de campo con los dos neonicotinoides y la pimetrocina.

Tabla 4. Toxicidad de imidacloprid, tiametoxam y pimetrocina para la población sensible (LAB-S) y poblaciones de campo de Bemisia en adultos.

\begin{tabular}{|c|c|c|c|c|}
\hline Insecticida & Población & Pendiente $( \pm$ ET $)$ & CL50 (mg L-1) $(95 \%$ LC) & FR50 \\
\hline \multirow[t]{7}{*}{ Imidacloprid } & LAB-S & $0,51( \pm 0,09)$ & $58,0(21,0-150,4)$ & 1 \\
\hline & MU-A & $0,67( \pm 0,22)$ & $287,7(90,8-1808,9)$ & 5 \\
\hline & MU-MA & $0,31( \pm 0,11)$ & $50763,0(4816,5-786211271,0)$ & 875 \\
\hline & MU-MI & - & $>9600$ & $>165$ \\
\hline & AL-BA & $0,39( \pm 0,11)$ & $15694,0(3205,9-749797,1)$ & 270 \\
\hline & AL-MO & $0,42( \pm 0,12)$ & $15226,6(2963,1-3928773,1)$ & 262 \\
\hline & AL-PA & $0,77( \pm 0,27)$ & $479,7(169,2-4114,4)$ & 8 \\
\hline \multirow[t]{7}{*}{ Tiametoxam } & LAB-S & $0,95( \pm 0,14)$ & $38,9(18,6-70,6)$ & 1 \\
\hline & MU-A & $0,81( \pm 0,23)$ & $470,1(221,1-1711,3)$ & 12 \\
\hline & MU-MA & $1,00( \pm 0,14)$ & $145,0(67,9-349,4)$ & 4 \\
\hline & MU-MI & $0,45( \pm 0,12)$ & $622,0(168,4-7824,9)$ & 16 \\
\hline & AL-BA & $0,57( \pm 0,12)$ & $1197,5(376,5-6852,6)$ & 31 \\
\hline & AL-MO & $0,42( \pm 0,10)$ & $332,9(62,7-28341,0)$ & 9 \\
\hline & AL-PA & $0,46( \pm 0,11)$ & $532,4(120,8-13546,0)$ & 14 \\
\hline \multirow[t]{7}{*}{ Pimetrocina } & LAB-S & $0,57( \pm 0,12)$ & $4,9(0,1-23,5)$ & 1 \\
\hline & MU-A & $0,75( \pm 0,20)$ & $2,0(0,0-7,5)$ & 0,4 \\
\hline & MU-MA & $0,57( \pm 0,11)$ & $4,1(0,6-11,8)$ & 0,8 \\
\hline & MU-MI & $0,49( \pm 0,09)$ & $1,6(0,1-7,2)$ & 0,3 \\
\hline & AL-BA & $0,79( \pm 0,10)$ & $29,8(14,4-53,0)$ & 6 \\
\hline & AL-MO & $0,79( \pm 0,15)$ & $158,4(35,7-398,1)$ & 33 \\
\hline & AL-PA & $0,54( \pm 0,13)$ & $3269,4(1130,8-20268,0)$ & 674 \\
\hline
\end{tabular}


Para el imidacloprid, todas las poblaciones menos la población MU-A, presentaron diferencias significativas con la población sensible de referencia. Para el tiametoxam, excepto dos poblaciones (MU-MA y AL-MO), también presentaron diferencias significativas con la población de referencia, contrariamente de lo que ocurría con las ninfas. Con estos resultados se confirma la hipótesis de que B. tabaci expresa su resistencia en los neonicotinoides en adultos, es decir que el mecanismo de resistencia es especifico del estado de desarrollo. Nauen et al. (2008) demuestran esto tanto para moscas biotipo B como Q, obteniendo una relación de los factores de resistencia entre adultos y ninfas de hasta 50. A pesar de estos datos, el uso de neonicotinoides sigue siendo efectivo en campo, ya que sobre ninfas realizan un buen control. Por ello es importante el conocimiento, no sólo del cultivo, sino también de la plaga y de los insecticidas que se apliquen, ya que en función de todo esto habrá que diseñar una estrategia adecuada. Por eso es importante realizar el estudio de los insecticidas no sólo en adultos, como aparece casi en la mayoría de las publicaciones, sino también en ninfas.

En la tabla 4, también aparecen los resultados obtenidos de las poblaciones para pimetrocina en adultos. Los valores de la $\mathrm{CL}_{50}$ de las poblaciones no presentaron diferencias significativas con la población de referencia, excepto AL-MO y AL-PA. Con la pimetrocina parece ser que pasa al revés que en imidacloprid y tiametoxam, la resistencia la expresan las ninfas, es decir, también depende del estado de desarrollo. Para confirmar esta hipótesis se realizó un bioensayo con pimetrocina en adultos de la población seleccionada R-PIME, aquella que se obtuvo de la selección de la población sensible LAB-S con pimetrocina. El valor de la $\mathrm{CL}_{50}$ fue $91 \mathrm{ppm}$ (la de ninfas fue $72499 \mathrm{ppm}$ ), con un factor de resistencia de 19 frente a 2485 que se obtuvo en ninfas. Esto verifica nuestra hipótesis, siendo las ninfas casi 800 veces más resistentes que los adultos.

Como conclusión a estos datos, podemos decir que existe resistencia cruzada entre los neonicotinoides, imidacloprid y tiametoxam, pero que no existe entre ellos y pimetrocina en nuestras poblaciones. Por lo tanto, debe existir otro mecanismo de resistencia para la pimetrocina diferente al de los neonicotinoides. Está demostrado que el mecanismo de la resistencia de B. tabaci para detoxificar los neonicotinoides es a través del citocromo P450 monooxigenasas tanto en poblaciones de biotipo B y Q de B. tabaci (Nauen et al. 2002, Karunker et al. 2008). También se ha demostrado que la pimetrocina es hidroxilada por CYP6CM1, una enzima del citocromo P450 (Nauen et al. 2013). Pero es necesario seguir 
realizando estudios que nos clarifiquen la existencia de otro mecanismo de resistencia para la pimetrocina, como confirman los datos obtenidos en este estudio.

También se puede concluir, que la expresión de la resistencia en Bemisia es en función del estado de desarrollo, expresándose en adultos en los neonicotinoides y en ninfas en pimetrocina. Esto, una vez más, refuerza la teoría de que al menos existen dos mecanismos de resistencia para la pimetrocina. Hay numerosos ejemplos en la bibliografía donde el insecto ha sido capaz de desarrollar más de un mecanismo de resistencia para un mismo insecticida (Alon et al. 2008 y He et al. 2007). 


\section{Bibliografía}

Ahmad M, Arif MI, Ahmad Z and Denholm I 2002. Cotton whitefly (Bemisia tabaci) resistance to organophosphate and pyrethroid insecticides in Pakistan. PestManag Sci 58:203-208.

Alon M, Alon F, Nauen R and Morin S 2008. Organophosphates resistance in the Bbiotype of Bemisia tabaci (Hemiptera: Aleyrodidae) is associated with a point mutation in an ace1-type acetylcholinesterase and over-expression of carboxylesterase. Ins BiochemMol Biol 38: $940-949$.

Boykin L M, Shatters R G, Rosell R C, McKenzie C L, Bagnall R A, De Barro P, Frohlich D R. 2007. Global relationships of Bemisia tabaci (Hemiptera: Aleyrodidae) revealed using Bayesian analysis of mitochondrial COI DNA sequences. Molecular Phylogenetics and Evolution, 44, 1306-1319.

Brown J K, Frohlich D R, Rosell R C. 1995. The sweetpotato or silverleaf whitefliesbiotypes of Bemisia tabaci or a species complex. Annual Review of Entomology, 40, 511-534.

Cahill M, Byrne FJ, Gorman K, Denholm I and Devonshire AL 1995.Pyrethroid and organophosphate resistance in the tobacco whitefly Bemisia tabaci (Homoptera: Aleyrodidae). Bull Entomol Res 85:181-187.

Cahill M, Denholm I, Byrne FJ and Devonshire AL 1996. Insecticide resistance in Bemisia tabaci - current status and implications for management. Proc Brighton Crop Prot Conf - Pests and Diseases Vol 1, pp 75-80.

Cahill M, Gorman K, Day S, Denholm I, Elbert A and Nauen R 1996. Baseline determination and detection of resistance to imidacloprid in Bemisia tabaci (Homoptera: Aleyrodidae). Bull Entomol Res 86:343-349.

Castle S, Palumbo J, Prabhaker N. 2009. Newer insecticides for plant virus disease management. Virus Research, 141, 131-139.

Elbert A and Nauen R 2000. Resistance of Bemisia tabaci (Homoptera: Aleyrodidae) to insecticides in southern Spain with special reference to neonicotinoids. PestManag Sci 56:60_ 64. 
Gorman K, Slater R, Blande J, Clarke A, Wren J, McCaffery A, Denholm I 2010. Crossresistance relationships between neonicotinoids and pymetrozine in Bemisia tabaci (Hemiptera: Aleyrodidae). Pest Management Science, 66, 1186-1190.

Harrewijn P, Kayser H. 1997. Pymetrozine, a fast-acting and selective inhibitor of aphid feeding. In-situ studies with electronic monitoring of feeding behaviour. Pesticide Science, 49, $130-140$.

He YX, Huang J, Yang XJ and Weng QY 2007. Pyrethroid resistance mechanisms in Bemisia tabaci (Gennadius). Acta Entomologica Sinica 50: 241-247.

Karunker I, Benting J, Lueke B, Ponge T, Nauen R, Roditakis E, Vontas J, Gorman K, Denholm I, Morin S. 2008. Overexpression of cytochrome P450 CYP6CM1 is associated with high resistance to imidacloprid in the B and Q biotypes of Bemisia tabaci (Hemiptera: Aleyrodidae). Insect Biochemistry and Molecular Biology, 38, 634- 644.

Kranthi KR, Jadhav DR, Wanjari RR, Ali SS and Russell D 2001. Carbamate and organophosphate resistance in cotton pests in India, 1995 to 1999. Bull Entomol Res 91:3746.

Liu SS, De Barro PJ, Xu J, Luan JB, Zang LS, Ruan YM, Wan FH 2007. Asymmetric mating interactions drive widespread invasion and displacement in a whitefly. Science 318: 1769-1771.

McKenzie CL, Bethke JA, Byrne FJ, Chamberlin JR, Dennehy TJ , Dickey AM, Gilrein D, Hall PM, Ludwig S, Oetting RD, Os borne LS, Schmale L, Shatters RG Jr, 2012. Distribution of Bemisia tabaci (Hemiptera: Aleyrodidae) biotypes in North America after the Q invasion. J Econ Entomol 105: 753-66.

Nauen R, Bielza P, Denholm I and Gorman K, 2008. Age-specific expression of resistance to neonicotinoid insecticides in the whitefly, Bemisia tabaci. PestManag Sci 64:1106-1110.

Nauen R and Denholm I 2005. Resistance of insect pests to neonicotinoid insecticides: current status and future prospects. ArchInsect Biochem Physiol 58:200-215.

Nauen R, Stumpf N and Elbert A 2002. Toxicological and mechanistic studies on neonicotinoid cross resistance in Q-type Bemisia tabaci (Hemiptera: Aleyrodidae). PestManag Sci 58:868-875. 
Nauen R, Vontas J, Kaussmann M and Wöfel K 2013. Pymetrozine is hydroxylated by CYP6CM1, a cytochrome P450 conferring neonicotinoid-resistance in Bemisia tabaci Pest Management Science Article in Press.

Oliveira M R V, Henneberry T J, Anderson P. 2001. History, current status, and collaborative research projects for Bemisia tabaci. Crop Protection, 20, 709-723.

Peric P, Marcic D. 2007. Pymetrozine: a biorational insecticide for aphid and whitefly control. Biljni Lekar (Plant Doctor), 35, 583-588.

Prabhaker N, Castle S, Henneberry TJ and Toscano NC 2005. Assessment of crossresistance potential to neonicotinoid insecticides in Bemisia tabaci (Hemiptera: Aleyrodidae). Bull Entomol Res 95:535-542.

Qiong R, Yong-hua X, Chen L, Hong-yu Z, Jones C M, Devine G J, Gorman K and Denholm I 2012. Characterisation of Neonicotinoid and Pymetrozine Resistance in Strains of Bemisia tabaci (Hemiptera: Aleyrodidae) from China. Journal of Integrative Agriculture, 11(2): 321-326.

Rao Q, Luo C, Zhang H, Guo X, Devine GJ 2011. Distribution and dynamics of Bemisia tabaci invasive biotypes in central China. Bull Entomol Res 101: 81-8.

Rauch N and Nauen R 2003. Identification of biochemical markers linked to neonicotinoid cross resistance in Bemisia tabaci (Hemiptera: Aleyrodidae). Arch Insect Biochem Physiol 54:165176.

Roditakis E, Grispou M, Morou E, Kristoffersen JB, Roditakis N, Nauen R, Vontas J, Tsagkarakou A, 2009.Current status of insecticide resistance in Q biotype Bemisia tabaci populations from Crete. Pest Manag Sci 65: 313-322.

Russell RM, Robertson JL and Savin NE 1977. POLO - a new computer program for probit analysis. Bull Entomol Soc Am 23:209-213.

Sivasupramaniam S, Dennehy TJ and Williams L III 1997. Management of pyrethroidresistant whiteflies in Arizona cotton: selection, cross-resistance and dynamics. Proc Beltwide Cotton Conf, Vol. 2, New Orleans, LA, pp. 1252-1259.

Tomizawa M, Otsuka H, Miyamoto T, Eldefrawi M E, Yamamoto I. 1995. Pharmacological characteristics of insect nicotinic acetylcholine receptor with its ion 
channel and the comparison of the effect of nicotinoids and neonicotinoids. Journal of Pesticide Science, 20, 57-64. 


\section{Capítulo 3}

Mecanismos de resistencia al acaricida METI piridabén en Bemisia tabaci Gennadius 


\section{Resumen}

La gran capacidad de esta plaga para desarrollar resistencias frente a diferentes insecticidas así como resistencias cruzadas ha hecho necesario la búsqueda de alternativas para crear estrategias de control eficaces. Piridabén es un acaricida METI que impide la transferencia de electrones en el complejo I de la cadena respiratoria mitocondrial. Además de su eficacia sobre ácaros, su uso en mosca es cada vez más extendido debido a sus excelentes resultados. La falta de estudios encontrados sobre este acaricida en Bemisia, no permite hacer un buen uso del piridabén como herramienta en las estrategias de control de la mosca. Por ello se hace necesario conocer no sólo su modo de acción sino los mecanismos de resistencia de Bemisia frente a este insecticida.

Siete poblaciones de campo fueron bioensayadas con piridabén tanto para ninfas como adultos. Se obtuvieron valores de la $\mathrm{CL}_{50}$ de 0,3 a 3,1 ppm para ninfas y 1,5 a $2187 \mathrm{ppm}$ para adultos. Todas las poblaciones fueron muy sensibles a piridabén cuando se bioensayaron para ninfas, con un factor de resistencia de 0,9 a 9, y de moderadas a muy resistentes en adultos con un factor de resistencia de 0,13 a 206. Por otro lado, para ver si existían resistencias cruzadas con otros insecticidas de uso en mosca, se seleccionó una población resistente para piridabén a partir de la población de referencia, siendo 108 veces más resistente. No se encontraron resistencias cruzadas con ninguno de los siguientes insecticidas: imidacloprid, tiametoxam, pimetrocina, azadiractín y piriproxifén.

Para determinar que posible mecanismo está implicado en la resistencia a piridabén se realizaron bioensayos de sinergistas con butóxido de piperonilo (PBO). Los resultados obtenidos mostraron que las P450 están implicadas en la resistencia de Bemisia a este acaricida.

$\mathrm{Al}$ igual que ocurre con otros insecticidas, la expresión de la resistencia en piridabén está en función del estado de desarrollo, siendo en ninfas una excelente herramienta de control. Otro aspecto muy importante que hace que sea necesario su uso para el control de la mosca, es que no se han encontrado resistencias cruzadas con numerosos insecticidas utilizados comúnmente en Bemisia. 


\section{Introducción}

Piridabén es un compuesto piridazina descubierto en 1984 por Nissan Chemical y comercializado en 1991 (Taniguchi et al 1985, Hirata et al. 1988, Kobayashi y Uchiyama 1993). Este acaricida controla todas las etapas de desarrollo de ácaros fitófagos y algunos insectos, como la mosca blanca, pulgones y trips (Hirata et al. 1995). Es también seguro para una amplia gama de insectos beneficiosos (Sterk y Versmissen 1992), lo que resulta interesante, ya que puede incorporarse a los programas de manejo integrado de plagas.

El compuesto afecta al metabolismo, pertenece al grupo inhibidor mitocondrial de transporte de electrones (METI) según la clasificación de los modos de acción de IRAC. (Comité de Acción para la Resistencia a los Insecticidas). Estos acaricidas se desarrollaron en la década de 1990 y se sabe que actúan mediante la inhibición del complejo I (NADH: ubiquinona oxidorreductasa) de la cadena respiratoria mitocondrial (Hollingworth y Ahammadsahib 1995, Wood et al. 1996).

En 1994 ya aparecieron las primeras resistencias a este tipo de acaricida en Tetranychus kanzawai (Kishida), recogida en los campos de té en Japón (Ozawa 1994). Desde entonces han aparecido resistencias de T. urticae a los acaricidas METI en Corea (Cho et. al., 1995), Bélgica (Bylemans y Meurrens 1997), Australia (Herron y Rophail 1998), e Inglaterra (Devine et al. 2001, Stumpf y Nauen 2001).

Respecto a los mecanismos de resistencia de la araña, según Stumpf y Nauen (2001), se cree que la hidroxilación es un mecanismo común de desintoxicación oxidativo para todos los acaricidas METI en T. urticae Esta desintoxicación metabólica es a través de las monooxigenasas del citocromo P450. A pesar que esto es apoyado por otros autores como Kim et al. (2004), también se han encontrado estudios donde las esterasas están implicadas en los mecanismos de la resistencia (Pottelberge et al. 2009).

Piridabén se utiliza comúnmente para el control de Bemisia en España. A pesar de ello hay una falta de información y estudio sobre la resistencia y susceptibilidad de la mosca a este acaricida. Esto es necesario para un buen manejo de la resistencia, así como la elaboración de estrategias adecuadas.

El objetivo en este estudio es averiguar los mecanismos de resistencia de Bemisia tabaci a piridabén a partir de siete poblaciones de campo biotipo Q de Almería y Murcia (sureste de España), tanto en ninfas como en adultos. 


\section{Material y Métodos}

\subsection{Poblaciones de Bemisia tabaci}

Las poblaciones utilizadas fueron una población sensible de referencia (LAB-S) recogida en un invernadero sin tratamientos químicos en la zona de Murcia y seis poblaciones de diferentes zonas de Murcia y Almería que ya han sido descritas en el capítulo de material y métodos. Se detallan a continuación en la tabla 1.

Tabla 1. Poblaciones de Bemisia tabaci.

\begin{tabular}{c|cccc} 
Poblaciones & Localización & Cultivo & Año & Biotipo \\
\hline LAB-S & Murcia & Pimiento & 2006 & Q \\
\hline MU-A & Murcia & Tomate & 2006 & Q \\
MU-MA & Murcia & Tomate & 2006 & Q \\
MU-MI & Murcia & Pimiento & 2006 & Q \\
AL-BA & Almería & Pimiento & 2006 & Q \\
AL-MO & Almería & Pimiento & 2006 & Q \\
AL-PA & Almería & Pimiento & 2006 & Q \\
\hline
\end{tabular}

\subsection{Insecticidas}

El insecticida formulado que se utilizó para los bioensayos fue piridabén $200 \mathrm{~g} \mathrm{~kg}^{-1}$ WP (Sanmite; BASF, Sevilla, España). Se prepararon diluciones seriadas del compuesto formulado con agua desionizada que contiene $1 \mathrm{~mL} \mathrm{~L}^{-1}$ de Tween 20 (como un humectante no iónico) en el día del bioensayo.

\subsection{Bioensayos de ninfas, adultos y huevos}

Ver capítulo 2 de Material y métodos generales (Apartados 3.6.2, 3.6.3. y 3.6.4.)

\subsection{Selección de poblaciones}

Ver capítulo 2 de Material y métodos (Apartado 3.6.5.) 


\subsection{Bioensayos de sinergistas}

Ver capítulo 2 de Material y métodos generales (Apartado 3.6.6.)

\subsection{Análisis de datos}

Cuando fue necesario, los datos del bioensayo fueron corregidos por la mortalidad del control (Abbott 1925). Los datos se analizaron utilizando el programa POLO-PC para el análisis probit (Russell et al. 1977). Se calcularon las concentraciones que causan una mortalidad del $50 \%\left(\mathrm{CL}_{50}\right)$ y sus límites fiduciales al 95\%. También se calcularon los factores de resistencia a nivel de $\mathrm{CL}_{50}\left(\mathrm{FR}_{50}\right)$ como la relación entre la $\mathrm{CL}_{50}$ de la población y la $\mathrm{CL}_{50}$ de la población de referencia. Las dosis de campo de los insecticidas utilizadas en este estudio fueron las más altas tasas recomendadas por el fabricante. 


\section{Resultados y discusión}

Los resultados obtenidos del análisis probit para los bioensayos de ninfas y adultos de las poblaciones de campo con el acaricida piridabén se muestran a continuación en las tablas 2 y 3. Tanto para ninfas como para adultos, los valores de la población LAB-S mostraron que es una población sensible, ya que fue la que obtuvo los valores más bajos o no fueron significativamente diferentes de la más susceptible, por ello se consideró como la sensible de referencia. Aunque en el caso de los adultos la población MU-A fue más sensible, las diferencias significativas entre ellas fueron pequeñas. Esto es debido a que MU-A fue una población recogida en un invernadero donde había ausencia de cualquier tratamiento químico durante el período de primavera (de marzo a julio) y donde se llevaba a cabo una estrategia de liberaciones masivas de Eretmocerus mundus Mercet (Hymenoptera: Aphelinidae).

Tabla 2. Toxicidad de piridabén para la población sensible (LAB-S) y poblaciones de campo de Bemisia en ninfas.

\begin{tabular}{c|cccc}
\hline Insecticida & Población & Pendiente $( \pm$ ET) & CL50 $\left(\mathrm{mg} \mathrm{L}^{-1}\right)(95 \%$ LC) & FR50 \\
\hline Piridabén & LAB-S & $0,98( \pm 0,11)$ & $0,3(0,2-0,5)$ & 1 \\
& MU-A & $0,93( \pm 0,10)$ & $0,3(0,0-1,1)$ & 1 \\
& MU-MA & $0,72( \pm 0,08)$ & $0,5(0,0-2,3)$ & 1 \\
& MU-MI & $1,85( \pm 0,31)$ & $2,9(1,0-5,0)$ & 9 \\
& AL-BA & $1,01( \pm 0,07)$ & $0,9(0,6-1,3)$ & 2 \\
& AL-MO & $0,60( \pm 0,07)$ & $0,8(0,1-2,4)$ & 9 \\
\hline
\end{tabular}

Tabla 3. Toxicidad de piridabén para la población sensible (LAB-S) y poblaciones de campo de Bemisia en adultos.

\begin{tabular}{c|cccc|}
\hline Insecticida & Población & Pendiente $( \pm$ ET) & CL50 $\left(\mathrm{mg} \mathrm{L}^{-1}\right)(95 \% \mathrm{LC})$ & FR50 \\
\hline \multirow{3}{*}{ Piridabén } & LAB-S & $0,88( \pm 0,11)$ & $11,8(6,0-21,4)$ & 1 \\
& MU-A & $0,62( \pm 0,10)$ & $1,6(0,3-4,1)$ & 0 \\
& MU-MA & $0,57( \pm 0,12)$ & $183,2(72,8-425,3)$ & 15 \\
& MU-MI & $1,34( \pm 0,41)$ & $2437,1(515,7-4668,0)$ & 206 \\
& AL-BA & $0,69( \pm 0,10)$ & $608,8(189,5-2052,7)$ & 51 \\
& AL-MO & $0,70( \pm 0,13)$ & $1810,9(602,6-5545,9)$ & 153 \\
& AL-PA & $0,92( \pm 0,13)$ & $2186,7(941,5-7476,5)$ & 185 \\
\hline
\end{tabular}


Los valores obtenidos de la $\mathrm{CL}_{50}$ para ninfas variaron entre 0,3 y 3,1 $\mathrm{ppm}$. Tres de las poblaciones de mosca bioensayadas presentaron diferencias significativas con la población sensible de referencia, siendo MU-MI, AL-BA y AL-PA. Teniendo en cuenta que los factores de resistencia no fueron superiores a 10 en ningún caso y que la dosis recomendada en campo para piridabén es 200 ppm, se puede decir que ninguna población presentó resistencia a este acaricida cuando se bioensayaron en estado de ninfa.

Con respecto a los valores obtenidos para los adultos de Bemisia, la población de referencia obtuvo un valor de la $\mathrm{CL}_{50}$ de 11,8 ppm. En este caso, todas las poblaciones mostraron diferencias significativas, variando su factor de resistencia de 0,1 a 206. La población MUMI fue la que obtuvo el resultado más alto, demostrando una vez más la resistencia adquirida por esta población debida a un uso intensivo de insecticidas (ver Capitulo 1), contrariamente a lo que le pasa a la población MU-A. Con respecto a estos resultados, se puede decir que las poblaciones de campo bioensayadas en estado de adultos son de moderadas a muy resistentes para el acaricida piridabén.

Comparando los resultados de ninfas y adultos, se observa claramente que todas las poblaciones presentaron una mayor resistencia cuando fueron bioensayadas en estado adulto. Destacando el caso de la población AL-MO, que fue hasta 2370 veces superior en adultos que en ninfas.

Por lo tanto, al igual que como ya habíamos observado para otros insecticidas, la expresión de la resistencia en B. tabaci para el acaricida METI piridabén es en función del estado de desarrollo, expresándose en adultos para todas las poblaciones de mosca bioensayadas.

Debido a que no se han encontrado estudios de la resistencia de Bemisia frente a piridabén, compararemos estos resultados con los obtenidos para poblaciones de T. urticae. Es conocida como araña roja y es una de las especies más polífagas de ácaros y una de las plagas más importantes en muchos cultivos hortícolas y ornamentales a nivel mundial. (Van de Vrie 1985, Rabbinge 1985 y Bolland et al. 1998).

Los estudios encontrados muestran que al igual que ocurre con Bemisia, hay diferencias en la expresión de la resistencia en ninfas y adultos. Nauen et al. (2001) obtuvieron para una población de $T$. urticae un valor de la $\mathrm{CL}_{50}$ de $0,14 \mathrm{ppm}$, bioensayada con piridabén en el primer estado larval. Este valor fue muy inferior (hasta unas 100 veces) al publicado en ensayos realizados sobre adultos por Herron y Rophail (1998), donde el valor de la $\mathrm{CL}_{50}$ fue de $50 \mathrm{ppm}$. Otros autores que realizaron sus estudios sobre adultos, también obtuvieron 
valores superiores. Así como Kim et al. (2004) donde su población presentó un valor de la $\mathrm{CL}_{50}$ de 42 ppm y Goka (1998), con un valor de $57 \mathrm{ppm}$.

A la vista de estos resultados, se observa que ocurre lo mismo que en el caso de los neonicotinoides, donde la expresión de la resistencia es en función del estado de desarrollo del individuo, expresándose en los adultos. Por ello se podría sospechar de la existencia de una resistencia cruzada entre neonicotinoides y piridabén Sin embargo, no existe una correlación entre los valores de las poblaciones, cuando fueron bioensayadas con los neonicotinoides imidacloprid y tiametoxam y con piridabén (ver capitulo 1).

Se seleccionó una población para piridabén y así poder verificar que realmente no existe resistencia cruzada entre ellos y estudiar si existe resistencia cruzada con otros insecticidas.

La población seleccionada R-PY se obtuvo a partir de la población sensible de referencia LAB-S, siendo tratada con piridabén en laboratorio durante dos años hasta obtener una población 108 veces más resistente en ninfas con un valor de la $\mathrm{CL}_{50}$ de 37 ppm y 46 veces más resistente para adultos con una $\mathrm{CL}_{50}$ de $540 \mathrm{ppm}$. A pesar que el factor de resistencia es más alto en las ninfas, el nivel de resistencia sigue siendo más alto en los adultos. (Tabla 4 y 5).

Tabla 4. Toxicidad de piridabén para la población sensible (LAB-S) y la población seleccionada para piridabén de Bemisia en ninfas.

\begin{tabular}{c|cccc|}
\hline Insecticida & Población & Pendiente $( \pm$ ET) & CL50 $\left(\mathrm{mg} \mathrm{L}^{-1}\right)(95 \%$ LC) & FR50 \\
\hline Piridabén & LAB-S & $0,98( \pm 0,11)$ & $0,3(0,2-0,5)$ & 1 \\
& R-PY & $1,42( \pm 0,14)$ & $36,6(18,0-61,4)$ & 108 \\
\hline
\end{tabular}

Tabla 5. Toxicidad de piridabén para la población sensible (LAB-S) y la población seleccionada para piridabén de Bemisia en adultos.

\begin{tabular}{c|cccc}
\hline Insecticida & Población & Pendiente $( \pm$ ET $)$ & CL50 $\left(\mathrm{mg} \mathrm{L}^{-1}\right)(95 \%$ LC $)$ & FR50 \\
\hline Piridabén & LAB-S & $0,88( \pm 0,11)$ & $11,8(6,0-21,4)$ & 1 \\
& R-PY & $1,95( \pm 0,48)$ & $540,5(251,5-940,1)$ & 46 \\
\hline
\end{tabular}


Esta población seleccionada fue bioensayada con distintos insecticidas para ninfas para ver sí existe resistencia cruzada con otros insecticidas de uso en Bemisia. En la tabla 6 se muestran los valores obtenidos de la $\mathrm{CL}_{50} \mathrm{y}$ sus limites fiduciales.

Tabla 6. Toxicidad de piridabén y de diferentes insecticidas para la población sensible (LAB-S) y población seleccionada para piridabén de Bemisia.

\begin{tabular}{c|cccc}
\hline Insecticida & Población & Pendiente $( \pm$ ET) & CL50 $\left(\mathrm{mg} \mathrm{L}^{-1}\right)(95 \% \mathrm{LC})$ & FR50 \\
\hline Piridabén & LAB-S & $0,98( \pm 0,11)$ & $0,3(0,2-0,5)$ & 1 \\
& R-PY & $1,42( \pm 0,14)$ & $36,6(18,0-61,4)$ & 108 \\
\hline Azadiractín & LAB-S & $0,88( \pm 0,10)$ & $2,7(0,5-6,6)$ & 1 \\
& R-PY & $0,00( \pm 0,00)$ & $7,6(2,2-19,6)$ & 3 \\
\hline Imidacloprid & LAB-S & $0,60( \pm 0,07)$ & $15,2(1,3-81,1)$ & 2 \\
& R-PY & $0,92( \pm 0,09)$ & $37,5(25,6-54,0)$ & 1 \\
\hline Pimetrocina & LAB-S & $1,03( \pm 0,09)$ & $29,2(3,2-107,4)$ & 1,1 \\
\hline Piriproxifén & R-PY & $1,37( \pm 0,16)$ & $30,9(6,5-72,2)$ & 1 \\
& LAB-S & $0,98( \pm 0,10)$ & $20,9(13,8-30,4)$ & 5 \\
\hline Tiametoxam & R-PY & $0,68( \pm 0,06)$ & $95,0(45,9-215,4)$ & 1 \\
\hline
\end{tabular}

Excepto para el insecticida piriproxifén, la población seleccionada R-PY no mostró diferencias significativas con respecto a la población sensible cuando fue bioensayada con el resto de insecticidas, presentando valores del factor de resistencia entre 1,1 y 3 .

Para el caso del imidacloprid, como la resistencia la expresan los adultos, también se realizó el bioensayo de la población seleccionada R-PY con imidacloprid en adultos, dando un valor de la $\mathrm{CL}_{50}$ de $26 \mathrm{ppm}$. No presentando diferencias significativas con la población de referencia (58 ppm).

La posible existencia de resistencia cruzada con el piriproxifén, hace sospechar que hay un mecanismo común en Bemisia que hace que sea resistente a ambos insecticidas.

Se obtuvo la población seleccionada para piriproxifén R-PIX a partir de la población sensible de referencia LAB-S, siendo 112 veces más resistente. Esta población fue bioensayada con piridabén, tanto en larvas como en adultos, dando un valor de la $\mathrm{CL}_{50}$ de 5 ppm y 32 ppm respectivamente. Siendo incluso más bajo, para las ninfas, que el valor obtenido para la población sensible $(21 \mathrm{ppm})$. Por tanto no se puede decir que exista una resistencia cruzada. 
A pesar de estos resultados, seguimos sospechando de la posible implicación de las P450 en los mecanismos de resistencia a piridabén de Bemisia. Por ello, se realizaron bioensayos con el sinergista butóxido de piperonilo (PBO), que es un inhibidor del citocromo P450. En la tabla 7 se muestran los valores obtenidos de los bioensayados con piridabén y PBO de la población sensible y de su seleccionada.

Tabla 7. Toxicidad de piridabén para la población sensible (LAB-S) y población seleccionada y piridabén + PBO para la población seleccionada en Bemisia.

\begin{tabular}{c|ccccc|}
\hline Insecticida & Población & Pendiente $( \pm$ ET $)$ & CL50 $\left(\mathrm{mg} \mathrm{L}^{-1}\right)(95 \% \mathrm{LC})$ & FR50 & FS \\
\hline Piridabén 2009 & LAB-S & $0,98( \pm 0,11)$ & $0,3(0,2-0,5)$ & 1 & - \\
& R-PY & $1,42( \pm 0,14)$ & $36,6(18,0-61,4)$ & 108 & - \\
\hline Piridabén 2010 & LAB-S & $0,64( \pm 0,11)$ & $12,4(5,1-70,3)$ & 1 & - \\
& R-PY & $1,09( \pm 0,22)$ & $127,9(78,4-192,6)$ & 10 & - \\
\hline Piridabén 2010+PBO & R-PY & $1,38( \pm 0,17)$ & $11,3(5,3-19,0)$ & 0,9 & 11,3 \\
\hline
\end{tabular}

Se observó un aumento de los valores de la $\mathrm{CL}_{50}$ tanto para la población sensible como de la resistente entre 2009 y 2010. La inestabilidad del nivel de resistencia o susceptibilidad en poblaciones mantenidas en laboratorio es un fenómeno corriente. Al mantener un número relativamente bajo de individuos se producen cambios en las poblaciones debido a la deriva genética, especialmente al cesar la presión de selección hacia la resistencia. Los resultados obtenidos muestran que el PBO disminuyó significativamente la resistencia de la población seleccionada, con un factor de sinergismo de 11,3, bajándola a niveles similares a la de la población sensible. Esto confirma nuestras sospechas de la implicación de las P450.

Por tanto, nuestros resultados sugieren que el citocromo P450 interviene en el metabolismo de detoxificación del acaricida METI. Sin embargo, no son los mismos enzimas que afectan otros insecticidas, ya que no existió resistencia cruzada.

Este estudio nos revela la importancia del piridabén como una buena herramienta para el control de Bemisia. A pesar de ser un acaricida de uso extendido sobre importantes plagas como T. urticae, su uso en mosca ha demostrado tener una gran eficiencia sobre ninfas y por tanto ser un buen candidato para incorporarlo a las estrategias de control. Además, es muy interesante porque no se han encontrado resistencias cruzadas con otros insecticidas aplicados para el control de la mosca en los cultivos hortícolas y ornamentales más comúnmente utilizados. 


\section{Bibliografía}

Bolland, H R, Gutierrez, J and. Flechtmann, CHW 1998. World catalogue of the spider mite family (Acari: Tetranychidae). Koninklijke Brill NV, Leiden, The Netherlands.

Bylemans, D and. Meurrens F 1997. Anti-resistance strategies for the two-spotted spider mite, Tetranychus urticae (Acari: Tetranychidae), in strawberry culture. Acta Hortic. 439: 869876.

Cho, J R, Kim Y J, Ahn, Y J, Yoo, J. K and Lee J O 1995. Monitoring of acaricide resistance in field collected populations of Tetranychus urticae (Acari: Tetranychidae) in Korea. Korean J. Appl. Entomol. 31: 40-45.

Devine, G J, Barber M, and Denholm, I 2001. Incidence and inheritance of resistance to METI-acaricides in European strain of the two-spotted spider mite (Tetranychus urticae) (Acari: Tetranychidae). Pest Manag. Sci. 57: 443-448.

Goka, K 1998. Mode of inheritance of resistance to three new acaricides in the Kanzawa spider mite, Tetranychus kanzawai Kishida (Acari: Tetranychidae). Exp. Appl. Acar. 22: 699708.

Herron, G A, and Rophail, J. 1998. Tebufenpyrad (Pyranica ${ }^{(R)}$ ) resistance detected in twospotted spider mite Tetranychus urticae Koch (Acari: Tetranychidae) from apples in western Australia. Exp. Appl. Acarol. 22: 633-641.

Hirata K, Kawamura Y, Kudo Mand Igarashi H, 1995. Development of a new acaricide, pyridaben. Nihon Noyaku Gakekaishi (J Pestic Sci) 20:177-179.

Hirata K, Kudo M, Miyake T, Kawamura Y and Ogura T 1988. NC- 129-a new acaricide, in Proc Brighton Crop Prot Conf-Pests Dis, BCPC, Farnham, Surrey, UK, pp 41-48.Kobayashi S and Uchiyama G, (1993). Sanmite-a new miticide. Agrochem Jpn 63:12-14.

Hollingworth R M, and. Ahammadsahib K I 1995. Inhibitors of respiratory complex 1: mechanisms, pesticidal actions and toxicology. Rev. Pestic. Toxicol. 3: 277-302.

Kim, YJ, Lee, SH, Lee, SW \& Ahn, YJ 2004. Fenpyroximate resistance in Tetranychus urticae (Acari: Tetranychidae): cross-resistance and biochemical resistance mechanisms. Pest Management Science 60, 1001-1006. 
Nauen R, Stumpf N, Elbert A C, Zebitz P W, and Kraus W 2001. Acaricide toxicity and resistance in larvae of different strains of Tetranychus urticae and Panonychus ulmi (Acari: Tetranychidae). Pest Manage. Sci. 57: 253- 261.

Ozawa, A. 1994. Acaricide susceptibility of Kanzawa spider mite, Tetranychus kanzawai Kishida (Acarina: Tetranychidae) collected from tea fields in Chuuen and Ogasa district in Shizuoka Prefecture. Bull. Tea Res. Stn. 79: 1-14.

Pottelberge, S V, Leeuwen, T V, Nauen, R and Tirry, L 2009. Resistance mechanisms to mitocondrial electron transport inhibitors in a field-collected strain of Tetranychus urticae Koch (Acari: Tetranychidae) Bulletin of Entomological Research 99, 23-31.

Rabbinge R, 1985. Aspects of damage assessment, in Spider mites: their biology, natural enemies and control, Vol 1B, ed by Helle W and SabelisMW, Elsevier, Amsterdam, The Netherlands, pp $261-272$.

Sterk G and Versmissen C 1992. Studies on the effects of piridabén on beneficial insects. Med Fac Landboum Univ Gent 57/3a:945-948.

Stumpf N and. Nauen R 2001. Cross-resistance, inheritance, and biochemistry of mitochondrial electron transport inhibitor-acaricide resistance in Tetranychus urticae (Acari: Tetranychidae). J. Econ. Entomol. 94: 1577-1583.

Taniguchi M, Hirose M, Baba M, Hirata K and Ochiai Y 1985. Pyridazinones, Japanese Patent JP 60004173.

Van de Vrie M, 1985. Control of Tetranychidae in crops: greenhouse ornamentals, in Spider mites: their biology, natural enemies and control, Vol 1B, ed by Helle W and Sabelis MW, Elsevier, Amsterdam, The Netherlands, pp 273-283.

Wood, E., B. Latli, and J. E. Casida. 1996. Fenazaquin acaricide specibc binding sites in NADH:ubiquinone oxidoreductase and apparently the ATP synthetase stalk. Pestic. Biochem. Physiol. 54: 135-145. 


\section{Capítulo 4}

Resistencia cruzada y mecanismos de resistencia entre insecticidas reguladores del crecimiento en Bemisia tabaci Gennadius 


\section{Resumen}

Bemisia tabaci es una plaga de una gran importancia económica que ha desarrollado resistencias a diferentes clases de insecticidas. La necesidad de controlar esta plaga ha hecho desarrollar nuevos insecticidas a lo largo de la historia. Éste es el caso de los reguladores del crecimiento que surgieron como alternativa a los insecticidas neurológicos existentes hasta el momento (Horowitz y Ishaaya, 1996). La resistencia a algunos grupos, como piretroides y neonicotinoides, ha sido ampliamente estudiada. Sin embargo, hay escasas investigaciones sobre los mecanismos involucrados en la resistencia a reguladores del crecimiento así como la resistencia cruzada entre ellos y otros insecticidas de otros grupos.

Nuestro estudio fue diseñado para investigar la resistencia cruzada entre tres reguladores del crecimiento, azadiractín, buprofecín y piriproxifén, y con insecticidas de otros grupos. Se investigó también los mecanismos implicados en la resistencia. Para ello poblaciones resistentes fueron seleccionadas y probadas en laboratorio. La selección con buprofecín aumentó la resistencia a buprofecín (95 veces) y azadiractín (56 veces), pero no afectó a piriproxifén. De igual manera, la selección con azadiractín aumentó la de ambos, azadiractín y buprofecín (39 y 18 veces respectivamente), pero no la de piriproxifén. Por otro lado, la selección con piriproxifén sólo aumentó la resistencia a piriproxifén (112 veces). Respecto a la resistencia cruzada con insecticidas de otros grupos, ninguna de las poblaciones seleccionadas presentaron resistencia cruzada al neonicotinoide imidacloprid. Sin embargo, la selección de buprofecín aumentó la de la pimetrocina con un factor de resistencia de 83.

Estos resultados apoyan los de las poblaciones de campo citados en el capítulo 1, que nos sugerían la existencia de resistencia cruzada entre azadiractín y buprofecín. Una explicación lógica a esto es la existencia de un mecanismo común de detoxificación, por ello realizamos bioensayos de sinergistas con butoxido de piperonilo (PBO) y S,S,S-tributil fosforotriotiato (DEF) sobre las población sensible y las seleccionadas. Los resultados mostraron que la resistencia a buprofecín y azadiractín de las poblaciones seleccionadas era reducida con el DEF pero no con el PBO.

Este estudio indica que azadiractín y buprofecín presentan el mismo mecanismo implicado en la resistencia, que no es el mismo que detoxifica las P450 que afecta a los neonicotinoides, y se sospecha que podrían ser las esterasas. 


\section{Introducción}

La mosca blanca, Bemisia tabaci es una plaga muy perjudicial a nivel económico en todo el mundo (Byrne y Bellows, 1991). Se alimenta de más de 700 especies de plantas en 86 familias botánicas (Greathead, 1986). Causa dos tipos de daños, directos mediante la extracción de savia del floema e indirectos mediante la transmisión de 111 virus de plantas (Horowitz et al., 2003; Mugiira et al., 2008).

Las principales razones de su expansión en importancia y extensión geográfica parecen ser la sustitución de un biotipo por otro capaz de invadir nuevos sistemas de cultivo, la capacidad de desarrollarse tanto en plantas huéspedes cultivadas como las no cultivadas, y el rápido desarrollo de resistencia a los nuevos insecticidas (Byrne y Bellows, 1991; Perring, 2001). Además, como resultado de la intensa exposición a insecticidas, Bemisia ha desarrollado resistencia a los insecticidas convencionales (organofosforados, carbamatos y piretroides), así como a los insecticidas neonicotinoides y a los reguladores del crecimiento (IRC, en inglés IGR) (Horowitz y Ishaaya, 1996; Ahmad et al., 2002; Luo et al., 2010).

Los IGR son insecticidas eficaces contra las etapas inmaduras de insectos al interferir ya sea en el equilibrio hormonal o en la formación de quitina (Gerling y Sinai, 1994). En este estudio nos hemos centrado en tres de ellos: buprofecín, azadiractina y piriproxifén. Esta elección es debida a que en el capítulo 1 vimos que en las poblaciones de campo había una correlación significativa $(r=0,98, \mathrm{P}<0,01)$ en la resistencia a los insecticidas buprofecín y azadiractina. Aunque no había con piriproxifén, también lo hemos sometido a estudio por ser otro de los IGR usados para el control de mosca.

Buprofecín fue el primer IGR selectivo introducido en el mercado para el control de mosca blanca (Horowitz y Ishaaya, 1992). Es un inhibidor de la síntesis de la quitina que mata el insecto durante la muda (Kanno et al., 1981). Actúa en el insecto en fase de vapor a través de la inhalación y por contacto directo a través de la absorción por el tegumento (De Cock et al., 1990).

La azadiractina es obtenida de los árboles de neem, Azadirachta indica A. Retrasa o impide la muda, reduce el crecimiento, el desarrollo, y la oviposición, y puede causar una mortalidad significativa, particularmente en inmaduros (Coudriet et al. 1985, Flint y Sparks 1989, Prabhaker et al. 1989, Schmutterer 1990, Liu y Stansly 1995, Mitchell et. al. 2004). Un inconveniente importante de los ingredientes activos del neem es su sensibilidad a la 
radiación UV, la temperatura y la rápida degradación bajo condiciones de campo abierto (Johnson et. al. 2003, Barrek et al. 2004).

Piriproxifén es un agonista de la hormona juvenil $(\mathrm{JH})$ que interfiere en la regulación hormonal de los insectos, obteniendo como resultado la interrupción de la embriogénesis, metamorfosis, y la formación de adultos (Itaya 1987, Ascher y Eliyahu 1988, Kawada 1988, Langley 1990, Koehler y Patterson 1991, Dhadialla et al. 1998). Tiene actividad persistente contra varias plagas agrícolas importantes (Ishaaya y Horowitz 1992, 1995; Ishaaya et al 1994), incluyendo Bemisia tabaci (Schaefer et al 1988.). Piriproxifén es extremadamente tóxico para los huevos y las pupas de B. tabaci y se ha demostrado que altera la embriogénesis a través de efectos transováricos cuando son los adultos los que están en contacto con el insecticida (Ishaaya y Horowitz, 1992).

En este capítulo, se investigó la resistencia cruzada entre buprofecín, azadiractín y piriproxifén en poblaciones de campo de Bemisia. También se han llevado a cabo bioensayos de sinergistas para ver el papel de los mecanismos metabólicos en la resistencia de Bemisia en buprofecín y azadiractín. La teoría del sinergismo se basa en la habilidad de una molécula para interferir en la detoxificación metabólica de otra molécula (Corbett, 1974). Para ello se utilizó el inhibidor butóxido de piperonido (PBO) para las P450 monooxigenasas y el S,S,S, tributil trifosforotritioato (DEF) para las esterasas. 


\section{Material y métodos}

\subsection{Poblaciones de Bemisia tabaci}

Las poblaciones utilizadas fueron una población sensible de referencia (LAB-S) recogida en un invernadero sin tratamientos químicos en la zona de Murcia y seis poblaciones de diferentes zonas de Murcia y Almería que ya han sido descritas en el capítulo de material y métodos. Se detallan a continuación en la tabla 1.

Tabla 1. Poblaciones de Bemisia tabaci

\begin{tabular}{c|cccc} 
Poblaciones & Localización & Cultivo & Año & Biotipo \\
\hline LAB-S & Murcia & Pimiento & 2006 & Q \\
\hline MU-A & Murcia & Tomate & 2006 & Q \\
MU-MA & Murcia & Tomate & 2006 & Q \\
MU-MI & Murcia & Pimiento & 2006 & Q \\
AL-BA & Almería & Pimiento & 2006 & Q \\
AL-MO & Almería & Pimiento & 2006 & Q \\
AL-PA & Almería & Pimiento & 2006 & Q \\
\hline
\end{tabular}

\subsection{Insecticidas}

Los siguientes insecticidas formulados fueron los que se utilizaron para los bioensayos: azadiractina $32 \mathrm{~g} \mathrm{~L}^{-1} \mathrm{CE}$ (Align; Sipcam Inagra, Valencia, España), buprofezín $250 \mathrm{~g} \mathrm{~kg}^{-1}$ WP (Aplaudd, Syngenta Agro, Madrid, España) y piriproxifén $100 \mathrm{~g} \mathrm{~L}^{-1} \mathrm{CE}$ (Juvinal $10 \mathrm{CE}$; Kenogard, Barcelona, España). Se prepararon diluciones seriadas de los compuestos formulados con agua desionizada que contiene $1 \mathrm{~mL} \mathrm{~L}^{-1}$ de Tween 20 (como un humectante no iónico) en el día del bioensayo.

\subsection{Bioensayos de ninfas y huevos}

Ver capítulo 2 de Material y métodos generales (Apartados 3.6.2. y 3.6.3)

\subsection{Selección de poblaciones}

Ver capítulo 2 de Material y métodos generales (Apartado 3.6.5.) 


\subsection{Bioensayos de sinergistas}

Ver capítulo 2 de Material y métodos generales (Apartado 3.6.6.).

\subsection{Análisis de datos}

Cuando fue necesario, los datos del bioensayo fueron corregidos por la mortalidad del control (Abbott 1925). Los datos se analizaron utilizando el programa POLO-PC para el análisis probit (Russell et al. 1977). Se calcularon las concentraciones que causan una mortalidad del 50\% $\left(\mathrm{CL}_{50}\right)$ y sus límites fiduciales al 95\%. También se calcularon los factores de resistencia a nivel de $\mathrm{CL}_{50}\left(\mathrm{FR}_{50}\right)$ como la relación entre la $\mathrm{CL}_{50}$ de la población y la $\mathrm{CL}_{50}$ de la población de referencia. Las dosis de campo de los insecticidas utilizadas en este estudio fueron las más altas tasas recomendadas por el fabricante. 


\section{Resultados y discusión}

A partir de la población considerada como la sensible de referencia LAB-S se obtuvieron las poblaciones seleccionadas a azadiractín, buprofecín y piriproxifén (R-AZA, R-BU y RPIX respectivamente). Éstos son los tres reguladores de crecimiento más usados en las estrategias de control de Bemisia. Estas poblaciones se obtuvieron en el laboratorio bajo una presión de insecticida entre 1 año para el caso del buprofecín y casi tres para piriproxifén. Los valores obtenidos de la $\mathrm{CL}_{50}$ de las poblaciones seleccionadas se muestran a continuación en la tabla 2.

Tabla 2. Toxicidad de azadiractín, buprofecín y piriproxifén para la población sensible, la seleccionada y las de campo en Bemisia.

\begin{tabular}{|c|c|c|c|c|c|}
\hline Insecticida & Población & Pendiente $( \pm$ ET $)$ & CL50 (mg L-1 $)(95 \% \mathrm{LC})$ & FR50 (S) & FR50 (R) \\
\hline \multirow[t]{8}{*}{ Azadiractín } & LAB-S & $0,88( \pm 0,10)$ & $2,7(0,5-6,6)$ & 1 & - \\
\hline & R-AZA & $0,82( \pm 0,14)$ & $102,7(62,1-197,6)$ & 39 & 1 \\
\hline & MU-A & $0,88( \pm 0,09)$ & $0,6(0,1-1,3)$ & 0,2 & 171 \\
\hline & MU-MA & $0,92( \pm 0,09)$ & $5,4(1,7-13,0)$ & 2 & 19 \\
\hline & MU-MI & $1,26( \pm 0,27)$ & $82,7(36,5-166,7)$ & 31 & 1,2 \\
\hline & AL-BA & $0,78( \pm 0,08)$ & $4,0(1,7-7,5)$ & 1,5 & 26 \\
\hline & AL-MO & $1,50( \pm 0,18)$ & $18,5(11,5-26,4)$ & 7 & 6 \\
\hline & AL-PA & $0,75( \pm 0,10)$ & $0,8(0,0-3,0)$ & 0,3 & 128 \\
\hline \multirow[t]{8}{*}{ Buprofecín } & LAB-S & $1,66( \pm 0,17)$ & $8,7(4,4-14,4)$ & 1 & - \\
\hline & $\mathrm{R}-\mathrm{BU}$ & $0,63( \pm 0,10)$ & $830,1(371,6-2325,1)$ & 95 & 1 \\
\hline & MU-A & $0,89( \pm 0,07)$ & $96,2(64,2-143,3)$ & 11 & 9 \\
\hline & MU-MA & $0,89( \pm 0,08)$ & $389,6(253,6-649,3)$ & 45 & 2 \\
\hline & MU-MI & $0,62( \pm 0,09)$ & $10159,0(2157,8-1389658,3)$ & 1164 & 0,1 \\
\hline & AL-BA & $0,49( \pm 0,06)$ & $125,1(31,9-519,9)$ & 14 & 7 \\
\hline & AL-MO & $1,56( \pm 0,22)$ & $390,4(127,4-724,5)$ & 45 & 2 \\
\hline & AL-PA & $0,59( \pm 0,13)$ & $518,1(115,3-1723,0)$ & 59 & 2 \\
\hline \multirow[t]{8}{*}{ Piriproxifén } & LAB-S & $0,98( \pm 0,10)$ & $20,9(13,8-30,4)$ & 1 & - \\
\hline & R-PIX & $0,66( \pm 0,08)$ & $2333,9(1052,3-7916,9)$ & 112 & 1 \\
\hline & MU-A & $0,92( \pm 0,07)$ & $25,9(16,2-40,7)$ & 1,2 & 90 \\
\hline & MU-MA & $1,03( \pm 0,08)$ & $15,4(7,5-28,3)$ & 0,7 & 152 \\
\hline & MU-MI & $0,91( \pm 0,10)$ & $402,4(274,0-634,3)$ & 19 & 6 \\
\hline & AL-BA & $1,17( \pm 0,09)$ & $117,1(73,5-196,9)$ & 6 & 20 \\
\hline & AL-MO & $1,00( \pm 0,08)$ & $322,2(167,0-805,4)$ & 15 & 7 \\
\hline & AL-PA & $1,19( \pm 0,12)$ & $243,3(118,7-547,9)$ & 12 & 10 \\
\hline
\end{tabular}


La población R-AZA mostró un valor de 102,6 ppm, es decir, 39 veces más resistente que la población de referencia. Si la comparamos con los valores obtenidos de las poblaciones de campo, se aprecian diferencias significativas con todas menos con la población MU-MI. Este resultado era esperable debido a que esta población cuando fue recolectada estaba tratada 4 veces con azadiractina en los últimos 4 meses (Capítulo 1). El factor de resistencia con el resto de las poblaciones varió entre 6, para la población AL-MO, y 171 para la población MU-A. Por tanto, a la vista de estos resultados podemos confirmar que la población R -AZA está seleccionada para el insecticida azadiractín.

Esta población seleccionada se bioensayó con diferentes insecticidas para poder ver si existía resistencia cruzada con algunos de los más usados para el control de Bemisia. Los valores obtenidos se muestran en la tabla 3.

Tabla 3. Toxicidad de azadiractín y de diferentes insecticidas para la población sensible (LABS) y población seleccionada para azadiractín de Bemisia.

\begin{tabular}{c|cccc}
\hline Insecticida & Población & Pendiente $( \pm \mathrm{ET})$ & CL50 $\left(\mathrm{mg} \mathrm{L}^{-1}\right)(95 \% \mathrm{LC})$ & FR50 \\
\hline Azadiractín & LAB-S & $0,88( \pm 0,10)$ & $2,7(0,5-6,6)$ & 1 \\
& R-AZA & $0,82( \pm 0,14)$ & $102,7(62,1-197,6)$ & 39 \\
\hline \multirow{2}{*}{ Buprofecín } & LAB-S & $1,66( \pm 0,17)$ & $8,7(4,4-14,4)$ & 1 \\
& R-AZA & $1,18( \pm 0,01)$ & $154,2(97,7-246,9)$ & 18 \\
\hline Imidacloprid & LAB-S & $0,60( \pm 0,07)$ & $15,2(1,3-81,1)$ & 1 \\
& R-AZA & $0,81( \pm 0,08)$ & $48,5(28,6-84,5)$ & 3 \\
\hline Pimetrocina & LAB-S & $1,03( \pm 0,09)$ & $29,2(3,2-107,4)$ & 1 \\
& R-AZA & $1,66( \pm 0,21)$ & $71,3(32,4-142,9)$ & 2,4 \\
\hline Piridabén & LAB-S & $0,98( \pm 0,11)$ & $0,3(0,2-0,5)$ & 1 \\
& R-AZA & $1,52( \pm 0,25)$ & $4,0(2,1-6,4)$ & 12 \\
\hline Piriproxifén & LAB-S & $0,98( \pm 0,10)$ & $20,9(13,8-30,4)$ & 1 \\
& R-AZA & $0,10( \pm 0,08)$ & $20,5(12,3-32,0)$ & 0,98 \\
\hline
\end{tabular}

No hubo diferencias significativas en los valores obtenidos de la $\mathrm{CL}_{50}$ respecto con la población sensible de referencia para el imidacloprid, la pimetrocina y el piriproxifén. Por tanto, no hay resistencia cruzadas con estos insecticidas. 
Para el piridabén, sí que existieron diferencias significativas respecto de la sensible, con un factor de resistencia de 12. Aunque con R-AZA fue ligeramente más resistente, no lo fue en el sentido inverso, es decir, R-PY (seleccionada para piridabén) no fue resistente a azadiractín (Capítulo 3). Con lo que no se puede considerar que haya resistencia cruzada.

En cambio, sí que existe una fuerte resistencia cruzada con buprofecín, con un factor de resistencia de 18. Y como se verá a continuación también existe resistencia cruzada a azadiractín para la población seleccionada para buprofecín (R-BU).

La población R-BU obtuvo un valor de la $\mathrm{CL}_{50}$ de $830 \mathrm{ppm}$, con un factor de resistencia de 95 veces (tabla 2). Con respecto a las poblaciones de campo, sólo hubo diferencias significativas con la población MU-A, ya que nuestras poblaciones presentaron valores muy elevados para este insecticida. Destaca sobre todo la población MU-MI con 10.159 ppm a pesar de nunca haber sido tratada con buprofecín. A pesar de esto, se confirma que la población R-BU está seleccionada.

$\mathrm{Al}$ igual que se hizo con la población R-AZA, la población seleccionada para buprofecín se bioensayó con diferentes insecticidas para evaluar las resistencias cruzadas. Los valores de la $\mathrm{CL}_{50}$ obtenidos se muestran en la tabla 4.

Tabla 4. Toxicidad de buprofecín y de diferentes insecticidas para la población sensible (LAB-S) y población seleccionada para buprofecín de Bemisia.

\begin{tabular}{c|cccc}
\hline Insecticida & Población & Pendiente $( \pm$ ET $)$ & CL50 (mg L-1)(95\% LC) & FR50 \\
\hline Buprofecín & LAB-S & $1,66( \pm 0,17)$ & $8,7(4,4-14,4)$ & 1 \\
& R-BU & $0,63( \pm 0,10)$ & $830,1(371,6-2325,1)$ & 95 \\
\hline Azadiractín & LAB-S & $0,88( \pm 0,10)$ & $2,7(0,5-6,6)$ & 1 \\
& R-BU & $2,25( \pm 0,32)$ & $148,1(103,1-194,2)$ & 56 \\
\hline Imidacloprid & LAB-S & $0,60( \pm 0,07)$ & $15,2(1,3-81,1)$ & 1 \\
& R-BU & $1,42( \pm 0,12)$ & $18,7(9,6-31,7)$ & 1,2 \\
\hline Pimetrocina & LAB-S & $1,03( \pm 0,09)$ & $29,2(3,2-107,4)$ & 83 \\
\hline Piridabén & R-BU & $1,19( \pm 0,30)$ & $2423,8(1398,0-5736,2)$ & 1 \\
& LAB-S & $0,98( \pm 0,11)$ & $0,3(0,2-0,5)$ & 18 \\
\hline Piriproxifén & R-BU & $2,52( \pm 0,29)$ & $6,2(3,2-9,7)$ & 1 \\
& LAB-S & $0,98( \pm 0,10)$ & $20,9(13,8-30,4)$ & 0,29 \\
\hline
\end{tabular}


Se aprecian diferencias significativas con respecto a la población original de la selección para todos los insecticidas menos con el imidacloprid. Esto también está reflejado en un estudio de Basit (2012), donde una población seleccionada para buprofecín (hasta 7000 comparada con la sensible) no vió afectada su susceptibilidad a varios neonicotinoides. Lo que lleva a plantearse la posibilidad de usar la mezcla de neonicotinoides con reguladores del crecimiento como un método eficaz en las estrategias de control de Bemisia. (Basit et al. 2013).

Por otro lado, hay que destacar los resultados obtenidos con azadiractín y pimetrocina, mostrando un factor de resistencia de 56 y 83, respectivamente, con respecto a la sensible. En caso del azadiractín, confirma las sospechas de la existencia de resistencia cruzada con buprofecín, a pesar de tener modos de acción diferentes.

El valor de la $\mathrm{CL}_{50}$ tan elevado obtenido cuando la población $\mathrm{R}-\mathrm{BU}$ se ha bioensayado con pimetrocina (2424 ppm) y con un factor de resistencia de 83, nos plantea la posibilidad de la existencia de resistencia cruzada entre estos dos insecticidas. Por ello se seleccionó a partir de la población de referencia LAB-S una población resistente a pimetrocina, RPIME, obteniendo un valor del factor de resistencia de 2485, por tanto, se considera que está seleccionada. A continuación, se bioensayó con buprofecín, mostrándose los resultados en la tabla 5 .

Tabla 5. Toxicidad de buprofecín y pimetrocina para la población sensible (LAB-S) y población seleccionada para pimetrocina de Bemisia.

\begin{tabular}{c|cccc}
\hline Insecticida & Población & Pendiente $( \pm$ ET $)$ & CL50 $\left(\mathrm{mg} \mathrm{L}^{-1}\right)(95 \%$ LC) & FR50 \\
\hline Pimetrocina & LAB-S & $1,03( \pm 0,09)$ & $29,2(3,2-107,4)$ & 1 \\
& R-PIME & $0,98( \pm 0,15)$ & $72499,0(21651,8-23208173,1)$ & 2485 \\
\hline Buprofecín & LAB-S & $1,66( \pm 0,17)$ & $8,7(4,4-14,4)$ & 1 \\
& R-PIME & $0,69( \pm 0,09)$ & $277,8(101,7-665,7)$ & 32 \\
\hline
\end{tabular}

Como se observa en la tabla hay diferencias significativas, con un factor de resistencia de 32, de la población seleccionada R-PIME cuando se le aplicó el buprofecín. Este resultado confirma por tanto la existencia de resistencia cruzada entre buprofecín y pimetrocina. 
Finalmente hablaremos de la población seleccionada para piriproxifén, R-PIX. El valor obtenido de la $\mathrm{CL}_{50}$ de $2334 \mathrm{ppm}$ (tabla 2), es muy superior a los obtenidos en nuestras poblaciones de campo, que varían desde 15 hasta $402 \mathrm{ppm}$. Presenta diferencias significativas con todas las poblaciones. Además hay que destacar que nuestras poblaciones obtuvieron los valores más altos encontrados en bibliografía cuando fueron bioensayadas con piriproxifén (Capitulo 1). Por tanto, se puede decir que es una población muy resistente a este insecticida y notablemente seleccionada.

$\mathrm{Al}$ igual que con las otras poblaciones seleccionadas para los otros dos reguladores del crecimiento, la población R-PIX se bioensayó con otros insecticidas usados para el control de la mosca. En la tabla 6 se muestran los resultados obtenidos.

Tabla 6. Toxicidad de piriproxifén y de diferentes insecticidas para la población sensible (LAB-S) y población seleccionada para piriproxifén de Bemisia.

\begin{tabular}{c|cccc}
\hline Insecticida & Población & Pendiente \pm ET $)$ & CL50 (mg L-1)(95\% LC) & FR50 \\
\hline Piriproxifén & LAB-S & $0,98( \pm 0,10)$ & $20,9(13,8-30,4)$ & 1 \\
& R-PIX & $0,66( \pm 0,08)$ & $2333,9(1052,3-7916,9)$ & 112 \\
\hline Azadiractín & LAB-S & $0,88( \pm 0,10)$ & $2,7(0,5-6,6)$ & 1 \\
& R-PIX & $0,84( \pm 0,15)$ & $25,8(4,9-77,2)$ & 10 \\
\hline Buprofecín & LAB-S & $1,66( \pm 0,17)$ & $8,7(4,4-14,4)$ & 1 \\
& R-PIX & $1,39( \pm 0,14)$ & $10,5(1,5-29,7)$ & 1 \\
\hline Imidacloprid & LAB-S & $0,60( \pm 0,07)$ & $15,2(1,3-81,1)$ & 3 \\
\hline Pimetrocina & R-PIX & $1,55( \pm 0,16)$ & $44,8(18,9-85,4)$ & 1 \\
& LAB-S & $1,03( \pm 0,09)$ & $29,2(3,2-107,4)$ & 3 \\
\hline Piridabén & R-PIX & $1,12( \pm 0,15)$ & $78,5(53,3-115,4)$ & 1 \\
\hline
\end{tabular}

Se observa que no existen diferencias significativas con azadiractín y buprofecín, y aunque les aumenta un poco la resistencia (26 y 10,5 ppm respectivamente), los valores no son comparables con el valor tan elevado que ha obtenido para piriproxifén. Por lo tanto, no existe resistencia cruzada con ninguno de ellos. 
Una vez conocida la existencia de resistencia cruzada entre azadiractín y buprofecín es interesante y necesario conocer el mecanismo de resistencia implicado para la detoxificación de estos insecticidas, para poder hacer un buen uso en las estrategias de control de Bemisia. Estos dos insecticidas tienen modos de acción distintos, ya que el buprofecín, según la clasificación de los modos de acción de IRAC (Comité de Acción para la Resistencia a los Insecticidas) está dentro de grupo 16 Inhibidores de la biosíntesis de quitina, tipo 1, homópteros; y azadiractina pertenece al grupo "un" compuestos de modo de acción desconocido o incierto. Por ello, debemos suponer que tienen que tener resistencia del tipo metabólica.

Se realizaron ensayos con sinergistas que inhiben la acción de las enzimas implicadas en los procesos metabólicos de detoxificación del insecticida. Se utilizaron la enzima butóxido de piperonilo (PBO) que es un inhibidor de las P450 y el S,S,S-tributil fosfotritioato (DEF) inhibidor de las esterasas. Debido a que el DEF es un desfoliante utilizado para la recolección de algodón y que nuestros ensayos se realizaron sobre plantas de algodón, surgieron muchos problemas y no se han podido conseguir todos los datos deseados. A pesar que se utilizaron diferentes dosis que fueran inofensivas para nuestras plantas de ensayo pero efectivas en el propósito de nuestros ensayos, no se alcanzaron todos nuestros objetivos. En la tabla 7 que se muestra a continuación, aparecen los datos conseguidos.

Tabla 7. Toxicidad de azadiractín y buprofecín para la población sensible (LAB-S) y sus seleccionadas y azadiractín y buprofecín + PBO o DEF para las poblaciones seleccionadas en Bemisia.

\begin{tabular}{|c|c|c|c|c|}
\hline Insecticida & Población & Pendiente $( \pm$ ET $)$ & CL50 (mg L-1 $)(95 \%$ LC) & FS \\
\hline \multirow[t]{3}{*}{ Azadiractín } & LAB-S & $0,88( \pm 0,10)$ & $2,7(0,5-6,6)$ & \\
\hline & R-AZA & $1,81( \pm 0,33)$ & $197,6(121,3-270,3)$ & \\
\hline & $\mathrm{R}-\mathrm{BU}$ & $0,63( \pm 0,08)$ & $38,8(10,4-301,0)$ & \\
\hline \multirow[t]{2}{*}{ Azadiractín + PBO } & R-AZA & $2,19( \pm 0,32)$ & $239,3(156,6-332,0)$ & 0,8 \\
\hline & $\mathrm{R}-\mathrm{BU}$ & $0,78( \pm 0,09)$ & $10,1(4,0-21,5)$ & 3,8 \\
\hline \multirow[t]{2}{*}{ Azadiractín + DEF } & R-AZA & - & - & - \\
\hline & R-BU & $0,53( \pm 0,08)$ & $2,0(0,3-5,7)$ & 19,2 \\
\hline \multirow[t]{3}{*}{ Buprofecín } & LAB-S & $1,66( \pm 0,17)$ & $8,7(4,4-14,4)$ & \\
\hline & R-AZA & $1,18( \pm 0,01)$ & $154,2(97,7-246,9)$ & \\
\hline & $\mathrm{R}-\mathrm{BU}$ & $365,13( \pm 0,12)$ & $365,1(184,1-701,9)$ & \\
\hline \multirow[t]{2}{*}{ Buprofecín + PBO } & R-AZA & $1,47( \pm 0,15)$ & $206,3(129,5-338,9)$ & 0,7 \\
\hline & $\mathrm{R}-\mathrm{BU}$ & $0,95( \pm 0,13)$ & $537,4(226,7-1322,0)$ & 0,7 \\
\hline \multirow[t]{2}{*}{ Buprofecín + DEF } & R-AZA & $1,22( \pm 0,11)$ & $23,8(7,9-53,3)$ & 6,5 \\
\hline & $\mathrm{R}-\mathrm{BU}$ & - & - & - \\
\hline
\end{tabular}


Ninguno de los bioensayos realizados con PBO mostraron diferencias significativas con la población de origen, no afectando por tanto la resistencia. Por lo contrario, en aquellos bioensayos donde se utilizó el DEF, disminuyó significativamente el valor de la $\mathrm{CL}_{50}$ respecto de donde solo se utilizó el insecticida. Obteniendo un factor de sinergismo (FS) de 19 en el caso de R-BU con azadiractín más DEF y de 6,4 para la población R-AZA con buprofecín más DEF.

A pesar de la falta de algunos resultados, éstos apuntan que no es el PBO el que afecta al mecanismo de resistencia, sino que parece que es el DEF. Por ello, hace sospechar que son las esterasas las que están involucradas. Aparte de nuestros estudios, poco se sabe sobre los mecanismos de resistencia de estos dos reguladores del crecimiento en Bemisia.

Por otro lado, sabemos que buprofecín no presenta resistencia cruzada con los neonicotinoides (Basit et al. 2012) y sí a la pimetrocina como hemos visto anteriormente. Y además como vimos en el capítulo 2, no siempre la pimetrocina y los neonicotinoides presentan resistencia cruzada por lo que se sospecha que existe otro mecanismo diferente a las P450 que afecta al mecanismo de resistencia de Bemisia frente a la pimetrocina. De todo esto, se puede extraer que aunque no podamos confirmar que las esterasas son las enzimas involucradas en los mecanismos de resistencia de azadiractín y buprofecín, sí que podemos decir que la enzima del citocromo P450 que inhibe los neonicotinoides no afecta a estos reguladores del crecimiento.

Finalmente, a pesar que para piriproxifén no se han realizado todavía bioensayos con sinergistas para poder averiguar los mecanismos implicados en la resistencia, hemos realizado una pequeña revisión que nos orienten para los próximos estudios.

Los mecanismos de resistencia de la mosca frente a piriproxifén no están claros todavía. En 1987 y 1998 Zhang publicó la implicación de las P450 monooxigenasas en la resistencia a piriproxifén en la mosca común, lo que ha llevado a pensar que este puede ser un posible mecanismo de resistencia en Bemisia. Devine en 1999 tras aplicar butóxido de piperonilo (PBO) con piriproxifén en poblaciones sensibles y resistentes de mosca observó que el PBO era muy antagónico en lugar de sinérgico para piriproxifén, especialmente en las poblaciones resistentes. Ma et al. en 2010 publican que los datos obtenidos sugieren que no sólo las P450 están implicadas en los mecanismos de la resistencia sino también las Glutatión S-transferasas. Karatolos en 2012 también implica a las P450, pero este caso es 
en Trialeurodes vaporariorum (mosca blanca de los invernaderos). Por tanto, más estudios son necesarios para poder confirmar cuál o cuáles son los mecanismos implicados en la resistencia a piriproxifén, y así lograr mejorar las estrategias de control sobre Bemisia.

En resumen, podemos decir que existe resistencia cruzada entre azadiractín y buprofecín pero no con piriproxifén. Y que además buprofecín presenta resistencia cruzada con pimetrocina. Respecto a los mecanismos implicados en la resistencia, se descarta la enzima del citocromo P450 que afecta a los neonicotinoides y que todo apunta a que estén involucradas las esterasas para los reguladores del crecimiento azadiractín y buprofecín. 


\section{Bibliografía}

Abbott WS, 1925. A method for computing the effectiveness of an insecticide. $J$ Econ Entomol 18:265-267.

Ahmad, M., Arif, M.I., Ahmad, Z., Denholm, I., 2002. Cotton whitefly, Bemisia tabaci resistance to organophosphates and pyrethroid insecticides in Pakistan. Pest Manag. Sci. 58, 203-208.

Ascher, K.R.S., and M. Eliyahu. 1988. The ovicidal properties of the juvenile hormone mimic Sumitomo S-31183 (SK-591) to insects. Phytoparasitica 16: 15-21.

Barrek, S., O. Paisse, and G.-L. Marie-Florence. 2004. Analysis of neem oils by LC-MS and degradation kinetics of azadirachtin-A in a controlled environment. Anal. Bioanal. Chem. 378: 753-763.

Basit, M.; Saeed, S.; Saleem, M. A.; Sayyed, A. H. 2013. Can resistance in Bemisia tabaci (Homoptera: Aleyrodidae) be overcome with mixtures of neonicotinoids and insect growth regulators? Crop Protection 44: 135-141.

Basit, M. Saleem, M.A., Saeed, S.. Sayyad A.H 2012. Cross resistance, genetic analysis and stability of resistance to buprofezin in cotton whitefly, Bemisia tabaci Genn. (Homoptera: Aleyrodidae). Crop Prot., 40: 16-21.

Byrne, D.N., Bellows, T.S., 1991. Whitefly biology. Ann. Rev. Entomol. 36, 431-457.

Corbett, J.R., 1974. The Biochemical Mode of Action of Pesticides. Academic Press Inc, New York.

Coudriet, D. L., N. Prabhaker, and D. E. Meyerdirk. 1985. Sweetpotato whitefly (Homoptera: Aleyrodidae): effects of neem-seed extract on oviposition and immature stages. Environ. Entomol. 14: 776-779.

Dhadialla, T. S., G. R. Carlson, and D. P. Le. 1998. New insecticides with ecdysteroidal and juvenile hormone activity. Annu. Rev. Entomol. 43: 545-569.

De Cock, A., Ishaaya, I., Degheele, D., Veierov, D., 1990. Vapor toxicity and concentration-dependent persistence of buprofezin applied to cotton foliage for controlling the sweet potato whitefly (Homoptera: Aleyrodidae). J. Econ. Entomol. 84, 1254-1260. 
Devine, G., I. Ishaaya, A. R. Horowitz, and I. Denholm. 1999. The response of pyriproxyfen-resistant and susceptible Bemisia tabaci Genn (Homoptera: Aleyrodidae) to pyriproxyfen and fenoxycarb alone and in combination with piperonyl butoxide. Pestic. Sci. 55: 405-411.

Flint, H. M., and N. J. Sparks. 1989. Effect of azadirachtin from the neem tree on immature sweetpotato whitefly, Bemisia tabaci (Homoptera: Aleyrodidae) and other selected pest species on cotton. J. Agric. Entomol. 6: 211-215.

Gerling, D., Sinai, P., 1994. Buprofezin effects on two parasitoid species of whitefly (Homoptera: Aleyrodidae). J. Econ. Entomol. 87, 842-846.

Greathead, A.H., 1986. Host plants, in Bemisia tabaci - a literature survey on the cotton whitefly with an annotated bibliography. In: Cock, M.J.W. (Ed.). CAB International Institute of Biological Control, Silwood Park, UK, pp. 17-26.

Horowitz, A.R., Gorman, K., Ross, G., Denholm, I., 2003. Inheritance of pyriproxyfen resistance in the whitefly, Bemisia tabaci (Q biotype). Arch. Insect Biochem. Physiol. 54, 177-186.

Horowitz, A.R., Ishaaya, I., 1996. Chemical control of Bemisia - management and application. In: Gerling, D., Mayer, R.T. (Eds.), Bemisia: 1995 Taxonomy, Biology, Damage, Control and Management. Intercept Ltd., Andover, Hants, UK, pp. 537-556

Horowitz, A.R., Ishaaya, I., 1992. Susceptibility of the sweet potato whitefly (Homoptera: Aleyrodidae) to buprofezin during the cotton season. J. Econ. Entomol. 85, 318-324.

Ishaaya, I., A. De Cock, and D. Degheele. 1994. Pyriproxyfen, a potent suppressor of egg hatch and adult formation of the greenhouse whitefly (Homoptera: Aleyrodidae). J. Econ. Entomol. 87: 1185-1189.

Ishaaya, I., and A. R. Horowitz. 1992. Novel phenoxy juvenile hormone analog (pyriproxyfen) suppresses embryogenesis and adult emergence of sweetpotato whitefly (Homoptera: Aleyrodidae). J. Econ. Entomol. 85: 2113-2117.

Ishaaya, I., and A. R. Horowitz. 1995. Pyriproxyfen, a novel insect growth regulator for controlling whiteflies: mechanism and resistance management. Pestic. Sci. 43: 227-232.

Itaya, W. 1987. Insect juvenile hormone analogue as an insect growth regulator. Sumitomo Pyrethroid World 8: 2-4. 
Johnson, S., P. Dureja, and S. Dhingra. 2003. Photostabilizers for azadirachtin-A (a neembased pesticide). J. Environ. Sci. Health B 38: 451-462.

Kanno, H.K., Asi, T., Maekawa, S., 1981. 2-tert-butylimino- 3-isopropyl-perhydro- 1,3,5thaidiazin-4-one (NNI 750), a new insecticide. In: Proceedings, Brighton Crop Protection Conference, Pests and Diseases, Brighton, England, pp. 56-69.

Karatolos, N.; Williamson, M.S.; Denholm, I.; Gorman, K.; Ffrench-Constant R.H.; y Bass, C. 2012 . Over-expression of a cytochrome P450 is associated with resistance to pyriproxyfen in the greenhouse whitefly Trialeurodes vaporariorum. PLoS ONE 7(2):e31077).

Kawada, H. 1988. An insect growth regulator against cockroaches. Sumitomo Pyrethroid World 11: $2-4$.

Koehler, P. G., and R. J. Patterson. 1991. Incorporation of pyriproxyfen in German cockroach (Dictyoptera: Blattellidae) management program. J. Econ. Entomol. 84: 917-921.

Langley, P. 1990. Control of the tsetse fly using a juvenile hormone mimic, pyriproxyfen. Sumitomo Pyrethroid World 15: 2-5.

Liu, T. X., and P. A. Stansly. 1995. Deposition and bioassay of insecticides applied by leaf dip and spray tower against Bemisia argentifolii nymphs (Homoptera: Aleyrodidae). Pestic. Sci. 44: 317-322.

Luo, C., Jones, C.M., Devine, G., Zhang, F., Denholm, I., Gorman, K., 2010. Insecticide resistance in Bemisia tabaci biotype Q (Hemiptera: Aleyrodidae) from China. Crop Prot. 29, 429-434.

Ma W, Li X, Dennehy TJ, Lei C, Wang M, et al. (2010) Pyriproxyfen resistance of Bemisia tabaci (Homoptera: Aleyrodidae) biotype B: metabolic mechanism. J Econ Entomol 103: 15865.

Mitchell, P. L., R. Gupta, A. K. Singh, and P. Kumar. 2004. Behavioural and developmental effects of neem extracts on Clavigralla scutellaris (Hemiptera: Heteroptera: Coreidae) and its egg parasitoid, Gryon fulviventre (Hymenoptera: Scelionidae). J. Econ. Entomol. 97: 916Đ923.

Mugiira, R.B., Liu, S.S., Zhou, X., 2008. Tomato yellow leaf curl virus and tomato leaf curl Taiwan virus invade south-east coast of China. J. Phytopathol 156, 217-221.

Perring, T.M., 2001. The Bemisia tabaci species complex. Crop. Prot. 20, 725-737. 
Prabhaker, N., N. C. Toscano, and D. L. Coudriet. 1989. Susceptibility of the immature and adult stage of the sweetpotato whitefly (Homoptera: Aleyrodidae) to selected insecticides. J. Econ. Entomol. 82: 983-988.

Russell RM, Robertson JL and Savin NE, 1977. POLO - a new computer program for probit analysis. Bull Entomol Soc Am 23:209-213.

Schaefer, C. H., T. Miura, E. F. Dupras, F. S. Mulligan, and W. H. Wilder. 1988. Efficacy, non-target effects and chemical persistence of S-31183, a promising mosquito (Diptera: Culicidae) control agent. J. Econ. Entomol. 81: 1648-1655.

Schmutterer, H. 1990. Properties and potential of natural pesticides from neem tree, Azadiracbta indica. Annu. Rev. Entomol. 35: 271-297

Zhang, L., K. Harada, and S. Toshio. 1997. Genetic analysis of pyriproxifen resistance in the housefly, Musca domestica L. Appl. Entomol. Zool. 32: 217-226.

Zhang, L., S. Kasai, and T. Shono. 1998. In vitro metabolism of pyriproxyfen by microsomes from susceptible and resistant housefly larvae. Arch. Insect Biochem. Physiol. 37: 215-224. 


\section{Conclusiones}

A partir de los resultados obtenidos en la presente tesis doctoral se extraen las siguientes conclusiones:

- Aunque se detectaron algunas poblaciones con resistencias altas a algunos insecticidas, las poblaciones de campo de mosca blanca biotipo Q recogidas en el sureste de España, en las zonas de Almería y Murcia, no mostraron una fuerte y amplia resistencia a los insecticidas alfa-cipermetrín, azadiractín, buprofecín, imidacloprid, metomilo, pimetrocina, piridabén, piriproxifén y tiametoxam utilizados para su control en los cultivos hortícolas y ornamentales.

- Existe resistencia cruzada entre los neonicotinoides, imidacloprid y tiametoxam, pero que no existe entre ellos y pimetrocina en nuestras poblaciones. Por lo tanto, debe existir otro mecanismo de resistencia para la pimetrocina diferente al de los neonicotinoides.

- La expresión de la resistencia en Bemisia es en función del estado de desarrollo, expresándose en adultos en los neonicotinoides y en piridabén y en ninfas en pimetrocina.

- El piridabén es una buena herramienta para el control de Bemisia, a pesar de ser un acaricida de uso extendido sobre importantes plagas como T. urticae. Es muy eficaz sobre ninfas y por tanto podría ser un buen candidato para incorporarlo a las estrategias de control.

- El citocromo P450 interviene en el metabolismo de detoxificación del piridabén. Además, no se han encontrado resistencias cruzadas con otros insecticidas aplicados para el control de la mosca en los cultivos hortícolas y ornamentales más comúnmente utilizados.

- Existe resistencia cruzada entre los reguladores del crecimiento (IGR) azadiractín y buprofecín pero no con piriproxifén. 
- Existe resistencia cruzada entre buprofecín y pimetrocina.

- Respecto a los mecanismos implicados en la resistencia de azadiractín y buprofecín, se descarta que sea la enzima del citocromo P450 que afecta a los neonicotinoides y que todo apunta a que estén involucradas las esterasas. 